Portland State University

PDXScholar

11-3-1995

\title{
John Rawls, Feminism, and the Gendered Self
}

Lori Kinder MacArthur

Portland State University

Follow this and additional works at: https://pdxscholar.library.pdx.edu/open_access_etds

Part of the Political Science Commons

Let us know how access to this document benefits you.

\section{Recommended Citation}

MacArthur, Lori Kinder, "John Rawls, Feminism, and the Gendered Self" (1995). Dissertations and Theses. Paper 5030.

https://doi.org/10.15760/etd.6906

This Thesis is brought to you for free and open access. It has been accepted for inclusion in Dissertations and Theses by an authorized administrator of PDXScholar. Please contact us if we can make this document more accessible: pdxscholar@pdx.edu. 


\section{THESIS APPROVAL}

The abstract and thesis of Lori Kinder MacArthur for the Master of Science in Political Science were presented November 3, 1995, and accepted by the thesis committee and the department.

COMMITTEE APPROVALS:

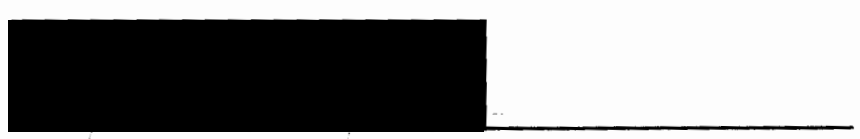

Craig L. Carr, Chair

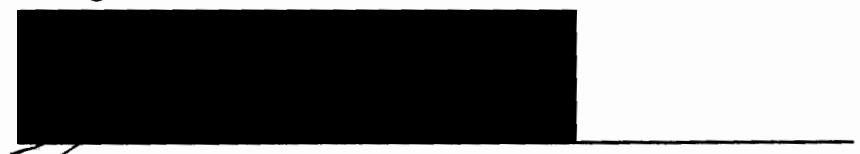

Gary L. Scott

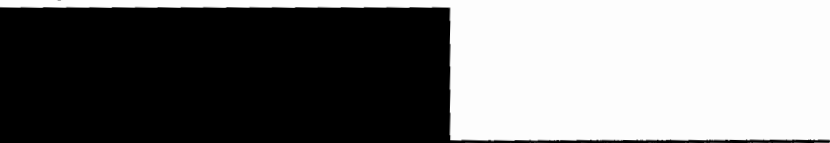

Sándra Wilde

Representative of the Office of Graduate Studies

DEPARTMENT APPROVAL:

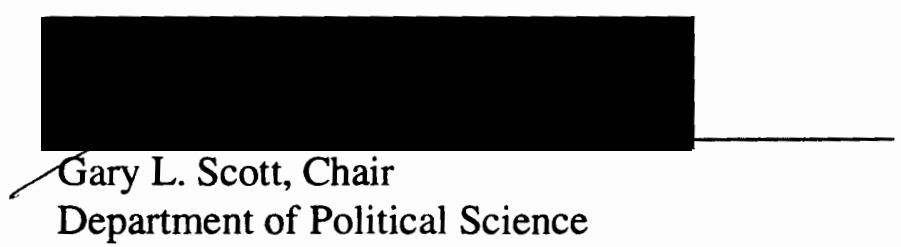

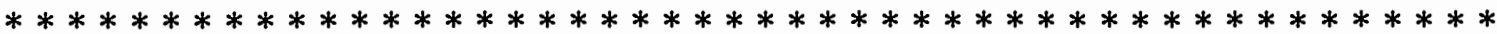

ACCEPTED FOR PORTLAND STATE UNIVERSITY BY THE LIBRAKY

by

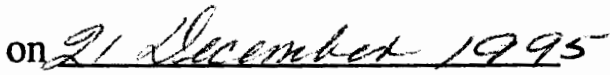




\begin{abstract}
An abstract of the thesis of Lori Kinder MacArthur for the Master of Science in Political Science presented November 3, 1995.
\end{abstract}

Title: John Rawls, Feminism, and the Gendered Self.

John Rawls's theory of justice, which he calls "justice as fairness," has proven to be most influential with regard to the course of contemporary political theory. In both of Rawls's books, A Theory of Justice and Political Liberalism, his aim was to present a theoretically-compelling defense of deontological liberalism, and to present a set of principles by which to fairly order a just society.

While Rawls's project has attracted a fair number of proponents over the years, it has also been a popular target for liberal and nonliberal critics alike. A recurrent theme among these criticisms has been an objection with Rawls's conception of the self as presented in A Theory of Justice.

This thesis will focus on feminists' criticisms of Rawls's conception of persons. In general, feminists contend that Rawlsian liberalism suffers a structural gender bias resulting from Rawls's conception of the self. Rawls's notion of the self, feminists argue, rests on male or masculine attributes. 
I will demonstrate in the course of this thesis that feminists' charges fail on two accounts. First, feminists do not present an accurate reading of Rawls's conception of persons in either A Theory of Justice or Political Liberalism. Second, in reviewing feminist approaches to gendering the self (which is integral to their critique), it will be shown that feminists are unable to gender the self in a theoretically defensible manner. Thus, feminists cannot make the claim that the Rawlsian self is a male or masculine concept. It follows from these twin defects that feminist contentions fail to prove that Rawls's theory is gender biased. 
JOHN RAWLS, FEMINISM, AND

THE GENDERED SELF

by
LORI KINDER MACARTHUR

A thesis submitted in partial fulfillment of the requirements for the degree of

\section{MASTER OF SCIENCE \\ in \\ POLITICAL SCIENCE}

Portland State University

1995 


\section{DEDICATION}

In memory of James Keith Torney. 


\section{ACKNOWLEDGEMENTS}

To Professor Carr, I wish to extend my sincerest gratitude not only for his work as thesis advisor, but also for providing an inimitable introduction to political theory. For that, I am indebted.

Special thanks are to due to my parents, sister, and husband. In addition, I would like to thank K. J. Boge and, my fellow graduate student, G. Thompson. While words cannot credit them enough, their patience and support through out this project has been much appreciated. 


\section{TABLE OF CONTENTS}

ACKNOWLEDGEMENTS $\ldots \ldots \ldots \ldots \ldots \ldots \ldots \ldots \ldots \ldots$. $\ldots \ldots \ldots \ldots$

\section{CHAPTER}

I INTRODUCTION $\ldots \ldots \ldots \ldots \ldots \ldots \ldots \ldots \ldots \ldots \ldots \ldots \ldots \ldots \ldots \ldots$

The Method, Concepts, and Contours of Inquiry . . . . . . . . . 11

Feminist Theory

The Gendered Self

Liberal Political Theory

John Rawls: A Theory of Justice and Political Liberalism

The Direction of Inquiry $\ldots \ldots \ldots \ldots \ldots \ldots \ldots \ldots \ldots \ldots \ldots \ldots \ldots \ldots \ldots \ldots$

II JOHN RAWLS'S CONCEPTION OF THE SELF: FROM A THEORY 26 OF JUSTICE TO POLITICAL LIBERALISM

The Conception of Persons in A Theory of Justice . . . . . . . . . 34

Moral Individualism

Social Context and Individuals

Equality and Moral Personality

Conceptions of the Good, Rational Plans, and Conflicting Interests

Freedom, Liberty and Autonomy

The Conception of Persons in Political Liberalism . ............. 56

Moral Individualism

Social Context and Individuals

Equality and Moral Personality

Conceptions of the Good, Rational Plans, and Conflicting Interests

Freedom, Liberty and Autonomy

Conclusion 
III THE FEMINIST CRITIQUE OF RAWLS'S CONCEPTION OF THE SELF 72

Moral Individualism

Social Context and Individuals

Equality and Moral Personality

Conceptions of the Good, Rational Plans, and Conflicting Interests

Freedom, Liberty and Autonomy

Conclusion ................................. 97

IV EVALUATING FEMINIST CRITIQUES OF THE RAWSIAN SELF . . . . . 99

Moral Individualism

Social Context and Individuals

Equality and Moral Personality

Conceptions of the Good, Rational Plans, and Conflicting Interests

Freedom, Liberty and Autonomy

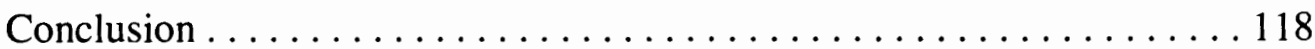

V CONCLUSION: PROBLEMATICS OF GENDERING THE SELF . . . . . 119

Relational Feminism

Cultural Feminism

Postmodern Feminism

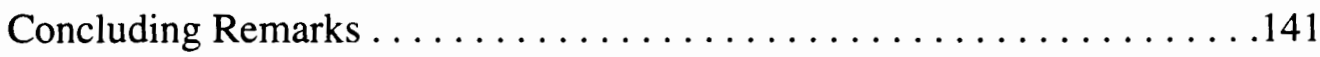

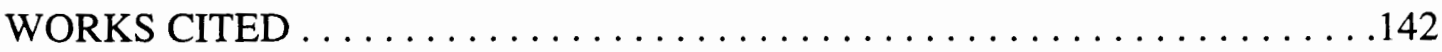




\section{CHAPTER I}

\section{INTRODUCTION}

During recent years, partisans and critics alike have acknowledged the magnitude of John Rawls's contribution to contemporary moral and political theory. ${ }^{1}$ His renown is largely the result of $A$ Theory of Justice-a work that served as the first systematic account of his theory of justice, otherwise denominated "justice as fairness," which can be broadly regarded as a theoretical defense of "deontological" liberalism. ${ }^{2}$ Since this publication, the corpus of his work has been steadfastly devoted to the advancement and clarification of "justice as fairness," and has been driven by the explicit intention of remaining faithful to "the spirit and content of $A$ Theory of Justice."3

In political theory, it has been observed that Rawls's venture yielded three noteworthy effects that have influenced the course of the discipline. Of Rawls's contributions meriting comment the first is perhaps the most profound: $A$ Theory of

\footnotetext{
${ }^{1}$ While "political theory" and "political philosophy" are often used interchangeably, the preference of the author is towards the former term as it is generally observed to be both broader in scope and more closely linked with the discipline of political study. On these related points, see John Gunnell, Political Theory: Tradition and Interpretation (New York: University Press of America, Inc., 1987), xiv; and Alison M. Jaggar, Feminist Politics and Human Nature (New Jersey: Rowman \& Allanheld, 1983), 22.

${ }^{2}$ John Rawls, A Theory of Justice (Cambridge, MA: Belknap Press, 1971). NB: Hereafter, A Theory of Justice will also be referred to as Theory, with the latter title denoting the former. As defined by Rawls, in Theory (30), a "deontological theory" is "one that either does not specify the good independently from the right, or does not interpret the right as maximizing the good." Or more commonly stated, the right is given priority over the good.

${ }^{3}$ John Rawls, Political Liberalism (New York: Columbia University Press, 1993), xiv.
} 
Justice signaled a renaissance within political theory during the 1970 s, with the project itself being the primary inspiration animating this movement.

For many, Rawls was perceived to have undertaken in Theory "a project of heroic proportion and classical: articulating a comprehensive and universal theory of justice founded on first principles." ${ }^{4}$ The publication of this work seemed to mark not only the restoration of political theorizing as a salient enterprise in the present-day study of politics-a project that had withered during the positivist ascendance of the 1950s and 1960s-but it also signified, in the words of Amy Gutmann, that "grand political theory [was] once again alive in the academy.,"5

Second, though there exists many historical and contemporary variants of liberalism, Rawls's theory of "justice as fairness" has been regarded as one of the most theoretically-compelling and influential defenses of liberalism to date. Theory, in turn, has been judged the "paradigm statement of contemporary liberal theory."6

Third, Rawls's project has been recognized as indelibly altering the conceptual framework of contemporary liberalism and-more broadly-the conventional lines of political discourse. Stephen Mulhall and Adam Swift outline:

${ }^{4}$ Patrick Neal, "Justice as Fairness: Political or Metaphysical?" Political Theory 18 (1990): 24.

${ }^{5}$ Amy Gutmann, "The Central Role of Rawls's Theory," Dissent (Summer 1989): 338. For a discussion of positivism in the discipline of political studies and history of political theory, see Gunnell, chap. I passim.

${ }^{6}$ Stephen Mulhall and Adam Swift, Liberals and Communitarians (Cambridge, MA: Blackwell Publishers, 1992), vii. 
his theory established the terrain upon which subsequent political-theoretical battles were to be fought... [so that both] critics and defenders of versions of liberalism other than that offered by Rawls have formulated their positions in terms that make explicit reference to his theory, so that in many ways Rawls simply did define the agenda and continues to do so. ${ }^{7}$

All told, the standard terms of political inquiry (such as, equality, liberty, freedom, etc.) were essentially reinterpreted by Rawls's theory, so that the very conceptual premises and principles on which political theory operate have shifted.

However the relative importance of the aforementioned factors are weighted, taken together they have indubitably secured for Rawls a central station within both liberalism and, more broadly, political theory. Though many sympathize with Rawls, and ardently defend his theory of justice, the conspicuousness of Rawls's position has also attracted a fair number of detractors. Their criticisms range from specific objections to the principles of "justice as fairness," to more encompassing challenges intended to undermine the entirety of the liberal tradition. Nevertheless, the attentiveness of both critics and liberal adherents to this so-called nonpareil statement of liberalism makes evident the significance of Theory and Rawls's ongoing project to fashion a theoretically cogent version of deontological liberalism.

In contemporary debate one recurrent point has loomed large in criticism of Theory, as Janet Moore explains, Rawls's "autonomous, self-conscious, and selfconstitutive subject has drawn heavy fire from feminist and other critical theorists, as well as structuralist, poststructuralist, and postmodern philosophers engaged in critiques of

\footnotetext{
${ }^{7}$ Ibid., 1.
} 
classical liberalism and its social contract theories." ${ }^{, 8}$ Much of the current controversy centering on Rawls's theory, spins around his liberal conception of the person. In examining a facet of this debate, this work will analyze feminists' criticisms of Rawls's conception of the person. Before delving into the fine points of this analysis, however, several preliminary considerations pertaining to the nature of feminist claims ought to be reviewed.

Because feminist arguments are directed towards Rawls's conception of persons, the very term "person" or "self" is of interest. ${ }^{9}$ To clarify, feminist contentions are not directed at any generic definition of the self (i.e., the combination of those elements that we consider requisite to be human, such as body, thoughts, emotions, etc.); rather, they are concerned with the more controversial assumptions about the self (i.e., particular characteristics, interests, predispositions, nature, etc.) which are indeed subject to disparate interpretations. Feminists are thus concerned with Rawls's "interpretation" of the self.

This aside, it seems as though the question of what constitutes an accurate interpretation of personhood would be a rather straightforward one. For theorists, however, the issue is a good deal more complex, and the way in which the question of personhood is answered is of consequence. The ontological commitments (i.e.,

${ }^{8}$ Janet Moore, "Covenant and Feminist Reconstruction's of Subjectivity within Theories of Justice," in Law and Contemporary Problems 55 (Summer 1992): 159.

9The distinction, if any, between the term "person" and "self" is negligible; accordingly, the terms will be employed interchangeably. 
interpretations of the self) of political theorists have important structural ramifications for their theories, because premises, concepts, principles and conclusions are-for the most part-rooted in their vision of persons.

Recognizing the significance of this fact, feminists have been concerned with how political theorists interpret the self as it relates to women. Importantly, feminists have introduced the notion of gender into the discussion of the self in what seems an attempt to redefine the contemporary debate over the liberal self. Illustrative of this point, feminist Alison Jaggar maintains that: "[S]ince every political theory is grounded on a certain conception of human nature, each political theory incorporates some assumptions about the nature of women and men." 10 On the surface, this statement seems rather innocuous and unassuming; however, it reveals two fundamental points of departure introduced by feminists. First, when discussing the notion of the self, gender is considered a relevant factor. Second, this statement implies that men and women may have distinct natures that cannot simply be subsumed under the single, broad category of human nature. What Jaggar and many other feminists conclude is that political theorists make assumptions about the self and, intentionally or not, make presumptions about the nature of men and women respectively.

Although feminists hold that Rawls employs a specific notion of the self based on assumptions about the nature of persons, it should be noted from the outset that in Theory, Rawls does not specifically address gender, much less does he imply that women

\footnotetext{
${ }^{10}$ Jaggar, 21.
} 
and men are either similar or distinct. Indeed, Rawls seems altogether reluctant to approach the issue of gender, or he is simply blind to the fact that women may possess a different nature than men.

It is precisely this "silence" on the issue of gender that has been problematic for feminists, because in their view it implies "either that there are no differences between women and men that are relevant to political philosophy or that women are not part of the subject matter of political philosophy." notion of the self applies only to men-in which case his assumptions of human nature, while seemingly generic, are only really indicative of man; or whether his notion of the self is applicable to either gender-in which case there is a single version of human nature common to both sexes.

Many feminists have found neither answer to that question acceptable. It seems obvious why feminists would reject the first alternative: women would be excluded entirely from the scope of analysis. However, it is not immediately evident as to why feminists would chafe at the second alternative. While some feminists (namely traditional liberal feminists) reaffirm the gender-neutral account of human nature that appears to be on display in Rawls's theory of justice, the most common response by feminists has been to debunk the notion that the nature or experiences of women are akin to those of men. ${ }^{12}$ Thus, they reject the gender neutral stance.

${ }^{11}$ Ibid.

${ }^{12}$ The strong thesis being that women's nature (i.e. biology) is essentially different, the weak thesis being that women's social experiences (i.e. social roles) are markedly divergent. 
If this is the case-that the notion of the self is in some fashion gendered male or female - to which gendered self is Rawls's theory applicable? Feminists have primarily responded by arguing that the constitutive assumptions of the liberal self are based on male (or, as postmodern feminists say, masculine) values. ${ }^{13}$ Liberal concepts of rationality, agency, and morality underlying this notion of personhood "have been defined exclusively in masculine terms." ${ }^{\prime 4}$ Insofar as Rawls's theory is applied to women then, they are either excluded altogether or marginalized as a result of being "forced to think through their experience via male categories."15

Rawls's seemingly gender-neutral approach to the conception of the self, for feminists, indicates a gender bias-albeit a bias more subversive and subtle than an explicit exclusion of women. Of feminists challenging Rawlsian liberalism, then, the full allegation is as follows: Rawlsian liberalism, similar to other variants of this political theory, exhibits a structural male gender bias, and this inherent prejudice rests on his conception of the person. ${ }^{16}$ Because Rawls's theory is grounded on an exclusionary

\footnotetext{
${ }^{13}$ The use of the term "male" denotes more of a biological position, while the term "masculine" denotes "not a biological category but a cognitive style, and epistemological stance." See Susan Bordo, "The Cartesian Masculinization of Thought," Signs: Journal of Women in Culture and Society 11, no. 3 (Spring 1986): 451.

${ }^{14}$ Susan J. Hekman, Gender and Knowledge: Elements of Postmodern Feminism (Boston: Northeastern University Press, 1990), 34.

${ }^{15}$ Beverly Thiele, "Vanishing act in social and political thought: Tricks of the trade," in Feminist Challenges: Social and Political Theory, ed. Carole Pateman and Elizabeth Gross (Boston: Northeastern University Press, 1987), 42.

${ }^{16}$ Sinopoli makes a similar note, claiming that feminist arguments of "structural gender bias in liberal political thought (at least in the social contract tradition) deriving from a liberal conception of the
} 
vision of the self, say feminists, he effectively denies true representation of women in his analysis.

For students of political theory, it is common knowledge that Rawls has responded to other critiques of his conception of the self, specifically those advanced by the communitarian camp. Rawls has not issued a parallel rejoinder to feminist critics, however. While Rawls did recently claim "that the alleged difficulties in discussing problems of gender...can be overcome," he has not expound upon this assertion. ${ }^{17}$ Given that this is the case, why Rawls's silence with regard to feminist criticisms? Perhaps Rawls does not find feminist critiques theoretically credible, and thus unworthy of a response. Then again, he may have neither the time nor the interest necessary to issue a rejoinder. The reason as to why a dialogue matching the communitarian-liberal debate has not emerged between Rawls and the feminists in the end is left open to conjecture.

It is plausible to suggest, however, that this absence of debate is to some degree a reflection of the fact that liberal political theory and feminism are considered separate, distinct disciplines or cannons of thought. ${ }^{18}$ "Feminist theory and political theory are often treated as if they operated in two separate worlds," notes Nancy Hirschmann.

self,". See Richard C. Sinopoli, "Feminism and Liberal Theory," in American Political Science Review 85, no. 1 (March 1991): 223.

${ }^{17}$ Rawls, Political Liberalism, xxix.

${ }^{18}$ The author's inclination is to refer to political theory as a discipline, and feminists theory as a cannon of scholarship or thought. 
"[B]ut if they are in two worlds, it is not because they are inherently opposed but rather because there are very few people who speak both languages."19

This comment-that there exist two languages that must be transcended prior to a meaningful dialogue-unmasks another potential obstacle. That is, these two languages may be rooted in two entirely different paradigms, each based on irreconcilable foundational assumptions and mutually-unintelligible conceptual frameworks. ${ }^{20}$ Indeed much of feminist theory has attempted to move beyond the theoretical confines of liberalism, but according to Hirschmann the problem is that "by circumventing [liberal theory] and setting up [feminist theory's] own assumptions and conceptual framework, feminist theory becomes incomprehensible in the epistemology that liberalism defines."21 Reflexively, feminist theory may have become equally incomprehensible to liberal theorists. If this is the case-that liberal and feminist theory, in some sense, represent two divergent paradigms - then discussing the two may be more troublesome than one might initially expect. ${ }^{22}$

${ }^{19}$ Nancy J Hirschmann, Rethinking Obligation: A Feminist Method For Political Theory (New York: Cornell University Press, 1992), 24. Richard Sinopoli, in "Feminism and Liberal Theory" (231), makes a similar argument by claiming that "political scientists cannot be expected to be familiar with [feminist] literature".

${ }^{20}$ For a discussion of the term "paradigm" and what is involved in "paradigm debates," refer to Thomas S. Kuhn's book, The Structure of Scientific Revolutions (Chicago: The University of Chicago Press, 1970), passim.

${ }^{21}$ Hirschmann, Rethinking Obligation, 26.

${ }^{22}$ On this point, in Scientific Revolutions (109-110), Kuhn suggests that when two "schools disagree about what is a problem and what [is] a solution, they will inevitably talk through each other when debating the relative merits of respective paradigms. In the partially circular arguments that regularly result, each paradigm will be shown to satisfy more or less the criteria that it dictates for itself and to fall short of a few of those dictated by its opponent." Thus, "logical contact" between two paradigms is problematic. 
Any attempt at constructing a dialogue between feminism and liberalism will necessarily confront the task of bridging the two languages. This may require the mere harmonization of the two different languages, or it may entail the more formidable task of transcending the cognate paradigms of liberalism and feminism. This brings us to the most general aim of the thesis: I intend to push the discussion beyond what could amount to an impasse of "disagreement" and to initiate a dialogue of "critical" inquiry between feminist theorists and Rawls. ${ }^{23}$

More specifically, the purpose of this inquiry is to explore the contours of feminist contentions with Rawls's liberal conception of the self and, in so doing, provide a critical analysis of the theoretical cogency and aptness of these criticisms. I will argue that feminist challenges to Rawls fail in two interrelated ways. First, feminist criticism is based on overdrawn and incorrect interpretations of Rawls's conception of persons. Second, feminists' arguments that posit the liberal conception of persons to be characteristically male or masculine are based on dubious evidence, at best. All told, feminist contentions do not correctly address the shortcomings of the Rawlsian self;

${ }^{23}$ Jerry Cederblom and David W. Paulsen make an important distinction between the terms "disagreement" and "critical reasoning" which aptly apply here: "When one person asserts a position and another merely denies it, or states an opposing position, this is disagreement, and it is indeed commonplace...Critical reasoning, however, is a process that involves looking at the reasons on which an opposing view is based and making an assessment of those reasons. Its immediate aim is to determine whether the position offered is worth believing, but it is also a basis for further inquiry and discussion which may move both participants to a better understanding of the issue at hand." See Jerry Cederblom and David W. Paulsen, Critical Reasoning (Belmont, CA: Wadsworth Publishing Company, 1986), 1. 
therefore, it can be shown that Rawls's conception of justice has the requisite theoretical resources to respond to feminist assertions.

\section{The Method, Concepts, and Contours of Inquiry}

Although the topic of inquiry lies at the crossroads between two disciplines or cannons of scholarship, this undertaking should be regarded as a work within the discipline of political theory. Presently, the dispute within academia over the proper scope and method of political theory, in juxtaposition to political science, has relented somewhat. Thus, the former line of demarcation between the study of political science (associated with logical positivism and the empirical goal of prediction) and political

theory (linked with more normative and conceptual concerns) has been blurred. ${ }^{24}$ Nevertheless, this inquiry treats issues that fall within the traditional purview of political theory; thus, it is methodologically fashioned by normative and conceptual analysis.

The remainder of this section will introduce and define for the reader concepts which together form the fabric and framework of the forthcoming analysis. These concepts include: (1) Feminist theory; (2) The gendered self; (3) Liberal political theory; and (4) Rawls's theories of "justice as fairness" and "political liberalism." By articulating the conceptual terrain in which this analysis is situated, and delineating the parameters of the debate, this section will thereby refine and narrow the scope of investigation.

\section{Feminist Theory}

${ }^{24}$ Gunnell, 10. 
Feminist theory can be primarily understood "as a network of normative, conceptual, empirical and methodological claims," the aim of which is to provide a theoretical framework capable of: (1) describing women's oppression; (2) explaining the reasons for their oppression; and (3) providing a systematic political or social theory capable of women's liberation. ${ }^{25}$ Beyond this definition of feminist theory, however, conceiving of feminist thought as a coherent or unified cannon of thought is difficult.

The stated goal of women's liberation, the amelioration of injustices done to women as a group, fails to provide any deeper cohesiveness of purpose for feminists. Indeed the ostensible solidarity of feminism is quickly riven asunder once we look beneath the superficial veneer of feminist consensus and recognize the wide range of feminist sub-versions: liberal feminism, Marxist liberalism, socialist feminism, radical feminism, postmodern feminism, existential feminism, and so on. ${ }^{26}$ While there is much overlap among feminist theories regarding the basic recognition that women have been and continue to be discriminated against based on their sex, the descriptive and explanatory accounts (and thus the prescribed paths to women's liberation) vary widely. ${ }^{27}$

25 Jaggar, 9.

${ }^{26}$ The enumerated list of approaches to feminist theory appears in Rosemarie Tong's book, Feminist Thought: A Comprehensive Introduction (Boulder, CO: Westview Press, 1989), 1.

${ }^{27}$ On this issue, Jean Grimshaw states that simply because most feminists believe that "women are badly treated and that they suffer from systematic social injustice because of their sex, it does not follow from this that any consensus is available as to the precise forms this oppression or injustice takes, or as to how they should be remedied." See Jean Grimshaw, Feminist Philosophers: Women's Perspectives on Philosophical Traditions (Brighton, Sussex: Wheatsheaf Books, 1986), 20. 
While feminists have made partial progress in the development of a theoretical route to women's liberation, they lament the fact that there exists a dearth of available comprehensive feminist political or social theories. Catherine MacKinnon explains: "Feminism has no theory of the state." ${ }^{28}$ Consequently, feminists have looked to mainstream political theories of state (e.g., liberalism, Marxism, socialism, etc.) as possible vehicles by which to achieve women's liberation. Despite this deficiency in feminist theory, the descriptive and explanatory principles alone (which feminist have proven prolific in generating) have facilitated feminism's rise to prominence as a method of critique.

Given the above description of feminist theory, several relevant considerations ought to be addressed regarding the treatment of feminism in this inquiry. For the task at hand, feminist theory is perhaps best understood as a method of critique rather than as a rival political theory akin to Rawls's theory of justice. ${ }^{29}$

Cognizant of the broad spectrum of ideas and theories existing within feminist thought, some limitations on the treatment of feminist theory must be imposed. While addressing only one version of feminist theory would limit the scope (and hence the value) of this project, an attempt to address feminist thought in all of its variegated forms is beyond the ambit of this inquiry. Subsequently, my approach to feminist theory will be

${ }^{28}$ Catherine A. MacKinnon, Toward a Feminist Theory of State (Cambridge, MA: Harvard University Press, 1989), 157.

${ }^{29}$ On this theme, see Seyla Benhabib and Drucilla Cornell, "Introduction: Beyond the Politics of Gender," in Feminism as Critique, eds. Seyla Benhabib and Drucilla Cornell (Minneapolis, MN: University of Minnesota Press, 1991). 
specifically organized around three distinguishable feminists' conceptions of the gendered self, which in large measure form the basis of their critiques of Rawls's notion of personhood.

Lastly, this seems the proper place to explain why I will focus only on feminists' critiques of the liberal self. In general, feminists have devoted increasing attention to questions surrounding the notion of persons, as it effects both mainstream and feminist theoretical inquiry. As feminists have had to concede that their standard critiques against liberalism could be accommodated within the purview of contemporary liberal theory, the trend within feminism has been to refocus their critique by concentrating specifically on the liberal self; a critique they believe cannot be subsumed and amended within the liberal framework. ${ }^{30}$ In addition, feminists have devoted much energy to exploring and developing their own conception of the gendered self, which they hope will prove superior to the allegedly gender-neutral liberal self. ${ }^{31}$ Given these factors, I think the focus of inquiry is warranted, as feminist critiques of the liberal self are of central importance in comprehending the contemporary debate between liberals and feminists.

${ }^{30}$ For a brief discussion on this matter, see Benhabib and Cornell, 11.

${ }^{31}$ Though Okin has concentrated her efforts on critiquing the position of the family within liberal theory, she notes that "much feminist intellectual energy in the 1980s" has been devoted to developing a conception of the self different than that defined by Rawls and other liberal theorists. See Susan Moller Okin, Justice, Gender, and the Family (New York: Basic Books, 1989), 15. 


\section{The Gendered Self}

In conceptual terms, the notion that the self should be gendered in some fashion has been a leitmotiv in feminist writings; ironically, it is also a notion that has been a rising source of disagreement among feminists. Broadly speaking, the concept "gendered self' can be taken to mean a description of persons that attempts to identify and take into account relevant differences between the sexes-a conception of persons that is in some sense constituted by one's gender identity. While a few feminists have been reluctant to support gendering the subject in this way, the overwhelming majority of feminists have been inclined to support some notion of a gendered self. Even so, feminist interpretations of this notion have taken on different complexions.

During the 1960s, feminists "pursued a traditional liberal model of equality, a model premised on the notion that women and men are in all important respects the same and should be treated the same." 32 Today, this position is associated with traditional liberal feminists, or "sameness feminists," who reject the notion of the gendered self and instead "advocate gender-neutral categories that do not rely on gender stereotypes to differentiate between men and women." ${ }^{33}$ The implication of this gender-neutral approach is that the underlying commonality between men and women is highlighted and

\footnotetext{
${ }^{32}$ Anne C. Dailey, "Feminism's Return to Liberalism," The Yale Law Journal 102 (1993): 1267.

${ }^{33}$ Joan C. Williams, "Deconstructing Gender," in Feminist Legal Theory: Readings in Law and Gender, eds. Katharine T. Bartlett and Rosanne Kennedy (Boulder, CO: Westview Press, 1991), 110.
} 
privileged over any account of the self that is gender differentiated (i.e. the self exists prior to a self that is specifically gendered).

During the early 1970s, many feminists began to reject the gender-neutral account of the self supported by traditional liberal feminism and found within liberal political theory, and instead emphasized the differences between the sexes. These feminists argued that the liberal notion of the self did not adequately take into account important sexual differences (i.e., biological, psychological, cultural, and/or epistemological) that exist between men and women. In turn, they began to question the ability of liberalism to implement equal opportunity if, in their view, the liberal model could not take into account relevant sexual differences in their description of the subject. No longer was feminist theory going to "aim for parity, equivalence, or disinterested treatment under the prevailing standards; rather, it starts from, and affirms, the difference between men and women., 34

Given this rejection of the gender-neutral approach to the self, the trend within feminism shifted toward what has been called the "difference approach," an approach that affirmed the notion of the gendered self. "The philosophy underlying the difference approach", explains MacKinnon, "is that sex is a difference, a division, a distinction, beneath which lies a stratum of human commonality, sameness." ${ }^{, 35}$ Juxtaposed with the

${ }^{34}$ Christine Sypnowich, "Justice, Community, and the Antinomies of Feminist Theory," Political Theory 21 (August 1993): 490.

${ }^{35}$ Catharine A. MacKinnon, "Difference and Dominance," in Feminist Legal Theory: Readings in Law and Gender, eds. Katharine T. Bartlett and Rosanne Kennedy (Boulder, CO: Westview Press, 1991), 82. 
neutral concept of the self explained above, the difference approach suggests that as persons we are gendered as women and men before any common humanity. In the view of these feminists, then, humans must be considered gendered selves and not simply gender-neutral selves-for gender-neutral selves deny the fundamental differences between men's and women's nature. The implication here is that the primary, fundamental determinant of our identity is gender.

In the 1980s, this difference theme continued to resonate in feminist theory; however, it took an interesting new turn. Feminists were no longer simply debating the inherent differences between men and women, they were also considering important differences between women themselves. For many feminists, the definition of the "essential" woman of the 1970s appeared flawed, as it excluded a whole range of women whose characteristics varied according to experience, color, race, ethnicity, class, and other factors. This, in turn, launched a new series of conflicts among feminists coined "the essentialism-anti-essentialism debates." ${ }^{36}$

Responding to charges of essentialism, the trend in feminist theory at present indicates a partial retreat from the 1970 s idea of the gendered self. ${ }^{37}$ In recoiling from

\footnotetext{
${ }^{36}$ Naomi Schor, "Introduction," in The Essential Difference, eds. Naomi Schor and Elizabeth Weed (Bloomington, IN: Indiana University Press, 1994), vii.

${ }^{37}$ Elizabeth Grosz defines essentialism as follows: "Women's essence is assumed to be given and universal and is usually, though not necessarily, identified with women's biology and "natural" characteristics. Essentialism usually entails biologism and naturalism, but there are cases in which women's essence is seen to reside not in nature or biology but in certain given psychological characteristicsnurturance, empathy, supportiveness, non-competitiveness, and so on. Or Women's essence may be attributed to certain activities and procedures which may or may not be dictated by biology observable in social practices, intuitiveness, emotional responses, concern and commitment to helping others, etc. Essentialism entails the belief that those characteristics defined as women's essence are shared in common by all women at al times: it implies a limit on the variations and possibilities of change-it is not possible
} 
this essentialist notion of the gendered self, however, many feminists have not advocated a return to the gender-neutral conception of persons. Instead they have attempted to dodge the charges of universalism and essentialism linked to the earlier notion of the self by describing the gendered self as a situated creature embedded within a particular historical, social and cultural context.

In light of this history, three feminist approaches to the subject that dominate contemporary feminism can be delineated and thus will be considered in this analysis: cultural feminism, relational feminism, and postmodern feminism. ${ }^{38}$ What "unites" these positions, argues Christine Sypnowich, is their "critique of the atomistic individual as a male construction with its roots in the Enlightenment and [their] suspicion of the masculine world of Cartesian epistemology, market contracts, impartial justice, equal rights, and indeed, we might add, political struggle itself." ${ }^{\text {,39 }}$ However, cultural, relational and postmodern feminism all take a somewhat different route to gendering the self. ${ }^{40}$

for a subject to act in a manner contrary to her nature." See Elizabeth Grosz, "Sexual Difference and the Problem of Essentialism," in The Essential Difference, eds. Naomi Schor and Elizabeth Weed (Bloomington, IN: Indiana University Press, 1994), 84.

${ }^{38}$ Feminist theorists have generally construed cultural feminism and relational feminism as one in the same. Indeed, there are important overlaps between relational and cultural feminism, however, I will make the distinction between the two. With regard to women's differences, relational feminism is more closely linked to biological accounts, while cultural feminism is associated with social accounts for explaining women's and men's differences.

${ }^{39}$ Sypnowich, 490 .

${ }^{40}$ The position held by traditional liberal feminist and "sameness" feminists, as indicated earlier, will not be discussed for obvious reasons. 
For the purpose of this analysis, by identifying and delineating the differences that exist between feminist conceptions of the self, we will see which of these approaches proves to be not only the most fruitful for feminists in gendering the self, but also which approach proves to make best the claim that the Rawlsian self is a male or masculine subject.

\section{Liberal Political Theory}

Marked by a long and successful history, the liberal tradition has undergone manifold transformations. Analogous to feminist theory, one finds across the terrain of liberalism's development many diverse variants of the theory. While there is some vague notion of liberty or freedom that appears to be threaded throughout all brands of liberalism, a comprehensive definition of liberalism seems elusive. Inasmuch as no single formulation of liberalism is inclusive of the spectrum of ideas present within the liberal tradition, often what counts as "liberal" is a source of disagreement among liberals themselves.

Nevertheless, despite the debate over what the definitive principles of liberalism are, and the apparent lack of consensus among contemporary liberals, there are a set of underlying assumptions--grounded on twin conceptions of the person and societywhich have allowed liberalism to remain "an integral outlook."41

\footnotetext{
${ }^{41}$ John Gray, Liberalism (Minneapolis: University of Minnesota Press, 1986), xi.
} 
Drawing on several liberal theorists, I will roughly outline the foundational tenets and assumptions found in contemporary liberalism. First, at the heart of contemporary liberal theory is the belief that all persons should be equally regarded as individual creatures of moral worth. It has followed from this that liberalism has been considered "individualistic, in that it asserts the moral primacy of the person against the claims of any social collectivity," and "egalitarian, inasmuch as it confers on all men the same moral status. ${ }^{, 42}$

The second assumption is that persons are beings who not only possess agency, but also actively "seek the capacity for agency." ${ }^{43}$ Liberal theorist Steven De Lue claims, "persons wish to define their own goals, develop their own talents, interests, and needs, and determine strategies for action that are effective means to attain self-determined purposes. ${ }^{44}$

Many liberal theorists, such as Rawls, have posited this assumption in terms of "the good": the assumption is that all persons have "a conception of their good" and thus want to lead a life that is good by pursuing their own self-defined vision of the good. ${ }^{45}$ Moreover, the actions of persons, notes Bruce Ackerman, "cannot be understood apart

${ }^{42}$ Ibid., $\mathrm{x}$.

${ }^{43}$ Steven M. De Lue, "The Idea of a Duty to Justice in Ideal Liberal Theory," in Liberals on Liberalism, ed. Alfonso J. Damico (Totowa, New Jersey: Rowman \& Littlefield, 1986), 97.

${ }^{44}$ Ibid.

${ }^{45}$ Rawls, Theory, 19. 
from their conceptions of the good." ${ }^{46}$ One's conception of the good is in some fashion constitutive of her identity.

The strategy with which we come to lead a good life is not a static process, however. As persons capable of agency, we consider and may even revise our conception of the good based on different experiences and access to information. These “deliberations," notes Will Kymlicka, are not simply a method for determining the most effective means for achieving our immediate goals, they are also "judgments about the value of those ends and projects, and we recognize that our current or past judgments are fallible."47

Third, in order for people to lead a life that is good, several preliminary factors must be secured. As individuals, we must be willing to "lead our life from the inside, in accordance with our beliefs about what gives value to life."48 In addition, the social scheme must be able to secure the essential freedom and resources necessary "to question those beliefs, to examine them in the light of whatever information and examples and arguments our culture can provide." 49 Thus, the social scheme must ensure equal liberty for all persons to pursue their conceptions of the good as well as ensuring that "all persons are provided the basic primary goods (such as rights and liberties, equality, self-

${ }^{46}$ As quoted by Richard E. Flathman, Towards a Liberalism (Ithaca, NY: Cornell University Press, 1989), 49.

${ }^{47}$ Will Kymlicka, Liberalism, Community and Culture (New York: Clarendon Press, 1989), 11.

${ }^{48}$ Ibid., 13.

${ }^{49}$ Ibid. 
respect, income and wealth) necessary for an agency-centered life." ${ }^{50}$ (Of course, what constitutes "equal liberty" and "basic primary goods" has been subject to wide interpretation.)

This definition should not be considered an exhaustive one; rather my purpose is: (1) To provide a general framework of some of the defining features of liberalism in which to situate the forthcoming analysis; (2) To highlight some of the foundational assumptions that undergird Rawls's liberalism; and (3) To bring attention to the difficulty of treating liberalism as a comprehensive doctrine (i.e., beyond a select set of assumptions). As Kymlicka warns: "Different critics of 'the liberal tradition' are often attacking different targets-some discussions are directed at the articulated premises or specific liberal theorists, others at the habits and predispositions of liberal-minded politicians and jurists, yet others at some more nebulous world-view which underlies Western culture generally, not just our political tradition."51 Heeding Kymlicka's caveat, my concern will be in evaluating feminist criticisms of Rawls's conception of the person and determining whether their interpretation can correctly be attributed to his version of liberalism.

${ }^{50}$ De Lue, 97.

${ }^{51}$ Kymlicka, Liberalism, Community and Culture, 9. 


\section{John Rawls: A Theory of Justice and Political Liberalism}

As noted, the breadth of the liberal tradition is great, and Rawlsian liberalism is simply one version among many. I submitted, however, that Rawls's Theory is of central importance in contemporary liberalism given the fact that this has been the pole around which liberals rally and the magnet of criticism for non-liberals. Accordingly, Rawls presents one of the most representative versions of liberalism-the version of liberal political theory from which I will mount my defense of liberal conceptions of the self against feminist claims of gender bias.

In approaching Rawls's work, however, an important distinction must be drawn between "justice as fairness" (hereafter referred to as JAF) and "political liberalism." Since the publication of Theory, Rawls published a series of articles that later culminated in the publication in 1993 of Political Liberalism. The significance of this book's production is that it seemed to signal a partial departure by Rawls from JAF. While the salience of this alteration is an open question, as Mulhall and Swift explain, "it is sufficient to make the point that Rawls himself clearly regards the significant change as that which now makes the theory a specifically political conception of justice, or a specifically political brand of liberalism.. ${ }^{, 52}$ By emphasizing the political, Rawls has attempted to shift JAF away from being considered a comprehensive moral doctrine whose universalism transcends specific historical or cultural embodiments to a more contextualized theory of justice. For our purposes, then, JAF will refer to Rawls's theory

\footnotetext{
${ }^{52}$ Mulhall and Swift, 168.
} 
of justice as defined in Theory, and political liberalism will refer to the Rawls's later work on JAF (i.e., JAF as a distinctly political theory of liberalism).

\section{The Direction of Inquiry}

The structure of this analysis is designed to address the question of whether Rawls's conception of the self is defensible against feminist charges of gender bias. In accordance with the stated purpose, then, the contents of the chapters are as follows. The analysis begins in chapter two with an expository discussion of Rawls's conception of justice as developed in Theory and in Political Liberalism. My purpose here is threefold. In the first section, I will present a brief and elementary introduction of Rawls's project of JAF as articulated in Theory. In the second section, I will draw out a list of themes that both reflect Rawls's conception of persons, and also the issues that I will later focus upon in discussing feminists' critiques of this notion. The third section will take up the themes detailed in second section and review how these have been altered by Rawls's political liberalism.

Next, chapter three will delineate specific feminist objections to the liberal conception of the person. Having identified these contentions, chapter four and chapter five will be devoted largely to evaluating the cogency of these critiques. In chapter four, I will be concerned with evaluating whether feminists have correctly interpreted Rawls's liberal notion of persons in either JAF or in political liberalism. In light of Rawls's shift to political liberalism and his development of a new political conception of persons, I will 
evaluate whether Rawls's conception of persons in Theory or in Political Liberalism is best able to counter feminists contentions.

In chapter five, I will be concerned with the success of feminists in gendering the self, and whether they prevail in proving that Rawls's notion of the self is male or masculine gendered. The issue of gendering the self is of chief importance for feminist arguments directed at the Rawlsian self. If feminists are unable to articulate a set of gender-based attributes (i.e., gender the self), they will necessarily lack the theoretical tools neccesary for making the subsequent claim that the Rawlsian self is male or masculine. I will conclude, then, by reviewing where feminists critiques have failed at proving Rawls's conception of the self (as articulated in Theory or Political Liberalism) is gender biased. 


\section{CHAPTER II}

\section{JOHN RAWLS'S CONCEPTION OF THE SELF: FROM A THEORY OF JUSTICE TO POLITICAL LIBERALISM}

As indicated in the previous chapter, the liberal conception of the self has figured prominently in feminist contentions with-and rejections of-liberal political theory. This chapter's aim is to review how the notion of persons is framed in Rawls's liberal conception of justice. Before turning to the task of explicating Rawls's conception of the self, however, several issues ought to be addressed for the purpose of clarifying the forthcoming exegesis.

The first issue of concern pertains to Rawls's presentation of the self in both Theory and Political Liberalism. As students of liberal theory will have noted from the outset, Rawls has emphatically disavowed any endorsement of a substantive account of human beings in his conception of justice. His stated rejection of a comprehensive or metaphysical portrayal of persons, unfortunately, makes an investigation of Rawls's conception of the self a great deal more complicated. ${ }^{53}$

${ }^{53}$ Here it is important to clarify the use of the terms "metaphysical" and "comprehensive." Rawls was initially concerned with not advancing any substantial metaphysical claims about persons in JAF. Later, when Rawls began to develop his political conception of justice, and therein his political notion of persons, he was not concerned with metaphysical claims, but rather with comprehensive claims about persons. By the term "comprehensive" (as in a comprehensive doctrine about persons), In Political Liberalism (59), Rawls states that: (1) it "covers the major religious, philosophical, and moral aspects of human life in a more or less consistent and coherent manner"; (2) "[i]t organizes and characterizes recognized values so that they are compatible with one another and express an intelligible view of the world"; and (3) "it normally belongs to, or draws upon, a tradition of thought and doctrine". According to Mulhall and Swift (177), the motive behind Rawls's switch "is that it is possible that even if the conception of the person involved were not merely that of the person as citizen but did indeed involve a comprehensive 
Human beings are depicted by Rawls as rather elusive and shadowy figures in the pages of both Theory and Political Liberalism. ${ }^{54}$ Indeed at no point does Rawls enumerate a comprehensive list of the essential qualities for conceiving of persons as human beings. One is left to speculate whether Rawls has even offered a conception of persons, or an interpretation of human nature, in his conception of justice. What is of interest here is: (1) Why Rawls does not want to provide a substantive visions of persons, and (2) Whether Rawls does in fact ascribe any characteristics or attributes to persons that might in turn frame some rudimentary conception of persons.

For the most part, the answer to the first question lies with Rawls's attempt to craft a liberal conception of justice capable of securing the fundamental rights of persons as moral beings, with their own conception of the good life, while remaining neutral between competing conceptions of the good. ${ }^{55}$ In matters of persons pursuing their conception of the good, Rawls believes that the state should remain neutral in providing a medium within which people can design, revise, and act upon their own vision of the

moral, philosophical or religious doctrine, such as a fundamental commitment to autonomy in all areas of life, still this might not commit the advocate of the theory to any genuinely metaphysical claim, where the term 'metaphysical' refers to an ontological claim about the essence of human beings".

${ }^{54}$ In Political Liberalism, Rawls presents a more detailed (political) conception of persons, but only in the sense that they are to be considered citizens in a particular political culture. That is to say, the scope of Rawls's concept of persons is sharply restricted only to those exclusive political ideals, convictions and conceptions implicitly shared by citizens in the "public political culture" of a democratic polity. Beyond this political conception of persons as citizens, however, Rawls remains intentionally vague about the nature of persons.

${ }^{55}$ Kymlicka, in Liberalism, Community and Culture (96-97), interprets Rawls's notion of neutrality to say "that governments cannot use as their justification for any action the fact that one person's way of life is more or less worthy than another's [since] government neutrality is part of what it is to treat people as equals." 
good. Moreover, the state should not institute or enforce its own conception of the good. $^{56}$

Had Rawls offered a "thick" or plenary conception of the good-either for persons or for persons via the community or the state, this would have resulted in two unsatisfactory outcomes. ${ }^{57}$ It would commit Rawls to a specifically metaphysical or comprehensive account of persons, which would ultimately prove unattractive and theoretically untenable. In addition, such a theory would fail to remain neutral in tolerating different conceptions of the good. It seems clear then why Rawls has not rendered a more elaborate version of a person's individual good-which would lead to a "thick" conception of persons-in his theory of justice. To do so would not only call into question the neutrality of, and therein the theoretical defensibility, of his liberal conception of justice, but would also fail to take seriously persons as moral beings worthy of respect. ${ }^{58}$

This brings us to the latter question: I will demonstrate in this chapter that on a close reading of Rawls's work one finds threaded throughout Theory a set of normative claims that taken together compose a distinctly liberal conception of persons. In Political

${ }^{56}$ For an informative discussion on the liberal ideas of state neutrality and toleration of different conceptions of the good, see the influential work of Susan Mendus, Toleration and the Limits of Liberalism (Atlantic Highlands, NJ: Humanities Press International, Inc., 1989), especially chap. 4.

${ }^{57}$ The following points were similarly made by Thomas W. Pogge in Realizing Rawls (Ithaca, NY: Cornell University Press, 1989), 94-95.

${ }^{58}$ For a general, yet informative, discussion on the idea of regarding persons as "moral" beings and the rational justification behind treating persons as creatures of respect, see S. I. Benn and R. S. Peters, The Principles of Political Thought (New York: The Free Press, 1959), chap. 2. 
Liberalism, Rawls takes a different tack in discussing personhood. Rawls formulates (or, rather, extracts) a set of normative claims based not on his own liberal conception of persons, but on an implicitly shared philosophical ideal among members of a democratic society. Persons inhabiting a specific political sphere, contends Rawls, view themselves as citizens with certain normative features in approaching matters of "political" justice. 59 Accordingly, Rawls is able to frame a set of normative conceptions on a distinctly political conception of persons qua citizens, not on a metaphysical or comprehensive conception of persons. ${ }^{60}$

The second issue of concern is in reference to the semantic, and therein the conceptual, problems that plague countless interpretations of Rawls's conception of persons. Failure to recognize the subtle distinctions between "persons," "parties," and "citizens," argues Rawls, has led many to misread his theoretical position on human beings. For purposes of clarification in the forthcoming analysis, Rawls interprets each of these concepts to embody a particular view in his conception of justice.

The notion of the person, explains Rawls, is used solely to capture the view "of you and me"-it is the view "from which justice as fairness, and indeed any other

${ }^{59}$ Note that I am using the term "political" justice, and not "social" justice here. In Political Liberalism (38), Rawls writes, that "the conception of justice affirmed in a well-ordered democratic society must be a conception limited to... 'the domain of the political' and its values." Thus, Rawls's political liberalism should be regarded as solely a conception of political justice and not a conception of social justice which was the focus of JAF.

${ }^{60}$ Following Mulhall and Swift (passim), I will employ the terms "person qua citizen" to denote Rawls's political conception of persons. In addition, when explicating Rawls's conception of persons as explicated in Political Liberalism, the terms "citizen," "person qua citizen" and "political conception of persons" will all be used interchangeably. 
political conception, is to be assessed." Liberalism) represents a specifically political conception of persons. As Rawls points out, the idea of the citizen is a normative (or more specifically a moral) conception, which begins from our everyday conception of persons as the basic units of thought, deliberation, and responsibility, and adapted to a political conception of justice and not to a comprehensive doctrine. It is in effect a political conception of the person, and given the aims of justice as faimess, a conception suitable for the basis of democratic citizenship. ${ }^{62}$

The view captured here is the way "you and I" think and understand ourselves as citizens in the political sphere-not the private realm-as members of a constitutional democracy.

Lastly, the term "parties" is used in reference to a particular hypothetical construct (i.e., the original position) that Rawls has modeled in his conception of justice. The original position, purports Rawls, "is set up by you and me in working out justice as fairness, and so the nature of the parties is up to us: they are merely the artificial creatures inhabiting our device of representation." either the representatives of persons (as outlined in Theory) or of citizens (as defined in Political Liberalism) in the original position, not in our veridical existence. Thus, the view captured here is how "you and I" want to be represented in the original position for the purpose of determining the fair and just way of distributing rights and duties. ${ }^{64}$

\footnotetext{
${ }^{61}$ Rawls, Political Liberalism, 28.

${ }^{62}$ Ibid., 18-19.

${ }^{63}$ Ibid., 28.

${ }^{64}$ Ibid., 3.
} 
Having commented on the three ways persons are conceived in Rawls's projectthat is, as persons, as person qua citizens, as persons or citizens qua parties in the original position-attention may now be devoted to the fundamental problem of interpretation. For many critics of Theory, the original position seems to circumscribe a definitive set of metaphysical assumptions about the nature of persons based on the characterization of the parties in this hypothetical contract. ${ }^{65}$ Rawls warns, however, that such a reading is erroneous: "[T]he idea of the original position and the description of the parties may tempt us to think that a metaphysical doctrine of the persons is presupposed...[However,] this interpretation is mistaken." 66

This points us to the crux of the problem when reviewing Rawls's conception of the person. We must determine: (1) whether we should count attributes given to the parties in the original position as characteristics of actual persons, contra Rawls's claims; and (2) we must decide if there are any significant features that Rawls has accorded to actual human beings outside of this original position.

${ }^{65}$ This problem of interpretation--that is, of ascribing characteristics of the parties to actual persons-seems to be more symptomatic of the presentation of these concepts in Theory than in Political Liberalism. In the later work, Rawls is much more careful in delineating and draw out the distinctions between the concepts. As noted, Rawls attempts to distinguish "parties" in the original position from actual persons. While at some points in the text this distinction between actual persons and parties (representing persons) in the original position is lucid in Theory, at other moments it seems less obvious. This lack of clarity on Rawls's part, I think, has in turn led many critics to wrongly assume that attributes given to the parties are those given to human beings generally. Whether fault lies with Rawls convoluted account of these two notions, or with critics "error" in misinterpreting these conceptions, is purely a speculative matter. However, I am inclined to think that culpability resides with both parties in the debate.

${ }^{66}$ Rawls, Political Liberalism, 29. 
Following Allen Buchanan, I am inclined to think that it is prima facie "wrong to extract Rawls' statements about the parties and read them as if they were his generalizations about human beings." ${ }^{67}$ However, we are similarly mistaken if we presuppose that Rawls's conception of justice does not rest on some conception of persons. The argument Mulhall and Swift adeptly make is that since Rawls's theory explicitly embodies the claim that, when it comes to matters of justice, people should be regarded as distinct from their particular natural endowments, social positions and ends, but possessed of a highest-order interest in their capacity to frame, revise and rationally pursue their conceptions of the good-such a claim amounts to an assessment of what is important about people, [and] what constitutes their well-being. ${ }^{68}$

One finds underlying Rawls's conception of justice, then, a thin outline of a conception of persons.

The third and final concern is Rawls's twin conceptions of the self: one as the conception of persons in Theory, the other the political conception of persons as citizens in Political Liberalism. Rawls's treatment of persons in Theory is presented in a manner that is somewhat different from the conception delineated in his more recent publication, Political Liberalism.

Since Rawls's conception of persons is embedded within the broader context of his work, we must look at the trends within these writings to render intelligible why this has culminated in two different, yet related, approaches to the self. Consonant with the

${ }^{67}$ Allen Buchanan, Marx and Justice: The Radical Critique of Liberalism (Totowa, NJ: Rowman and Littlefield, 1982), 135.

${ }^{68}$ Mulhall and Swift, 206-207. 
opinions of other liberal theorists, Chandran Kukathas and Philip Pettit have detected two philosophical trends within Rawls's writings since the publication of Theory. In the first “movement," from 1971-1982, "Rawls offers a series of replies to objections, along with some changes to and elaboration's of his theory of justice, which go to provide a deeper understanding of the Kantian nature of his moral philosophy." 69 In the second "movement," from roughly 1982 to 1989 , "Rawls forswears Kantianism and recasts his philosophical enterprise as a political rather than a moral endeavor." ${ }^{, 70}$

Recently, however, Rawls has labored to reconcile these two contrasting philosophical movements under one coherent theory in Political Liberalism. ${ }^{71}$ I will assume, then, that this latest work by Rawls is the definitive statement of his newly fashioned political conception of justice, political liberalism. More importantly, this structural development in Rawls's venture has yielded two different approaches to the conception of justice by Rawls, which in turn has effected how the conception of the self has been articulated in Theory and Political Liberalism. Recognizing this requires us to treat these two conceptions separately in the exposition.

${ }^{69}$ Chandran Kukathas and Philip Pettit, Rawls: A Theory of Justice and lts Critics (Stanford, CA: Stanford University Press, 1990), 120. This first temporal period includes the following works by Rawls: (1) "Concepts of Distributional Equity. Some Reasons for the Maximin Criterion" (1974); (2) "The Independence of Moral Theory" (1974-75); (3) "Fairness to Goodness" (1975); (4) "The Basic Structure as Subject" (1978); (5) "A Well-Ordered Society" (1979); (6) "Kantian Constructivism in Moral Theory" (1980); and (7) "The Basic Liberties and Their Priority" (1982).

${ }^{70}$ Ibid. This second temporal period includes the following works by Rawls: (1) "Social Unity and Primary Goods" (1982); (2) "Justice as Fairness: Political not Metaphysical" (1985); (3) "The Idea of an Overlapping Consensus" (1987); (4) "The Priority of Right and Ideas of the Good" (1988); and (5) "The Domain of the Political and Overlapping Consensus" (1989).

${ }^{71}$ Rawls, Political Liberalism, xiv. 
With these preliminary remarks, we now may turn to the general outline of the chapter. Having divided the chapter into two sections, the first part will present a brief and general introduction to JAF as delineated in Theory. The purpose of this sketch is to provide the necessary background in which to situate the discussion of Rawls's conception of the self. With this orientation, I will turn to an exegesis of the Rawlsian self by drawing out several themes and normative claims that underlie this conception.

The second section of the exposition will be devoted to Rawls's conception of persons as delineated in Political Liberalism. In summation, the major theoretical contrasts between the notion of the self developed in Theory and in Political Liberalism will be highlighted.

\section{The Conception of Persons in A Theory of Justice}

In Theory, the underlying purpose, for Rawls, was to articulate a set of moral principles; that taken together would frame a conception of justice by which the fundamental institutions of society could be regulated in a fair and just manner. ${ }^{72}$ The foremost question for us, then, is by what method are these principles of justice to be chosen, and in what sense are these principles to be considered fair or just? To answer these questions, we must briefly unpack the two main concepts that lie not only at the heart of JAF, but also his conception of persons: the "original position" and the "veil of ignorance."

${ }^{72}$ Rawls, Theory, 11. 
The original position is designed by Rawls as a hypothetical social contract-an abstract and procedural model that frames an initial situation through which "parties" can determine principles of justice. ${ }^{73}$ When contemplating matters of social justice, we are to envision what parties in the original position would agree to for the purpose of regulating the "basic institutions" of society. In this way the original position provides both a method for determining principles of justice and "an independent justificatory source."

The principles of justice-agreed to by parties in the original position-will be just because the procedure itself is fair. ${ }^{75}$ In other words, since the procedure is fair, the principles agreed to by the parties will in turn be fair. This, Rawls notes, "explains the propriety of the name 'justice as fairness': it conveys the idea that the principles of justice are agreed to in an initial situation that is fair." ${ }^{76}$

The question that follows, then, is what moral basis does Rawls have in establishing the fair conditions to be embodied in the original position? In reply, Rawls holds that the conditions fixed in the original position will presumably coalesce with our intuitive moral judgments as to what would be considered a fair and just situation (as

${ }^{73}$ Rawls views social justice (i.e., the fair distribution of rights and duties to member's in society), as the proper subject of "pure procedural justice." In Theory (85), Rawls claims that social justice, as a pure procedural justice, establishes (1) "an independent criterion for what is a fair division, a criterion defined separately from and prior to the procedure which is to be followed." And, thus, made it "possible to devise a procedure that is sure to give the desired outcome." 1990), 72.

${ }^{74}$ Tom Campbell, Justice (Atlantic Highlands, NJ: Humanities Press International, Inc.,

${ }^{75}$ Rawls, Theory, 136.

${ }^{76}$ Ibid., 20. 
yielded in "reflective equilibrium"). ${ }^{77}$ We would set certain limiting conditions on the original position in order for the procedure to be considered fair.

This brings us to the second idea in JAF-the notion that parties in the original position are to be situated behind a "veil of ignorance" for the purposes of rendering a fair position. As a limiting condition, parties in the original position will not have access to certain knowledge. Rawls outlines,

First of all, no one knows his place in society, his class position or social status; nor does he know his fortune in the distribution of natural asserts and abilities, his intelligence and strength, and the like. Nor, again, does anyone know his conception of the good, the particulars of his rational plan of life, or even the special features of his psychology such as his aversion to risk or liability to optimism or pessimism. More than this, I assume that the parties do not know the particular circumstances of their own society. ${ }^{78}$

The aim of excluding these factors is to (1) rule out those "contingencies" that are morally arbitrary with regard to choosing principles of justice; and (2) to nullify those aspects that would set parties against each other. Left intact, these contingencies would surely render any agreement in the original position unfair and thus unjust.

Beyond the above facts, however, Rawls does include the more general facts about society and social life to parties in the original position. It is assumed that parties

${ }^{77}$ Ibid., 120. For Rawls, the way to match our considered moral judgments, with that which we consider to be fair conditions for determining fair principles of justice in the original position, is rendered through a process of "reflective equilibrium." This method, as relayed by Tom Campbell in Justice (73), "involves selecting our strongest and surest moral convictions as the provisional fixed point and then working backwards to the principles which would justify such intuition...In this way we move towards the elaboration of a set of consistent principles which, together with knowledge of social circumstances, lead us to make the judgments we do for the reasons we make them...And, so, by a to-and-fro process of reflection in which judgments are developed and revised and principles tested and refined, we finish with an 'equilibrium' of consistent judgments and principles."

${ }^{78}$ Rawls, Theory, 137. 
will "understand political affairs and the principles of economic theory; they know the basis of social organization and the laws of human psychology."79 $T$ This general knowledge is allowed primarily in order to fit the principles of justice to the realities of life, and therein the conditions that make a conception of justice necessary.

One more significant postulate is that parties in the original position would act in a rational manner when selecting principles of justice. ${ }^{80}$ With the above conditions taken together-the exclusion of individual particularities, the inclusion of "general information" of society, and the fact that parties are rational-Rawls believes he has modeled a foundational situation in the original position that proves capable of yielding a definitive conception of justice.

The two principles of justice that would herein be agreed to by the parties in the original position are as follows. ${ }^{81}$ The first principle-denoted The Greatest Equal Liberty Principle - to be chosen by the parties orders that: "Each person is to have an

${ }^{79}$ Ibid.

${ }^{80}$ While I will elaborate on Rawls's notion of rationality as outlined in Theory later in the thesis, it seems appropriate here to make a few notes. In the conditions that frame the original position, Rawls assumes that parties will have the following information: (1) a conception of the good, (2) a sense of justice and (3) a ranking of the primary social goods of society. Based on this information, Rawls contends that parties will be able to "make a rational decisions in the ordinary sense." That is to say, "the original position has been defined so that it is a situation in which the maximin rule applies." The principle of maximin, writes Rawls, "tells us to rank alternatives by their worst possible outcomes: we are to adopt the alternative the worst outcome of which is superior to the worst outcomes of the others." Thus given the information allowed into the original position, parties in the original position will conduct themselves in a rational manner according the principles of maximin in selecting the principles of justice. (Rawls, Theory, $143,155,152-153)$.

${ }^{81}$ The first principle of liberty is to be held lexically prior to the second principle of distribution and opportunity. Thus, the concerns of the second principle should not at any time take precedence over the first principle. 
equal right to the most extensive total system of equal basic liberties compatible with a similar system of liberty for all., 82

The second principle-labeled The Difference Principle and The Fair Equality of Opportunity Principle - to be chosen by parties demands that: "Social and economic inequalities are to be arranged so that they are both: (a) to the greatest benefit of the least advantaged, consistent with the just savings principle, and (b) attached to offices and positions open to all under conditions of fair equality of opportunity." ${ }^{, 83}$

Though this account of Rawls's theory is selective and in no way an exhaustive account of JAF, it sufficiently conveys the gist of Rawls's project. The rest of this section is devoted to outlining those relevant themes that, in some sense, shape Rawls's conception of persons. In drawing out the principal components that frame the Rawlsian self, it should be noted that many of these concepts overlap extensively with other points being canvassed. Nevertheless, the following sections cover what I take to be the ideas significant in Rawls's conception of persons.

\section{Moral Individualism}

At the heart of Rawls's conception of persons, lies the commitment to a form of methodological individualism. Following Kant's moral theory, Rawls's underlying desideratum in JAF is to take seriously the idea of treating persons as creatures worthy of

\footnotetext{
${ }^{82}$ Rawls, Theory, 302.

${ }^{83}$ Ibid.
} 
individual merit and respect in their own right. "To regard persons as ends in themselves in the basic design of society," writes Rawls, "is to agree to forgo those gains which do not contribute to their representative expectations." ${ }^{84}$ Society, to some degree, endures primarily for the welfare of individual persons; hence, the rights of individuals cannot be prima facie trumped simply for the good of the state, the community, or others. ${ }^{85}$

This endorsement of individualism by Rawls is modeled into the conditions of the original position. Rawls holds that in this position parties representing persons will "have equal representation as moral persons who regard themselves as ends and the principles they accept will be rationally designed to protect the claims of their person." ${ }^{.86}$ The relevant point here is that Rawls regards individual persons as the rudimentary determinant of analysis in choosing and adopting the principles of justice.

From the outset, this raises the issue of what we mean by the term "individualism." We need a description of individualism that goes beyond the simple claim that individuals are considered to be the theoretical core of JAF. A distinction

${ }^{84}$ Ibid., 180.

${ }^{85}$ For Rawls, to suggest that the good of society trumps the rights of individuals, would be to rely either on a perfectionist account of community or on an organic notion of society. Since both notions are unsatisfactory because they fail to treat persons in an appropriate manner, Rawls contends in Theory (264) that "we do not want to rely on an undefined concept of community, or to suppose that society is an organic whole with a life of its own distinct from and superior to that of all its members in their relations with one another."

${ }^{86}$ Rawls, Theory, 180. 
between a metaphysical account of individualism and a moral account of individualism would be beneficial. ${ }^{87}$

On the one hand, a metaphysical account of individualism, has already, in some sense, fixed the essential features of personhood and what the good of individuals entails. On the other hand, moral individualism, explains Kukathas and Pettit, is a theory of individualism that focuses only on how the institution of justice would be judged; that is, "a socio-political arrangement ought to be judged, and only judged, by how it affects individuals; it ought to be judged favorable for promoting the good of individuals [and] unfavorably for not doing so." ${ }^{\text {88 }}$ Beyond this, moral individualism does not depend on or endorse a specific good for individuals or make statements about their metaphysical constitution.

Paralleling the description of moral individualism, the scope of JAF focuses only on "socio-political arrangements" (i.e., "basic structure") of society. ${ }^{89}$ Rawls's rationale behind this focus is that he believes that this basic structure fundamentally affects a person's chances in life- "what they can expect to be and how well they can hope to do."90 Thus, a conception of justice must be judged on account of how justly or fairly the basic structure allocates primary rights and duties to individuals. ${ }^{91}$

${ }^{87}$ For a further exegesis of the ideas of metaphysical individualism and moral individualism, see Kukathas and Pettit's excellent discussion in Rawls, 11-16.

${ }^{88}$ Ibid., 12.

${ }^{89}$ The "basic structure of society," lists Rawls in Theory (7), is "the political constitution and the principal economic and social arrangements."

${ }^{90}$ Rawls, Theory, 7. 
Following Kukathas and Pettit, Rawls's individualism is best characterized as that of a moral individualist, not a metaphysical individualist. ${ }^{92}$ Rawls's conception of justice aims to treat persons (both men and women) as unique individual moral agents by taking "seriously the plurality and distinctness of individuals." $" 93$ While Rawls is making a normative claim to the extent that in matter's of social justice individuals wish to be taken as the primary starting point (i.e., the rudimentary determinant of analysis), and the ultimate standard by which to assess a conception of justice, he is not necessarily positing a metaphysical account of individualism.

\section{Social Context and Individuals}

Rawls's individualism has raised a number of criticisms regarding the nature of the relationship between individuals and society. The communitarian camp has advanced the popular accusation that Rawls fails to recognize that persons are socially situated, embedded creatures that depend on their social environment for personal identity and conceptions of the good. ${ }^{94}$

${ }^{91}$ Ibid., 9-10.

${ }^{92}$ According to Kukathas and Pettit in Rawls (12), "Rawls is an outstanding example of a moral individualist."

${ }^{93}$ Rawls, Theory, 29.

${ }^{94}$ This argument can be found in a multitude of communitarian works. For a few noteworthy examples, see Michael Sandel, Liberalism and the Limits of Justice (Cambridge, MA: Cambridge University Press, 1982); Alisdair MacIntyre, After Virtue (South Bend, IN: Notre Dame University Press, 1984); Liberalism and Its Critics, ed. Michael Sandel (New York: New York University Press, 1984); and Charles Taylor, Sources of the Self (Cambridge, MA: Cambridge University Press, 1990). 
Despite what communitarian objections may imply, Rawls does not deny the importance of social contexts and society in his conception of justice. ${ }^{95}$ Rawls has a cardinal interest in society (and therein the primary institutions of this system) since it forms the primary scope of his conception of justice. As understood in JAF, Rawls discusses social factors in four significant ways.

In the first case, Rawls defines society as a cooperative enterprise between individuals. Persons in society cooperate in their relations with one another by acknowledging the fact that "certain rules of conduct [are] binding." 96 Thus, persons act cooperatively when they show a willingness to act according to these publicly recognized rules. While this explains how persons are supposed to act in a cooperative enterprise, it does not demonstrate why persons in society would want to cooperate.

Accordingly, Rawls states that persons in society cooperate for their "mutual advantage" because the principles of justice frames a set of "rules [which] specify a system of cooperation [that is] designed to advance the good of those taking part in it." 97 Despite the myriad interests that drive persons apart in society, they nevertheless have a

\footnotetext{
${ }^{95}$ Note that I use the term "social context" and "society" instead of community in discussing Rawls's conception of justice. In Political Liberalism (40), Rawls holds that the notion of community is "a special kind of association, one united by a comprehensive doctrine" that exists within the border context of a society. In this sense, we should regard communities as private associations that subscribe to, and are in turn constituted by, a specific comprehensive doctrine. A society is much broader in scope-and in turn a proper subject of justice-than a single community, one can find a matrix of smaller communities operating within the larger social system." Accordingly, Rawls notion of social context is aimed more at the broader level of society instead of particular sub-groupings - that is, communities-that comprise it.

${ }^{96}$ Rawls, Theory, 4.

${ }^{97}$ Ibid.
} 
common interest in a society peopled with cooperative individuals. The reason, asserts Rawls, is that "social cooperation makes possible a better life for all than any would have if each were to live solely by his own efforts." ${ }^{98}$ Based on our mutual motivation for the increased benefits of social cooperation, it is in the interest of individuals to band together, according to the recognized rules and procedures of conduct, into a cooperative social organization. In this way, Rawls's portrait of society is best viewed here as a prudential or instrumental basis for society.

In the second case, Rawls recognizes the way in which society, and therein the common social existence of its members, effects individuals when it comes to fashioning their wants, needs, and identity. Rawls explains: "The social system shapes the wants and aspirations that its citizens come to have. It determines in part the sort of persons they want to be as well as the sort of persons they are." ${ }^{99}$ The existing social system and its basic institutions is able to reproduce and replicate itself because individuals have formed a particular need or desire for the goods produced or secured by these institutions.

In the third case, Rawls presupposes that the character of human beings is inclined towards sociability. Rawls does not want to establish the basis of human sociability on the fact that we have the capacity —as persons sharing a common social life-for developing a common language and culture which allows us to express our wants, beliefs, desires, thoughts, and so on. This proves to be a weak and "trivial interpretation of
${ }^{98}$ Ibid.
${ }^{99}$ Ibid., 259. 
human sociability" according to Rawls. ${ }^{100}$ Rather, Rawls grounds sociability on the "three psychological laws" that are requisite for developing a sense of justice. ${ }^{101}$ Rawls states that having the "capacity for a sense of justice... would appear to be a condition of human sociability." 102 Given that Rawls presupposes that persons have this moral power (as will be discussed in the forthcoming section), one can conversely assume that one aspect requisite for human sociability is attained.

The other condition underlying Rawls's conception of human sociability is founded on peoples' natural desire to form, join, and partake in the activities of "social unions." That is, Rawls associates persons' propensity for sociability with their natural desire to form social unions with people having similar goals and ends in order to pursue their visions of the good jointly. As participants in a social union laboring towards a shared common end, we derive a sense of gratification and regalement that one could not achieve hermetically. Humans form social unions, explains Rawls, because "[w]e need one another as partners in ways of life that are engaged in for their own sake, and the success and enjoyment of others are necessary for and complimentary to our own good." ${ }^{\prime 03}$ Since pursuing our vision of the good life is intricately bound up with other

\footnotetext{
${ }^{100}$ Ibid., 522.

${ }^{101}$ See Rawls, in Theory (490), for a further discussion of these psychological laws.

${ }^{102}$ Rawls, Theory, 495.

${ }^{103}$ Ibid., 522-523.
} 
member's engaged in commensurate activities, it follows for Rawls then that individuals have a natural affinity for the "tie of community."104

Having introduced the notion of social union, carries us then to our fourth and final point: Rawls's maintains that society, and therein social life, should be regarded as good in themselves; or, rather, society should be viewed as a shared common good. ${ }^{105}$ (On this account, it seems as though Rawls is tempering his earlier instrumentalists account of society.) ${ }^{106}$ Rawls envisages society as "a social union of social unions." 107 Akin to participants in smaller social unions, members in the social union of a "wellordered society (corresponding to justice as fairness)" also have "shared final ends and they value their common institutions and activities as good in themselves." 108 It is in this "sentimental" sense society is recognized as a common good. ${ }^{109}$

${ }^{104}$ Ibid., 526.

${ }^{105}$ The notion that liberals, such as Rawls, negate the presence of a shared common good has been a familiar criticism of liberal theory. In part this is because, as Stephen Holmes explains (240), liberals have historically "distrusted the idea of the common good to the extent that "the good" was identified with certain dangerous and oppressive values". Even so, it seems plain in the above passage that Rawls is attempting to envision some notion of the common good. Given liberals distrust of some forms of the common good, we must be careful in discerning what Rawls intends to the common good to be. Following Holmes, I believe the good to which Rawls speaks is linked more with the idea of the "common good of collective welfare" and not necessarily a package of virtues (or "goods") that should be endorsed by the state for the entirety of society. See Stephen Holmes, "The Permanent Structure of Antiliberal Thought," in Liberalism and the Moral Life, ed. Nancy L. Rosenblum, Cambridge, MA: Harvard University Press, 1992).

${ }^{106}$ A society based on mutual advantage, notes Rawls in Theory (521), runs analogous to the idea of the "private society," whereby individuals judge "social arrangements solely as a means to his private aims".

${ }^{107}$ By claiming that persons are sociable creatures, Rawls is following in line with other renowned social contract theorist. For example, the idea of sociability is capitalized on in the works of both Samuel Pufendorf and John Locke.

${ }^{108}$ Rawls, Theory, 522 . 


\section{Equality and Moral Personality}

For Rawls, the actual "state of nature" is a situation rife with inequalities of all persuasions. People do not associate with one other on a level basis due to nature's inequitable distribution of physical powers, mental capabilities, natural talents, resources, and so on among persons. ${ }^{110}$ Given that this inequitable distribution is vagarious and arbitrary, in the sense that inequalities are allocated by sheer luck, it follows for Rawls that these personal attributes are to be considered "morally" arbitrary. Individuals ought to receive equal consideration in matters of social justice, irrespective of whether they have fared well or ill in nature's cosmic lottery.

Two implicit assumptions are being made by Rawls here: (1) that persons ought to be regarded as morally equal in thinking about social justice; and (2) that persons ought not to benefit from undeserved attributes and talents gained through chance. Rawls contends that these assumptions, which are constituted in the depiction of the original position, for the most part, capture our intuitive or moral judgments. We would accede to supporting the condition of equality in the original position, because when thinking about social justice, we believe persons, as moral beings worthy of respect, ought to have equal consideration in determining the principles of justice.

${ }^{109}$ Following Michael Sandel's interpretation in Liberalism and the Limits of Justice (149), I believe this notion of society should be labeled "sentimental" in the sense that it is based on "the feelings and sentiments of those engaged in a co-operative scheme."

${ }^{110}$ This point is made by Will Kymlicka, Contemporary Political Philosophy: An Introduction (New York: Clarendon Press of Oxford University Press, Inc., 1990), 61. 
Rawls places the parties behind the veil of ignorance in the original position so that they will not be rewarded for morally arbitrary attributes. If parties are not "advantaged or disadvantaged by social and natural contingencies", then they can each deliberate from a position of equal liberty whereby parties can freely choose the principles of justice. ${ }^{11}$ Thus, Rawls's motive in situating parties behind a veil of ignorance then is to exemplify equality between persons as moral beings.

In conjunction with the intuitive argument, much of Rawls's attempt to provide a theoretical justification for this equality hinges on his account of "moral personality." Moral personality, claims Rawls, consists of two moral powers or "natural attributes" that human beings are assumed to possess, which in turn provides the "natural basis of equality.""12 First, Rawls states that we "are capable of having (and are assumed to have) a conception of their good (as expressed by a rational plan of life)."113 Second, Rawls states that we "are capable of having (and are assumed to acquire) a sense of justice, at least to a certain minimum degree." 114 By having a "sense of justice," Rawls maintains that human beings are capable of adequately comprehending and acting in a manner consistent with the chosen principles of justice.

${ }^{111}$ Rawls, Theory, 19.

${ }^{112}$ It is important to note that the term "human beings" is being employed in Theory (453). Thus, on my reading, Rawls seems to be attributing these characteristics-that is, the two moral powers--to actual persons and not just parties in the original position.

${ }^{113}$ Rawls, Theory., 505.

${ }^{114}$ Ibid. 
The idea that equality should be based on the possessorship of these natural attributes to a minimal degree (whether manifest or latent), leads to an immediate question. How will a standard by which "a minimum degree" of moral personality be fixed, without invoking a basis for equality that is exclusionary? According to Rawls,

All we have to do is to select a range property (as I will say) and to give equal justice to those meeting its conditions...[W] hether there is a suitable range property for singling out the respect in which human beings are to be counted equal is settled by the conception of justice. But the description of the parties in the original position identifies such a property, and the principles of justice assure us that any variations in ability within the range are to be regarded as any other natural asset. There is no obstacle to thinking that a natural capacity constitutes the basis of equality. ${ }^{115}$

Accordingly, an acceptable range parameter can be set so that it comprehensively encompasses all human beings and thus they can all be eligible for equal consideration.

The minimal standard of moral personality thus provides the theoretical justification requisite for regarding persons, in matters of social justice, as individuals with "a distinct claim to equal consideration." 116

Above we find Rawls making several normative claims about the nature of human beings: (1) persons are capable of having, and indeed are assumed to have, a conception of their good; (2) persons are both capable of, and do have, a sense of justice; (3) persons ought to be considered morally equal; (4) equal consideration of persons ought not be based on morally arbitrary characteristics. Unlike the first two descriptive based claims

${ }^{115}$ Ibid., 508.

${ }^{116}$ Kymlicka, Liberalism, Community and Culture, 32. 
(i.e., as an attribute of persons per se), the latter two claims are normative in the sense that he is claiming how persons "ought to be treated alike." 117

\section{Conceptions of the Good, Rational Plans, and Conflicting Interests}

As outline in the foregoing section, Rawls assumes that persons have "an identity of interests" which informs their conception of the good or "plan of life."118

Correspondingly, individuals will be inclined to pursue and affirm a wide range of diverse goals, lifestyles, projects, values, and so on. The relevant point here is that Rawls makes the normative assumption that persons have a conception of their good, and that by extension they have a stake in making claims on the basic structure of society for the purpose of facilitating their attainment of the good life.

Rawls takes up this assumption in modeling the sort of claims to be advanced in the original position. Though parties are considered to be behind the veil of ignorance, they will be cognizant of the fact that they have a conception of the good which comprises their life plan, and that it will be in their interest to advance this conception. Given that this is the case, Rawls lists two additional attributes that parties in the original position will be ascribed. First, in pursing their conception of the good, selecting the range of primary goods, and in choosing the principles of justice, parties are to be

${ }^{117}$ S. I. Benn and R. S. Peters, The Principles of Political Thought, 124.

${ }^{118}$ In Theory (408), the relationship between the terms "conception of the good" and "plan of life" are highlighted by Rawls in the following definition: "The rational plan [of life] for a person determines his good". 
considered rational. Second, due to the factors requiring justice, Rawls states that parties must also be considered rationally disinterested.

To elaborate on the first point: Rawls maintains that behind the veil of ignorance parties "know that they have some rational plan of life."119 What does being rational entail for Rawls? The answer is that Rawls's notion of rationality is grounded in a type of rational choice theory, which is, in part, the kind of rationality on display in Kant's hypothetical imperative (that "directs us to take certain steps as effective means to achieve a specific end"). ${ }^{120}$ Rational participants in the original position, posits Rawls, will: (1) establish "a coherent set of preferences between the options open to him"; (2) "[rank] these options according to how well they further his purposes"; and, (3) "follow the plan which will satisfy more of his desires rather than less, and which has the greater chance of being successfully executed."121

Because these tenets of rational choice at times fail to rationally order the long term plans of parties, Rawls introduces a supplemental conception of rationality - that is, "deliberative rationality" - to augment the basic (short-term) conception of rational choice. By deliberative rationality, Rawls means that rational persons can work through, by way of self-reflection and self-critique, various options in order to determine which one is in the long run their best interest. It is assumed then by Rawls that a participant in

\footnotetext{
${ }^{119}$ Rawls, Theory, 142.

${ }^{120}$ Ibid., 253.

${ }^{121}$ Ibid., 143.
} 
the original position: (1) knows "the general features of his wants and ends both present and future"; (2) can approximate "the relative intensity of his desires, and to decide if necessary what he really wants"; (3) will "envisage the alternatives open to them and establish a coherent ordering of them"; and lastly, (4) after a plan is decided, participants are "able to adhere to it and...resist present temptations and distraction that interfere with its execution."122 Taken together, these cognate notions of rationality highlight Rawls's conception of parties as participants capable of rational decision-making in the original position.

This brings us to the discussion of conflicting interests and therein the need for a condition of rational disinterest to be modeled in the original position. To begin, Rawls presumes that within society there inheres a set of descriptive or empirical conditions that together necessitate a conception of justice. Rawls has divided these "circumstances of justice" into "subjective" and "objective" factors. The objective determinants create "a condition of moderate scarcity" in society. ${ }^{123}$ This condition generates conflicts among persons because, as Rawls explains, they "are not indifferent as to how the greater benefits produced by their collaboration are distributed, for in order to pursue their ends they each prefer a larger to a lesser share." 124

\footnotetext{
${ }^{122}$ Ibid., 419.

${ }^{123}$ Ibid., 126-127.

${ }^{124}$ Ibid., 4.
} 
The subjective factors relate to person's intellectual propensities for exacerbating conflict. Since it is a natural circumstance that there will be a melange of religious, philosophical, economic, political, and social doctrines affirmed by individuals, there will necessarily be discord between these individuals as each attempts to advance claims against the scarce resources in society. Sharpening this tension, human beings also "suffer from various shortcomings of knowledge, thought, and judgment" merely because it is a "natural situation.", 25

These circumstances of justice-the condition of moderate scarcity and the conflict between persons over visions of the good-have led Rawls's to hold that the proper motivation behind parties in the original position should be that of "mutual disinterest." Parties will be neither envious, revengeful, or interested in assisting other participants conception of the good. The interests of parties in the original position, declares Rawls, "are in himself, not merely, as they must always be, interests of a self. ${ }^{126}$

At first glance, the tenant of mutual disinterest seems to be an odd way to conceive of parties in the original position as it implies that parties are egoisticinterested only in themselves-and that they cannot be motivated "by benevolence, or an interest in one another's interests." ${ }^{27}$ On this point, Rawls contends that mutual disinterest does not collapse into egoism, as "Schopenhauer thought of Kant's
${ }^{125}$ Ibid., 127.
${ }^{126}$ Ibid., 129.
${ }^{127}$ Ibid., 148. 
doctrine." ${ }^{\prime 28}$ Remember that the life plans of the parties are not interests "in a self"; they are interests "of a self that regards its conception of the good as worthy of recognition and that advances claims in its behalf as deserving satisfaction." ${ }^{29}$ As rightly understood by Buchanan, parties do not know "whether these conceptions [of the good] turn out to be egoistic, altruistic, or something in between [because it is] shielded from them by the veil of ignorance." 130

Though parties are mutually disinterested in the original position, Rawls is not by extension claiming that actual persons are not motivated by the web of personal relationships (evoking strong and sincere emotions for others) that often comprise social life. ${ }^{131}$ "[O]nce the veil of ignorance is removed, the parties find that they have ties of sentiment and affection, and want to advance the interests of others and to see their ends attained." ${ }^{132}$ It is only when thinking about matters of justice that parties, cloaked behind the veil of ignorance, that the bonds of personal ties become opaque.

\section{Freedom, Liberty and Autonomy}

Like the normative claim of equality, Rawls similarly affirms that we ought to consider persons morally free. This claim, however, immediately raises the question of

\footnotetext{
${ }^{128}$ Ibid., 147.

${ }^{129}$ Ibid., 127.

${ }^{130}$ Buchanan, 136.

${ }^{131}$ Rawls, Theory, 148.

${ }^{132}$ Ibid., 129.
} 
what Rawls intends by this concept of freedom. ${ }^{133}$ First and foremost, Rawls assumes that persons are free in the sense that they have a free will; their fate is not predetermined by some cosmic order of things. Thus, persons have the capacity to make intentional choices in life and can in turn be held accountable for these choices.

Second, Rawls notion of freedom is that of a political ideal. In the words of Isaiah Berlin, political freedom (in the negative sense of the word) is "the area within which a man can act unobstructed by others." 134 For Rawls, like Berlin, the notions of political liberty and freedom overlap in meaning. Rawls poses that "liberty can always be explained by a reference to three items: the agents who are free, the restriction or limitations which they are free from, and what it is that they are free to do or not to do." 135 It is these two accounts of freedom-as freedom of the will and as the political ideal of liberty - that are employed by Rawls in JAF.

The original position is modeled by Rawls to frame a conception of justice that fits with the conception of persons as free agents (and will also yield a principle of freedom as a political idea in "justice as fairness"). ${ }^{136}$ If we take parties in the original position as participants freely pursuing their conceptions of the good, whatever that might

\footnotetext{
9 and chap. 10.

${ }^{134}$ Isaiah Berlin, "Two concepts of Liberty," in Liberalism and Its Critics, ed. Michael Sandel (New York: New York University Press, 1984), 22.

${ }^{135}$ Rawls, Theory, 202.

${ }^{136}$ Mulhall and Swift, 5.
}

${ }^{133}$ With regard to the idea of freedom, I follow the distinctions made by Benn and Peters, see chap. 
be, it follows for Rawls that these individuals will necessarily consider liberty the primary social good requisite for executing their life plans. The "highest-order interest," for both the parties in the original position and persons in general, claims Rawls, is "in preserving one's freedom to revise one's ends, and hence in choosing institutions that will shape our ends." 137

This right to freedom, via principles of JAF, is correspondingly a right to autonomy, which Rawls considers important in parties choosing principles of justice and in persons exercising their agency. ${ }^{138}$ The notion of autonomy employed by Rawls is applicable to two positions in JAF: the original position and actual society. In the first case, the conditions in the original position are set up so that parties, being free and equal, can act autonomously in choosing principles of justice. The second case applies to persons acting autonomously once principles of justice have been chosen. When actual persons conduct themselves in a manner consistent with principles delineated in JAF "they are acting from principles that they would acknowledge under conditions that best express their nature as free and equal rational beings." 139 In other words, they are able to act autonomously under this conception of justice.

${ }^{137}$ Buchanan, 137.

${ }^{138}$ I believe Rawls conception of autonomy, as described by Stepen Macedo, is employed in a "situated" sense: That is, "to situate autonomy in a social context by emphasizing the roles played by language and articulation in the process of deliberation." See Stephen Macedo, Liberal Virtues: Citizenship, Virtue, and Community in Liberal Constitutionalism (Oxford, MA: Clarendon Press, 1991), 216.

${ }^{139}$ Rawls, Theory, 515. 


\section{The Conception of Persons in Political Liberalism}

Since the publication of Theory, Rawls has made several modifications to his original conception of justice, JAF. Broadly speaking, Rawls's revisions should be viewed as a shift in emphasis from what Rawls has called a "comprehensive philosophical doctrine" (as delineated in Theory) to that of a specifically political conception of justice (as laid out in Political Liberalism). ${ }^{140}$

The principal motivation inspiring Rawls to make this philosophical shift was for the purpose of remedying what he believed to be the theoretical flaws and inconsistencies plaguing JAF. ${ }^{141}$ One should accordingly regard this latest statement of justice as fairness in Political Liberalism, then, as a revision and further evolution of Rawls's original conception of justice. Aside from the emendations made in Political Liberalism, Rawls maintains that "the structure and content of Theory [are] to remain substantially the same." $" 142$

The question of interest then is what are the key points in which justice as fairness should now be regarded as strictly a political conception of justice? To answer, there are three fundamental ways in which justice as fairness should be considered a political conception. In the first case, the application of political liberalism, as a conception of

\footnotetext{
${ }^{140} \mathrm{NB}$ : The terms "political conception of justice" and "political liberalism" will be used here interchangeably.

${ }^{141}$ These are sentiments expressed by Rawls in Political Liberalism, xv-xvi.

${ }^{142}$ Rawls, Political Liberalism., xvi.
} 
justice, is to be narrower in scope than in JAF: that is, it applies only to "the domain of the political."143

Here two points should be made plain. First, Rawls only intends the principles of justice to apply to "political" (including the primary public, social and economic) institutions. Private (social) institutions in society - such as families, companies, clubs, associations, communities, and the like-are not the proper subject of political liberalism. ${ }^{144}$ Rawls holds that these institutions fall beyond the purview of political justice. $^{145}$ The second point is that the political institutions Rawls is referencing are only those of a constitutional democracy, and not just any ideological regime.

The second respect in which justice as fairness should be considered political is that it should be understood as a "freestanding" political conception of justice: it is not "presented as" or "derived from" any one comprehensive moral doctrine, rather it stands independent of such doctrines. ${ }^{146}$ Rawls explains that citizens in a democratic society, through an "overlapping consensus" of comprehensive doctrines, can construct a mutually agreeable conception of political justice. ${ }^{147}$ This overlapping consensus,

${ }^{143}$ Ibid., 38.

${ }^{144}$ See n. 53 above.

${ }^{145}$ Here one can view Rawls, then, as having erected in some fashion a dichotomy between the socalled public (i.e., political) and private spheres of society in matters of justice.

${ }^{146}$ Rawls, Political Liberalism, 12.

${ }^{147}$ For a fuller account on Rawls's ideas of "political constructivism" and "overlapping consensus" in Political Liberalism, refer to Lecture III and IV. 
summarizes Rawls, "develops the principles of justice from public and shared ideas of society as a fair system of cooperation and of citizens as free and equal by using the principles of their common practical reason." 148

The last way in which justice as fairness is to be considered a political conception is that its content is formulated in terms derived from the fundamental political ideas implicit in the "background culture" of a democratic society (which is constituted by a plethora of various conceptions of the good, comprehensive moral doctrines, ethos of private institutions, and so on). ${ }^{149}$ Drawing on those intuitive notions and ideas embedded in the fabric of our social life-those historical traditions and shared social conceptions implicit in our view of the basic structures of society-justice as fairness aims to systematically articulate a coherent matrix of shared political values for the purpose of framing a conception of justice.

Having made these brief points concerning political liberalism, I will now discuss Rawls's political conception of persons. It is important to remember the differences sketched earlier between human beings, citizens (in a specific political society), and parties (acting as representatives of citizens in the original position). Rawls pays little attention to the notion of human beings and their nature in political liberalism, except to suggest that those attributes of human nature that we deem significant are contingent

\footnotetext{
${ }^{148}$ Rawls, Political Liberalism, 59.

${ }^{149}$ Ibid., 14.
} 
upon on our point of view. ${ }^{150}$ Thus, Rawls is concerned only with one aspect of personhood given the aim of justice as fairness: persons qua citizens within a constitutional democracy. The scope of this conception, Mulhall and Swift explain, "applies only to the person insofar as she is an inhabitant of the public political realm and not to any other aspect of her life."151 Rawls intends only to speak about persons-that is, as citizens-in this very limited sense.

\section{Moral Individualism}

As in JAF, Rawls continues to emphasize the primacy of the individual in matters of justice. This is demonstrated by his continued use of individuals (whether it be as actual persons, as persons qua citizens, or as parties in the original position ) as the primary unit of analysis and the standard by which to judge the "justness" of a theory of justice.

In Political Liberalism, however, it seems Rawls has tempered—or perhaps further clarified--his earlier position on moral individualism. ${ }^{152}$. This modification (or attempt to qualify his moral individualism) has been made in three ways.

${ }^{150}$ Ibid., 18.
${ }^{151}$ Mulhall and Swift, 207.
${ }^{152}$ One can further speculate that this subtle move was intended to cut short the prevalent criticism that JAF subscribed to a metaphysical account of individualism. On this point, Rawls notes, in Political Liberalism (196), that Thomas Nagel was one of the theorists that has attempted to demonstrate that his "well-ordered society of justice as fairness has a strong individualistic bias." Accordingly, it seems that Rawls has set out to diffuse some of the more polarized versions of this claim. 
First, by contending that rights do not only apply to individuals, but to (private) groups as well, Rawls seems to have widen his initial focus. On this matter, Rawls states that "[i]t is incorrect to say that liberalism focuses solely on the rights of individuals; rather, the rights it recognizes are to protect associations, smaller groups, and individuals, all from one another in an appropriate balance specified by its guiding principles of justice." ${ }^{153}$ One can infer then that Rawls is implying that associations and groups also become standards, like individual citizens, by which to judge the fairness of theories of justice. In addition, by acknowledging the rights of groups, Rawls is in turn recognizing the importance of community and associations for individuals in society.

Second, Rawls claims that the moral individualism underlying justice as fairness is based on our shared political conception of persons: that is, our conception of persons qua citizens is an idea implicit in our shared public political culture. As inhabitants of a constitutional democracy, Rawls contends, our political conception of persons is "one that begins from our everyday conception of persons as the basic units of thought, deliberation, and responsibility." 154 In this sense, individualism-that is, the idea that as citizens we should be treated as distinct and individual beings-is to be regarded as a publicly shared political value that all members of the society hold when it comes to thinking about ourselves as citizens.

${ }^{153}$ Rawls, Political Liberalism, 221.

${ }^{154}$ Ibid., 18. 
Third, because "justice as fairness itself is a political conception of justice," Rawls posits that it escapes "a strong individualistic bias." 155 The individualism underlying justice as fairness is not based on any brand of metaphysical or comprehensive moral doctrine; rather, it is a feature latent within our own political and social culture. ${ }^{156}$ The normative claim that we ought to treat citizens as distinct individuals in matters of justice, is an ideal derived from our shared social life which all citizens within a democratic society can agree upon. Not only does this notion of individualism indubitably place the importance of social context at the center of this conception of justice, it renders moot some of the criticisms that alleged justice as fairness was based on a form of metaphysical individualism.

Though Rawls has recast the theoretical underpinnings of individualism from the sort of normative claim implicitly made in JAF, his commitment to the idea of individualism (as a normative claim) in political liberalism remains intact.

\section{Individuals and Social Context}

One of the chief aims of Rawls's political conception of justice was to situate justice as fairness within a particular social and political context. By doing so, Rawls accounts for the way in which our formal conception of justice depends upon and is framed by our implicitly shared political values constituted by our shared social life. We

${ }^{155}$ Ibid., 196.

${ }^{156}$ It should be clear that this normative claim is part of a moral doctrine regarding the political conception of persons qua citizens, it is not however part of any specific comprehensive moral doctrine about the nature of human beings. 
must consider, then, "the principles of justice as designed to form the social world in which our character and our conception of ourselves as persons, as well as our comprehensive ties and their conception of the good, are first acquired, and in which our moral powers must be realized, if theory are to be realized at all."157

Justice as fairness is not to be viewed as a "foreign" conception to be mapped on to just any political society; it is a conception constituted by the implicitly shared notions of citizens embedded within a constitutional democracy. On this account, society for these citizens is viewed not only as "fair system of cooperation over time", but also as the "fundamental organizing idea of justice as fairness, within which the other basic ideas are systematically connected." 158

In order for society to be considered a fair system of cooperation, Rawls outlines three requisite conditions that must be in place. The political system is fair if the publicly acknowledged principles of justice are those that citizens follow and form their actions to be consistent with the conception of justice that citizens agreed were fair. ${ }^{159}$ Fair social cooperation involves reciprocity, which "lies between the idea of impartiality, which is altruistic (as moved by the general good), and the idea of mutual advantage understood as everyone's being advantaged with respect to one's present or expected situation as things

\footnotetext{
${ }^{157}$ Rawls, Political Liberalism, 41.

${ }^{158}$ Ibid., 15.

${ }^{159}$ Ibid., 16.
} 
are." ${ }^{160}$ Citizens must coexist with other citizens who are equally willing to abide by the fair rules and procedures of a "well-ordered democratic society."

One final ingredient remains in order to make the idea of social cooperation both a necessary and plausible conception: individuals and groups must have a sense of their conception of the good. This "specifies what those who are engaged in cooperation...are trying to achieve, when the scheme is viewed from their own standpoint."161 If citizen's did not have a conception of their good-that is, if they did not want to make claims against society in pursuing their vision of the good life, then, there would be no need for a fair system of cooperation.

Rawls claims that society as a fair system of cooperation is a good in itself based on a shared common end. In "supporting just institutions and of giving one another justice accordingly, not to mention many other ends they must also share and realize through their political arrangements," citizens are provided with a shared common end. ${ }^{162}$ In short, "the good realized is social: it is realized through citizens' joint activity in mutual dependence on the appropriate actions being taken by others."163

A well-ordered society is not only presented as a good for citizens as a group, observes Rawls, it is also good for individual citizens for two specific reasons. Society is

\footnotetext{
${ }^{160}$ Ibid., 50.

${ }^{161}$ Ibid., 16.

${ }^{162}$ Ibid., 202.

${ }^{163}$ Ibid., 204.
} 
good for citizens in that it allows them the requisite freedom to utilize their moral powers, and this venture is deemed in itself a good thing. Another reason is that by fairly allocating the primary political goods necessary for exercising their moral powers, this has given citizens a private base for self-respect. ${ }^{164}$ The distribution of primary goods, based on the political conception that citizens are free and equal, amounts to an acknowledgment in a public forum that all citizens have an equal status, and must be treated accordingly.

\section{Equality and Moral Personality}

This discussion on equality in political liberalism is similar to that in JAF, however, two substantial differences should be noted. The first dissimilarity is that Rawls is referring to citizen's as being morally equal, not a conception of persons as presented in JAF. In this respect, citizens are to be counted as morally equal by virtue of the fact that as members in a democratic society they regard themselves as equal when deliberating over issues of political justice.

Akin to the description given to persons in JAF, Rawls also claims that citizens are to be regarded as equal because they possess certain moral powers which, taken together, constitute a citizen's moral personality. Citizens must have a sense of justice"the capacity to understand, to apply, and to act from the public conception of justice which characterizes the fair terms of social cooperation"-and they must have a

\footnotetext{
${ }^{164}$ Ibid., 203.
} 
"determinate" conception of their good which they would rationally act upon in order to achieve their ends as defined by their good. ${ }^{165}$ (As an addendum to JAF, Rawls assumes that citizens possess the above capacities throughout their lives.)

This moral propensity, Rawls notes, should in no way be regarded as a physical or psychological attribute of human beings based on a form of biological determinism or universal interpretation of human nature. Rather it should be regarded as a philosophical conception constituted by "a scheme of concepts and principles for expressing a certain political conception of the person and an ideal of citizenship."166

The primary differences in the conception of equality from JAF to political liberalism is that we should regard persons qua citizens as morally equal based upon our public political culture. And, that moral personality should be considered a philosophical concept, or a political ideal.

\section{Conceptions of the Good, Rational Plans, and Conflicting Interests}

Rawls assumes that citizens in a democratic society have a conception of their own good. What is good is that which

normally consists of a more or less determinate scheme of final ends, that is, ends we want to realize for their own sake, as well as attachments to other persons and loyalties to various groups and associations. These attachments and loyalties to various groups and associations who are the objects of these sentiments is also part of our conception of the good. We also connect with such a conception of a view of our relation to the world-religious, philosophical, and moral-by reference to which the value and significance of our ends and attachments are

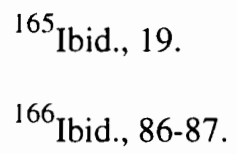


understood. Finally, persons' conceptions of the good are not fixed but form and develop as they mature, and may change more or less radically over the course of life. ${ }^{167}$

The significant difference between this account of the good and that given in JAF is that here Rawls draws more attention to the personal attachments of citizens to other individuals and to associations in the framing their conception of the good.

As in JAF, Rawls presupposes that these citizens are rational in their pursuit of their life plan. However, in political liberalism, this notion of rationality is better articulated. Rawls introduces a distinction between citizens being "reasonable" and being "rational." 168

Reasonableness is how citizens are expected to interact, according to their sense of justice, with other members in political society. It is evidenced by the acknowledgment of citizens to bear the burdens of responsibilities and "willingness to propose fair terms of cooperation and to abide by them provided others do." 169

What is rational applies to (1) "a single, unified agent (either an individual or corporate person) with the powers of judgment and deliberation in seeking ends and interests peculiarly its own"; (2) the way "these ends and interests are adapted and

${ }^{167}$ Ibid., 19-20.

${ }^{168}$ In Political Liberalism (52), Rawls holds that the notion of the reasonable and the rational are not only mutually compatible ideas, but are both requisite components in his conception of justice. On this matter, Rawls summarizes: "As complementary ideas, neither the reasonable nor the rational can stand without the other. Merely reasonable agents would have no ends of their own they wanted to advance by fair cooperation; merely rational agents lack a sense of justice and fail to recognize the independent validity of the claims of others."

${ }^{169}$ Rawls, Political Liberalism, 54. 
affirmed, as well as to how they are given priority"; and (3) "the choice of means, in which case it is built by such familiar principles as: to adopt the most effective means to ends, or to select the more probable alternative, other things equal."

Analogous to JAF, Rawls assumes that citizens in a democratic society will have a maelstrom of conflicting interests. Rawls moves beyond the discussion in JAF, however, in affirming that at the heart of political liberalism lies the presupposition that pluralism is an endemic and "permanent feature of the public culture of democracy." 171 It is a enduring feature given "the political and social conditions secured by the basic rights and liberties of free institutions," explains Rawls. ${ }^{172}$ With reasonable pluralism-that is, there exists an irreducible plurality of reasonable conceptions of the good-and conflict as endemic features of democratic society, the political stage, and therein the task, for political liberalism is set: justice as fairness is given the monumental task of achieving reasonable "unity and stability" within a political society, whose inclinations are always teetering towards the brink of anarchical dissent. ${ }^{173}$

In conclusion, the notion of the good, rationality, and conflict have all received a recasting in political liberalism. Rawls has expanded the notion of the good to encompass the meaningful personal and communal attachments that seemed to be

${ }^{170}$ Ibid., 50.

${ }^{171}$ Ibid., 36.

${ }^{172}$ Ibid.

${ }^{173}$ Ibid., 133-134. 
marginalized in JAF's account of a person's good. With respect to rationality, Rawls made the necessary theoretical distinctions that seemed only implicit in JAF. Lastly, the idea of conflict in society, or pluralism of interests, based on long-standing operation of a democratic regime was the most marked divergence from JAF.

\section{Freedom, Liberty and Autonomy}

Rawls states that citizens should be considered morally free by virtue of the fact that they view themselves as such. Citizen's should be regarded as free in three respects. First, they are capable of exercising their will in freely choosing their life plans. Second, citizens consider themselves free in the sense that they are "self-authenticating sources of valid claims." 174 That is to say, citizens "regard themselves as being entitled to make claims on their institutions so as to advance their conceptions of the good (provided these conceptions fall within the range permitted by the public conception of justice)."175 Lastly, citizens are seen as free because "they are viewed as capable of taking responsibility for their ends and this affects how their various claims are assessed."176

Because citizens are free in these ways, they are also considered both "rationally" and "fully" autonomous. Citizens are rationally autonomous because they have the capacity to create, revise, and act upon the their conceptions of the good. Rawls models
${ }^{174}$ Ibid., 72.
${ }^{175}$ Ibid., 32.
${ }^{176}$ Ibid., 33. 
this conception in the original position so that parties, as citizen representatives, will act autonomously when deliberating over the principles of justice.

Just as citizens are rationally autonomous in two ways-they are free within the limits of political justice to pursue their permissible conceptions of the good; and they are motivated to secure their higher-order interest associated with their moral power-so the parties are rationally autonomous in two ways: they are free within the constraints of the original position to agree to whatever principles of justice they think most to the advantage of those they represent; and in estimating this advantage they consider those persons' higher-order interests. ${ }^{177}$

Full autonomy, in contrast to rational autonomy, cannot be modeled in the original position. "[F]ull autonomy is [only] realized by citizens," claims Rawls, "when they act from principles of justice that specify the fair terms of cooperation they would give to themselves when fairly represented as free and equal persons." ${ }^{, 178}$ Thus citizens exercise full autonomy by acting according to principles of justice as fairness in their pursuit of the good life.

Contrasted with JAF, Rawls has posited that citizen's are morally free based on their own perception of themselves as citizens. As revealed by the public political culture of a democratic society, political liberty is esteemed as the primary social good given citizen's conception of themselves as free beings. While the concept of autonomy was analogous to the idea delineated in JAF, Rawls provided a more lucid treatment of the idea in political liberalism.

\footnotetext{
${ }^{177}$ Ibid., 75.

${ }^{178}$ Ibid., 77.
} 


\section{Conclusion}

Recall from chapter one the discussion from liberal political theory. In reviewing Rawls conception of persons in Theory and in Political Liberalism, it seems as though we find a similar set of normative assumptions outlined by Rawls. In Theory, he assumes that persons ought to be treated as morally equal and free individuals who have the capacity for a conception of the good with a complementary desire for the requisite liberty to pursue their life plans. While these conceptions outline a more individualistic account of persons, let us not forget Rawls's normative assumption in JAF that persons are indeed social creatures. Having outlined the normative features of the Rawlsian self modeled in the original position, it has been demonstrated that JAF is framed around a distinctly liberal conception of persons.

In Political Liberalism, Rawls posits a similar set of assumptions about persons (with some minor exceptions); however, he has substantially altered the source and characterization of the former claims delineated in Theory. These normative assumptions are derived from implicitly shared political values generated by our public political culture and should be observed as a philosophical ideal concerning how persons regard themselves as citizens. Rawls's political liberalism in turn endorses a liberal conception of persons only to the extent that as citizens in a democratic society we publicly support the liberal "ideal of democratic citizenship."179

${ }^{179}$ Ibid., 216. 
This move by Rawls from defending a conception of persons to a political conception of persons qua citizens has been significant for one cardinal reason. Since Rawls has mapped all of the normative assumptions sketched in Theory on to a political conception of persons as citizens, he avoids one of the primary shortcomings-namely, of invoking a metaphysical or comprehensive account of persons—of JAF. Thus, Rawls's political conception of justice as fairness, by and large, leaves the notion of actual person free from theoretically damaging normative entanglements. 


\section{CHAPTER III}

\section{THE FEMINIST CRITIQUE OF RAWLS'S CONCEPTION OF THE SELF}

Given the matrix of substantive and normative claims Rawls has ascribed to persons in his theory of justice, feminists have concluded that the Rawlsian self is a gender-biased conception. The Rawlsian self, assert feminists, entails certain metaphysical, ontological and epistemological assumptions that when taken together reveal a figure which is distinctively "male" or "masculine." 180

The aim of this chapter is to sketch out some of the principal allegations which have led feminists to make the above conclusion. In rendering a general account of feminist contentions with Rawls's conception of the self, this exegesis will necessarily be selective. I have favored only those feminist critiques that are most representative of this body of criticism. ${ }^{181}$ In addition, the material is not drawn from a single group of feminists, but rather from a myriad of feminist theorists. ${ }^{182}$

${ }^{180}$ The trend within feminist political theory favors the use of the term "masculine" over the term "male," however, both terms are used with some frequency in the literature. The term "male" has been primarily linked to feminists relying on essentialist or biological explanations for men's and women's differences. While the term "masculine," has been associated with postmodern arguments.

${ }^{181}$ It should be noted that in critiquing the Rawlsian self, feminist at times have directed their attentions specifically at Rawls's theory. However, more often than not, feminists have lumped Rawls's conception of the self in with a whole host of other liberal (and some not so liberal) theorists. It should be remembered in the course of this exposition that feminist critiques, while they are meant to pertain to the Rawlsian conception of the self, are as a rule directed at liberal conceptions of the self in general.

${ }^{182}$ It should be recognized then that among any broad group of theorists there will inevitably arise some discontinuities between their arguments; therefore, feminist contentions in general will not necessarily 
Before moving to the task of unpacking specific critiques of the Rawlsian self, the provision of a framework for purposes of illuminating both the nature and direction of feminists' allegations would be prudent. To begin, regardless of whether contentions were formulated by cultural, relational, or postmodern feminists, for the most part, one finds three broad types of arguments launched against the Rawlsian self.

The first argument feminists' advance alleges that Rawls's conception of the self is a metaphysical construct, with metaphysical attributes that are distinctly male or masculine in orientation. The second argument is that Rawls's conception of the self exists ontologically prior to its ends and social context. For feminists, this notion of the "separate" self is more consistent with male or masculine conceptions of the self than with female or feminine "relational" selves. The third argument is directed at Rawls's epistemology. Here feminists claim that Rawls employs a distinctively male or masculine conception of rationality. While each of the aforementioned arguments target a different perceived weakness of the Rawlsian self, they are all inspired by a shared belief: certain features of the Rawlsian self can be identified as embodying male or masculine attributes.

This belief raises two important questions. First, what basis do feminists have for fashioning such a claim? Second, what characteristics do feminists consider distinctly female or feminine as opposed to characteristics that are male or masculine? In reference to the first question, the chief route feminists have taken in substantiating their claims has

fit neatly together into a coherent and comprehensive critique. Different feminists have to some degree focused their critiques on different aspects of Rawls's conception of the self. 
come in the form of a descriptive-type argument. By this I mean that feminists have generated two catalogs of gender attributes, one that is male or masculine and a another that is female or feminine. Feminists have used this catalog of descriptions to judge whether Rawls's interpretation of the self is one that is embodied with male or masculine attributes.

Regardless of whether feminists have employed a socio-historical or cultural account of gender-identity construction or a psychological or psychoanalytic account of gender-identity construction, both have come to the same conclusion: a woman's sense of self is relational. Women consider themselves connected to others by way of a web of intimate and personal attachments which are not only constitutive of women's' identity, but also influence the way in which women act and reason from a relational perspective.

In contrast to this vision of the relational self, feminists have interpreted the Rawlsian self-an alleged concatenation of male or masculine attributes-as an exceedingly "autonomous, independent, individualistic, and [impartially] rational" creature. ${ }^{183}$ Moreover, feminists claim that Rawls's separate self is asocial, detached, and self-interested individual.

In overviewing the nature of feminist allegations, the examination will now look specifically at feminists' critiques of Rawls's conception of the self. In the interest of consistency and continuity with the design of the preceding chapter, I have roughly

${ }^{183}$ Mary M. Brabeck, "Moral Judgement: Theory and Research of Differences between Males and Females," in An Ethic of Care, ed. Mary Jeanne Larrabee (New York: Routledge, 1993), xi. 
organized feminists' arguments under the headings set forth in the last chapter: moral individualism, social context and individuals, and so on.

\section{Moral Individualism}

It was stated in chapter two that Rawls subscribes to a form of moral individualism, which is inextricably tied to the belief that individuals ought to be treated: (1) as beings of incomparable worth; (2) as the primary locus of analysis; and (3) as the ultimate standard by which to judge the fairness of his theory of justice.

According to feminists (and other critics), this first-order moral assertion necessarily invokes a metaphysical view of human beings. To explain, Rawls's “ethical view of the locus of human worth presupposes in turn a particular second-order theory of the self and its constitution...; it presupposes a foundational account of the person." 184

Feminists have formulated their claim of metaphysics in one of two ways. ${ }^{185}$ The first and most common argument feminists make to uphold their allegation of metaphysics is presented as a historical fact, one endemic to all liberal theories of justice. The argument ordinarily runs as follows: since liberal theorists have historically subscribed to a metaphysical conception of persons, and given the fact that Rawls's theory of justice is a liberal conception, by extension Rawls's conception of persons is presumed to be a metaphysical conception.

${ }^{184}$ Mulhall and Swift, 45.

${ }^{185}$ Upon surveying feminist literature, however, more often than not, feminists simply tacitly assume that Rawls's conception of persons is metaphysical; rather, than presenting any theoretical inquiry as to why the Rawlsian self is metaphysical. 
An instance of this brand of argument is found in Jaggar's outline of liberal theory's conception of persons. Jaggar states that "Liberal theory is unified...by certain assumptions about human nature that constitute the philosophical foundation of the theory." 186 From this broad assumption that all liberal theories-including Rawls'smake especial assumptions about persons, Jaggar then enumerates a list of "metaphysical assumption[s]" that undergirds the liberal conception of human beings. ${ }^{187}$ In doing so, Jaggar infers that Rawls, consonant with other liberal theorists, employs a metaphysical conception of persons.

A second and more recent trend within feminist theory has been to make the charge of metaphysics by way of a communitarian-type argument. ${ }^{188}$ (Regardless of whether feminists explicitly or implicitly rely upon communitarian arguments, feminists have nevertheless begun to employ an argument unmistakably communitarian in appearance. ${ }^{189}$ )

To understand the direction this argument takes, recall two postulates in Rawls's theory of justice. The first is the assumption that parties in the original position are to be

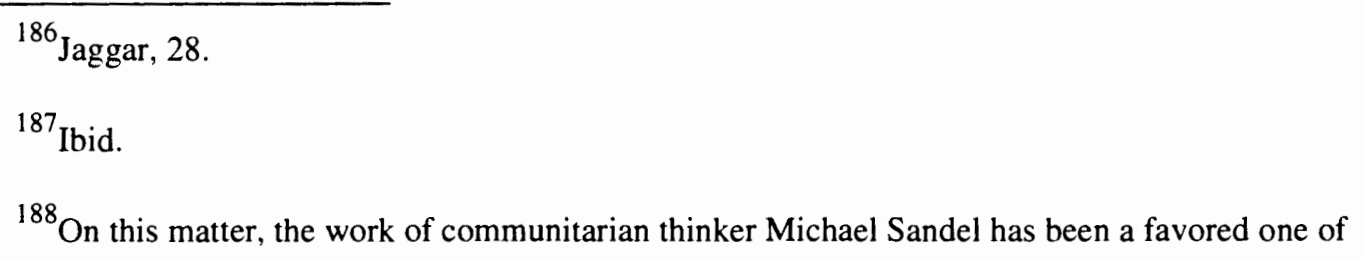
feminists.

${ }^{189}$ Some feminists, such as Marilyn Friedman, simply draw parallels between communitarian arguments and feminist political theory, thereby relying on the communitarians to make her "metaphysical" case. Other feminists, such as Seyla Benhabib, rely explicitly on the arguments of communitarians thinkers (namely, Sandel). 
consider a self "prior to the ends which are affirmed by it," 190 which is to say that the self should be considered a subject prior to the ends (or conception of the good) that it pursues. ${ }^{191}$ The second is the way in which Rawls models the original position so that knowledge about one's particularities would be disallowed in this initial position. Taken together, these two postulates have led feminists to conclude that Rawls's description of parties implies a conception of the self that is: (1) ontologically prior to their ends and social context; and (2) possessing certain metaphysical qualities.

Rawls's description of parties in the original position, according to feminists, relies on a "veiled" yet discernible metaphysical view of persons, which is "empty of all metaphysical content except abstract reason and will." 192 That is to say, it is a conception of the self which is barren save for two discernible metaphysical qualities: agency (i.e., the ability to act autonomously in choosing one's ends or conception of the good) and the capacity to reason based on abstract, universal principles of impartiality. ${ }^{193}$

These two metaphysical qualities ascribed to the Rawlsian self-in conjunction with the notion that the self exists ontologically prior to its ends-have led feminists to

${ }^{190}$ Rawls, Theory, 560.

${ }^{191}$ Ibid., 561.

${ }^{192}$ Marilyn Friedman, "Feminism and Modern Friendship: Dislocating the Community," in Justice and Economic Distribution, eds. John Arthur and William S. Shaw (Englewood, NJ: Prentice Hall, 1991), 306.

${ }^{193}$ Akin to feminist arguments, Sandel claims that "implicit in the design of the original position, is to conceive the self as a subject of possession," with certain veiled attributes. Having defined Rawls's conception of persons as a subject of possession with certain veiled qualities, Sandel claims that Rawls's presupposes a metaphysical conception of persons. See Michael Sandel, Liberalism and the Limits of Justice, 54. 
claim that the Rawlsian selves exist "metaphysically prior to their individuating characteristics."194 Rawls's assumption here, as critics like Jaggar point out, "is that the essential human characteristics are properties of individuals and are given independently of any particular social context." 195 This is problematic, say feminists, for to regard selves as possessing qualities of rationality and agency prior to their individuating circumstances necessarily "slips into a metaphysics according to which it is meaningful to define a self independently of all the ends it may choose and all and any conception of the good it may hold."196

For feminists, then, Rawls's moral individualism is not simply a first-order moral view, but one that necessarily entails-and relies upon-a metaphysics of personhood. In relation to individualism, feminists claim that Rawls subscribes to a particular form of metaphysical individualism, which necessarily evokes certain assumptions about the character of persons. As will be enumerated in the following section, feminists believe that Rawls's metaphysical individualism supports a notion of the self that is necessarily antithetical to society, social context, and personal attachments.

${ }^{194}$ Seya Benhabib, "The Generalized and the Concrete Other: The Kohlberg-Gilligan Controversy and Feminist Theory," in Feminism as Critique, eds. Seyla Benhabib and Drucilla Cornell (Minneapolis, MN: University of Minnesota Press, 1991), 90.

${ }^{195}$ Jaggar, 42.

${ }^{196}$ Benhabib, 89 . 


\section{Individuals and Social Context}

As indicated, feminists contend that it follows from Rawls's description of parties in the original position to mean that "human individuals are ontologically prior to society." 197 By way of this argument, feminists have concluded that Rawls's conception of persons "begins from the premise of radical or abstract individualism." 98 This premise, according to feminists, is indicative of the way in which Rawls perceives the self as (metaphysically) abstracted from social context. Rawlsian persons, as it were, "exist as actors logically, if not temporally, prior to the entry onto the social stage", which are endowed with metaphysical attributes prior to their casting in the human drama. ${ }^{199}$

In arguing that Rawls subscribe to a brand of abstract individualism, feminists have made the following assumptions about the Rawlsian self and its relationship to society and social context. First, feminist charge that Rawls portrays humans as atomistic units. Elizabeth Wolgast claims that Rawlsian selves represent creatures that are "complete in themselves, they are self-contained, independent, self-motivated, energized from within-by passions and desires, Hobbes would say." 200 Invoking a similar

${ }^{197}$ Jaggar, 28.

${ }^{198}$ Hirschmann, Rethinking Obligation, 113. In tandem with Hirshmann's definition of abstract individualism, Friedman and Tong advance a similar definition. "Abstract individualism," explains Friedman in "Feminism and Modern Friendship" (304), "considers persons as social atoms, abstracted from their social contexts, and disregards the role of social relationships and human community in constituting the very identity and nature of human beings." In Feminist Thought (36), Tong claims that an "abstract individual is one whose emotions, beliefs, abilities, and interests can supposedly be articulated and understood without any reference whatsoever to social context."

${ }^{199}$ Jaggar, 86.

${ }^{200}$ Elizabeth H. Wolgast, The Grammar of Justice (Ithaca, NY: Cornell University Press, 1987), 11. 
Hobbesian "man as mushroom" imagery, Benhabib asserts that Rawls presumes "that people are by nature separate, self-contained, unrelated beings, somehow sprung into the world fully adult and independent,"201 as Diana from Zeus's head.

Second, the Rawlsian self depicts human beings as asocial—or, to use Jaggar's term, "solipsistic"- selves. Portrayed as isolated and removed from social relations and communal attachments, feminists claim that Rawls's description of parties in the original position as both mutually disinterested and ontologically prior to their ends intimates a self that is alienated.

As a result, feminists have interpreted the Rawlsian self as liable to be averse-if not diametrically opposed-to communal attachments. Hirschmann claims that Rawls "depends on a conception of the individual that is at odds with community."202 Similarly, MacKinnon maintains that for liberals such as Rawls "what it is to be a person is to be a unique individual, which defines itself against, as distinct from, as not reducible to, a group." ${ }^{203}$ Feminists conclude that given Rawls's depiction of persons they are naturally predisposed towards antagonistic relationships with others, and with communal goals. Such persons are considered not only asocial but competitive (with inclinations of

\footnotetext{
${ }^{201}$ Hanna Fenichel Pitkin, Wittgenstein and Justice (Berkeley, CA: University of California Press, 1972), 199.

${ }^{202}$ Hirschmann, Rethinking Obligation, 9.

${ }^{203}$ MacKinnon, Toward a Feminist Theory of State, 45-46.
} 
violence and aggression), which burdens those around them with the fear of being "potentially threatened."204

Third, stemming largely from the assumption of mutual disinterest, feminists have understood the Rawlsian self to be egoistic in disposition. Moreover, as an abstract individual free from the entanglements of social context and the circumscription imposed by social life, the Rawlsian self is predisposed to be the perfect egoist.

The Rawlsian self, Benhabib explains, "is a narcissist who sees the world in his own image; who has no awareness of the limits of his own desires and passions; and who cannot see himself through the eyes of another." ${ }^{205}$ Satisfied with only selfish desires and interests in securing its own welfare, the Rawlsian self appears to care not for others. It is highly unlikely then, say feminists, that women would "formulate a conception of [disinterested] rationality that stressed individual autonomy and contained such a strong element of egoism as the liberal conception."206

Fourth, feminists claim that the Rawlsian self is a disembedded and disembodied subject. By holding that the self possesses an identity prior to having a particular conception of the good, Rawls implies that ends and conceptions of the good are not constitutive of a person's identity. As it were, he supposes that a person's identity-which enjoys ontological priority—can be extirpated from a person's conception of the good.

${ }^{204}$ Anne Phillips, "Introduction," in Feminism and Equality, ed. Anne Phillips (New York: New York University Press, 1987), 15.

${ }^{205}$ Benhabib, 84 .

${ }^{206}$ Jaggar, 46. 
For feminists this implies two things. First, that "human beings are not necessarily constituted by society but instead are capable, in principle of withdrawing from society to redefine their own identity." ${ }^{207}$ Rawls's assumption here "is that the essential human characteristics are properties of individuals and are given independently of any particular social context." ${ }^{208}$ Second, a self's identity exists ontologically prior to those communal, cultural, familial relationships in which people generally find themselves embedded. ${ }^{209}$

Feminists claim that what Rawls fails "to recognize is that all rational human persons are always and already in human community." ${ }^{210}$ People are embedded within a particular social context that necessarily affects both their identity and their conception of the good: their identity is "socially constituted.",111 To consider persons as existing beyond a particular social context is to not consider "human selves at all." 212

The fifth and final assumption, concerns Rawls's depiction of society-a depiction that has proven troublesome to feminists. If the Rawlsian self is indeed such an atomistic, asocial, violent being-whose interests surely do not lie towards a social

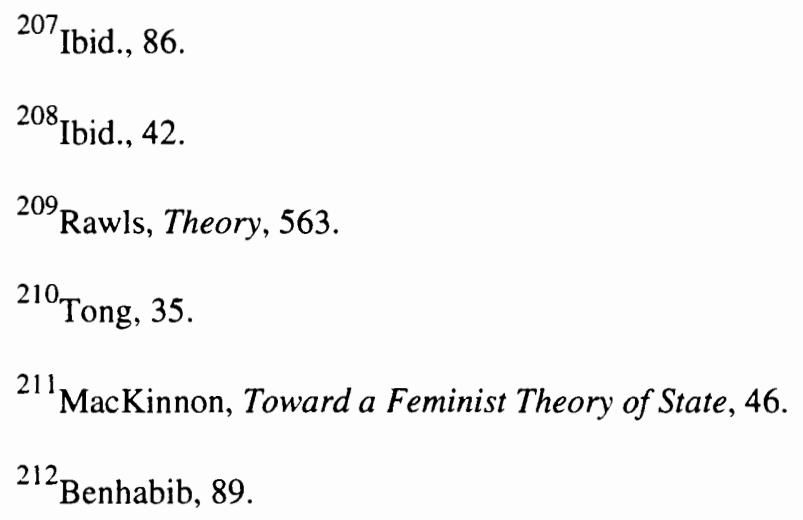


direction - then why would a society be formed at all? Why would it be rational for such beings, given their nature, to confederate into such a social organization?

Feminists state that "the only satisfying explanation [Rawls] can offer for why and how individuals form community is the contractarian one" based on mutual self-interest (derived from rational choice). ${ }^{213}$ According to Benhabib and Cornell, "Whether it be welfare liberals like John Rawls and Ronald Dworkin, or libertarian, market liberals like Friedrich Hayek and Robert Nozick, both groups view society as a system of mutually advantageous arrangements. ${ }^{214}$ As an arrangement of mutual advantage, Rawlsian society is not the focus of communal goal or constitutive connections. Society is simply instrumental in promoting an individuals' self-interests; thus, "the selfish self [is] forced into community, on essentially empirical grounds," claims Rosemarie Tong. ${ }^{215}$

\section{Equality and Moral Personality}

Given feminists' central program-the achievement of equality between the sexes-one would assume that feminists would prima facie welcome Rawls's normative claim that persons ought to be treated with equal consideration. Though feminists support the notion of equality between the sexes in theory, the quandary for feminists, according to Sally Alexander, "may be summed up in the tension between the plea for

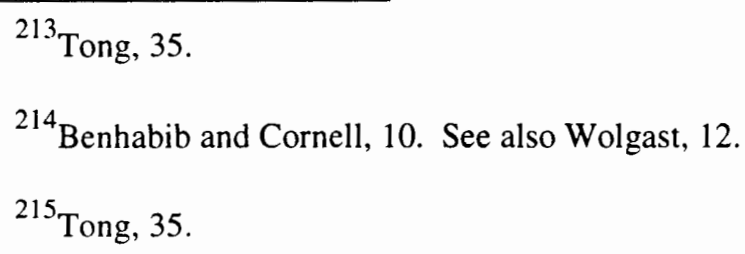


equality and the assertion of sexual difference. If the sexes are different, then how may that difference (and all that it implies for the relative needs and desires of women and men) be represented throughout culture, without the sex that is different becoming subordinated?"216 Feminists' contentions with liberal equality then hinge on whether Rawls's theory can account for the relevant differences between men and women's needs-as defined by feminists—when distributing political and social goods.

On the whole, feminists have concluded that Rawls's notion of equality will generate sexual inequalities due to the fact Rawls's conception of persons is grounded on a gender-neutral conception of persons (which feminists have interpreted to be a male or masculine). Selma Sevenhuijsen explains that for liberals such as Rawls "[t]he route to liberation [via normative equality] involves the breaking down of inequalities and differences. Justice can be perceived as consisting of a collective effort to dismantle all mechanisms that maintain the division of humanity into two sexes."217 Phrased differently, equality as a normative claim aims not to treat persons differently based on gender, but only to treat persons alike.

According to feminists, the reason sexual inequalities exist in the "relations between the sexes" is because liberal theorists like Rawls have failed to recognize that inequalities are "based on inherent differences" between the sexes. ${ }^{218}$ Because Rawls

${ }^{216}$ Sally Alexander, "Women, Class and Sexual Differences," in Feminism and Equality, ed. Anne Phillips (New York: New York University Press, 1987), 162.

${ }^{217}$ Selma L. Sevenhuijsen, “The Morality of Feminism," Hypatia 6 (Summer 1991): 176.

${ }^{218}$ MacKinnon, Toward a Feminist Theory of State, 37-38. 
does not account for these differences between the sexes in his (gender-neutral) treatment of persons, feminists claim that women will be discriminated against. Jaggar argues that "the liberal insistence on 'formal' equality, which comes from viewing people as abstract [and gender-neutral] individuals makes it easy not only to ignore the varying needs [and interests of women] but even to claim that satisfying the needs of a certain group would amount to 'reverse discrimination' or giving special privileges to women."219 Rawls's liberal equality, conclude feminists, refuses to treat women differently which "will undermine rather than promote the cause of equality (understood in more substantive terms) between men and women."220

On another front, feminists argue that Rawls notion of equality is based on an objectionable ideal of moral personality: that is, that parties in the original position would have the capacity for a "sense of justice" and a conception of their good. (I will discuss the feminist objections to the capacity for a sense of justice here, and explore feminist contentions with Rawls's conception of the good under the next section.)

Feminists argue that the notion of having a sense of justice is applicable only to a male or masculine gendered self, not to a female or feminine gendered self. As described by Carol Gilligan, men's moral "voice" is that of an "ethic of justice," much like Rawls's, whereas women's moral "voice" is of an "ethic of care."

${ }^{219}$ Jaggar, 47.

${ }^{220}$ Cass Sunstein, "Introduction: Notes on Feminist Political Thought," in Feminist and Political Theory, ed. Cass Sunstein (Chicago: The University of Chicago Press, 1990), 5. 
Following the work of Gilligan and others, many feminists contend that men make moral judgments from a justice perspective as depicted in Rawls's theory, while women make moral judgments from an empathetic or relational perspective. Women and men describe the "moral domain" in different terms: women view moral dilemmas "as a problem of care and responsibility in relationships rather than a one of rights and rules," whereas men view moral dilemmas as a problem of "equality and reciprocity." 221 Gilligan explains "the logic underlying an ethic of care is a psychological logic of relationships, which contrasts with the formal logic of fairness that informs the justice approach."222 The significance for feminists is that the "justice approach" articulated by Gilligan is associated with men's moral judgment or reasoning which is, by extension, linked to Rawls's theory of justice and therein his conception of the self. Rawls's derives moral principles based on an ethic of justice. Analogous to Gilligan's description of men's moral reasoning, the Rawlsian self claims rights and applies universal and impartial moral principles to determine what is to be considered fair and equitable in social relations. In contrast, women's moral reasoning accords with the "care approach," which is based on responsibilities (not rights) and on the concrete relationships and social context (not abstract or hypothetical situations as depicted in the original position).

Feminists conclude that women's notions of the moral domain-and therein their moral judgments-are not applicable to Rawls's conception of persons possessed of a

\footnotetext{
${ }^{221}$ Carol Gilligan, In a Different Voice (Cambridge, MA: Harvard University Press, 1982), 73. ${ }^{222}$ Ibid.
} 
sense of justice. By grounding moral equality on the capacity of having a sense of justice, feminists conclude, Rawls fails to acknowledge that women's moral reasoning differs from that of men.

\section{Conception of the Good, Rational Plans, and Conflicting Interests}

While feminists do not generally challenge the idea that persons have a conception of their good, they do object to the manner in which Rawls depicts this notion. Here feminists claim that Rawls's conception of the good fails on two accounts. First, as previously mentioned, Rawls does not account for the way in which a person's conception of the good and values are communally derived. Second, feminists object to Rawls's description of the parties as having a conception of their own good, yet being "mutually disinterested" in the conceptions of the good held by others. Feminists interpret Rawls as stating that "each human individual has desires, interests, etc., that in principle can be fulfilled quite separately from the desires and interests of other people."223

A person's conception of the good life, say feminists, is inextricably bound up with and constituted by a web of personal attachments. Persons (particularly women who are considered other-oriented) take as their conception of the good the welfare and interests of others. However, such other-orientation is precluded, claim feminists because Rawls's conception of the good fails to admit of the plausibility that persons will take as their good the good of other persons.

${ }^{223}$ Jaggar, 30 . 
This brings us to feminist contentions with Rawls employment of rationality.

Following from rational choice theory, Rawls postulates that parties would be rational in selecting principles of justice. The notion that it would be rational for parties to choose principles of justice according to the maximin principle, however, has been met with a barrage of critiques. Summarizing these critiques, Kymlicka relates:

Many people have criticized Rawls claim that that 'maximin' is the rational strategy. Some claim that it is equally rational, if not more rational, to gamble on utilitarianism. Others claim that it is impossible to assess the rationality of gambling without knowing something about the odds, or about one's riskaversion. These critics allege that Rawls only comes up with the difference principle because he rigs the description of the veil of ignorance so as to yield it, or because he makes gratuitous psychological assumption which he is not entitled to make. ${ }^{224}$

Feminist criticism of Rawls's use of rational choice, however, is of a different color. They are generally not concerned with whether Rawls's notion of rationality effectively yields the difference principle or if it is indeed rational. ${ }^{225}$ Feminists are concerned with whether Rawls's notion of rationality favors men on a broader scale. Many feminists claim that Rawls's methodology "of individualism and rational choice," necessarily, "betrays a masculinist [or male] bias."226

${ }^{224}$ Kymlicka, Liberalism, Community and Culture, 66.

${ }^{225}$ A notable exception: Susan Okin argues that Rawls's notion of rationality fails to meet the criteria for rational choice. In contrast to Kant, Okin claims in Justice, Gender and the Family (98) that "Rawls clearly recognizes the importance of feelings, first nurtured within supposedly just family families, in the development of the capacity for moral thinking." Okin argues (101) that there is an element of empathy and benevolence in the original position: Parties must "think for the perspective of everybody, in the sense of each in turn. To do this requires, at the very least, both strong empathy and a preparedness to listen carefully to the very different points of view of others." While many feminists find this to be an interesting argument, it is widely recognized as a theoretical incoherent position.

${ }^{226}$ Hirschmann, Rethinking Obligation, 119 
Recent feminist scholarship has devoted much attention to illustrating how historically the notion of rationality has epistemologically reflected the interests, views, and experiences of men. Throughout antiquity women have been associated with irrationality stemming from their link to the body via their reproductive capacities, while men have been associated with rationality originating from the mind. ${ }^{227}$

The result of women's association with irrationality has led to women's exclusion both from the sphere of rationality and the sphere of the political, because a person's capacity for reason has long been the standard by which to judge a person's ability to participate in the political domain. ${ }^{228}$ According to Susan Hekman, the idea that "women have been excluded from both politics and rationality since the inception of western thought has become a commonplace that is rarely challenged."229

While the above reading of history by feminists is theoretically questionable (as it relies upon dubious contemporary psychological theories), we must ask why feminists believe this pertains to women in contemporary society? Since women appear to have been fully incorporated into the political domain as citizens in society, why do feminists

${ }^{227}$ Genevieve Lloyd, The Man of Reason: "Male" and "Female" in Western Philosophy (Minneapolis, MN: University of Minnesota Press, 1984).

${ }^{228}$ For a further exegesis on the ides that women's political exclusion is based on their expulsion from the domain of rationality, see Jean Bethke Elshtain, Public Man, Private Woman: Women in Social and Political Thought (Princeton, NJ: Princeton University Press, 1981); Susan Moller Okin, Women in Western Political Thought (Princeton, NJ: Princeton University Press, 1979).

${ }^{229}$ Hekman, Gender and Knowledge, 35. 
still consider rationality a notion that works to exclude women from the political sphere? Are not women as rational as men?

Feminists have answered this question in one of three ways. First, the "feminist rationalism" standpoint claims that women in the past were "unfairly excluded from the respect which they are due as human beings on the basis of an insidious assumption that they are less rational" than their male counterparts. ${ }^{230}$ Thus, men and women should be considered equally rational. Second, the "feminist anti-rationalism" position claims that we should re-valorize what has been historically touted as feminine irrationality (i.e., partiality, empathy, etc.). Third, the "feminist postrationalist" position has been to reject the idea of rationalism altogether and call for a new discourse that would transcend the present dialogue of rationalism. They advocate that neither the traditional "male" nor "female" paths of rationality ought to be employed.

Of these three positions, the second has been the common position taken in feminist evaluations of Rawls. ${ }^{231}$ Feminists argue that it is the male notion of rationality that is given priority in Rawls's theory of justice. What can be considered "male" rationality, as illustrated in Rawls's theory of justice, and "female" rationality?

${ }^{230}$ Christine Di Stefano, "Dilemmas of Difference," in Feminism/Postmodernism, ed. Linda J. Nicholson (New York: Routledge, 1990), 67-68.

${ }^{231}$ NB: I suggest that the second position has been the favored position for several reasons. First, of the three positions, only feminist anti-rationalism and feminist postrationalism have contentions with Rawls's epistemology. Second, while feminist postrationalism has been instrumental in critiquing Enlightenment epistemologies, it also calls into question feminism itself. Di Stefano in "Dilemmas of Difference" (75) explains: "the postmodern call to give up the privileging of gender, along with subjectcentered forays into women's ways of thinking, acting, and reconcieving theory and politics, is met with suspicion and hostility" by many feminists. 
To make this distinction between male and female rationality, feminists claim that men and women reason differently: women reason from a care-based perspective and men from a justice-based perspective. The connection between moral reasoning and rationality is that based on differences in moral reasoning, feminist argue that men and women have different interpretations of what is to be rational.

Feminists believe that the Enlightenment conception of rationality employed by Rawls emphasizes the justice-based approach to moral reasoning that relies exclusively on abstract, universal, and impartial criteria for choosing principles of justice. This conception of rationality accords well with men's moral reasoning; however, "women, who view moral problems in contextual, relational terms, are defined as inferior moral beings, as deformed males." 232

Unlike women who reason morally from a contextualized position characterized by personal relationships, Rawls attempts to achieve impartial rationality through a hypothetical situation "by imagining that you and other rational, self-interested individuals have to make decisions about basic social principles in ignorance of your particular social position, special interests, sex, race, etc." ${ }^{233}$

Contrasting impartial reasoning, feminists argue that women reason from a social position of empathy "for they enable one to understand people who are different from

${ }^{232}$ Hekman, Gender and Knowledge, 55.

${ }^{233}$ Janna Thompson, "Sex Equality is Not Enough for Feminism," in Feminist Challenges: Social and Political Theory, eds. Carole Pateman and Elizabeth Gross (Boston: Northeastern University Press, 1987), 104. 
oneself, and they are moral, for they prepare one to respond to people's needs."234

Dissimilar to the generalizing involved in impartial reasoning that eliminates a sense of the other and the particularity of their situation, empathy yields relevant information about people and their unique needs. ${ }^{235}$ It allows one the "capacity to put oneself in another's positions" and effectively understand the needs of the other. ${ }^{236}$

In sum, feminists reject Rawls's notion of rational choice as part of a larger critique of Rawls's methodology: that is, Rawls's attempt to derive moral principles based on an abstract, hypothetical model. This methodology, feminists argue, parallels men's way of moral reasoning, not women's way of moral reasoning. As a result, the "liberal conception of reason and rationality have rendered women's point of view either 'irrational or particularistic' or 'concretistic and trivial'," claim Seyla Benhabib and Drucilla Cornell. ${ }^{237}$

Lastly, we can turn to the issue of conflicting interests. Rawls's view that there naturally arises a conflict of interest between persons due to the circumstances of justice, feminists argue, presents an incorrect picture of society and personal relationships. That is, Rawls portrays society as riven with conflictual and competitive human relationships,

${ }^{234}$ Diana T. Meyers, "Moral Reflection: Beyond Impartial Reason," Hypatia 8 (Summer 1993): 24.

${ }^{235}$ Iris Marion Young, "Impartiality and the Civic Public: Some Implications of Feminist Critiques of Moral and Political Theory," in Feminism as Critique, eds. Seyla Benhabib and Drucilla Cornell (Minneapolis, MN: University of Minnesota Press, 1991), 62.

${ }^{236}$ Sevenhuijsen, 181 .

${ }^{237}$ Benhabib and Cornell, 11. 
whereby "human beings are seen as tending naturally toward egoism or the maximization of their own individual utility."238

This depiction of persons, claim feminists, contradicts women's moral relational disposition. For women, the self is "nurturant," "not competitive," "giving" and "caring" of others in society. ${ }^{239}$ Rawls's assumption of conflicting interests appears to be depicting the experiences and moral orientation of men in his description of persons, not women.

\section{Freedom, Liberty and Autonomy}

Rawls's interpretation of autonomy, according to feminists, miscasts the nature of human beings (particularly women) and human relationships as it evinces a notion of the self whose "only legitimate connection to others are those initiated by the individual or agreed by him of his own free choice."240

Feminists instead want to focus on moral autonomy for relational selves, which must be viewed as "a morality of responsibility and care [that] begins with a self who is enmeshed in a network of relations to others, and whose moral deliberation aims to maintain these relations."241 Feminists have delineated two types of autonomy-one

238 Jaggar, 32.

${ }^{239}$ Benhabib, 85 .

${ }^{240}$ Hirschmann., Rethinking Obligation, 4.

${ }^{241}$ Eva Feder Kittay and Diana T. Meyers, "Introduction," in Women and Moral Theory, eds. Eva Feder Kittay and Diana T. Meyers (New Jersey: Rowman and Littlefield, 1987), 10. 
pertaining to men's autonomy, and another to women's. Hirschmann explains, "the differences in masculine and feminine experience can be seen to turn on two different conceptions of autonomy, just as they turn on two different senses of self." ${ }^{242}$

While most feminists view moral autonomy based on a conception of persons as "self-in-relation," and not Rawls's "separate self," there is no consensus among feminists as to how one should approach the notion of moral autonomy. ${ }^{243}$ Some feminists, building on Gilligan's research, believe that "autonomy represents a peculiarly masculine point of view," and thereby it should be abandoned for a notion of agency based on women's intrinsic connectedness to others. ${ }^{244}$ Because of autonomy's link with " "selfish' individualism", feminist writers "have long viewed the conception of autonomy as antithetical to feminists values [and their ethic of care]."245

A majority of feminists, however, are not willing to dismiss the notion of autonomy and human agency all together for some vague notion of interconnectedness. ${ }^{246}$ In the wake of feminist theorists' "growing distrust of communitarian politics," and a mounting skepticism of relational feminism, Anne Dailey notes, that there has been "a

${ }^{242}$ Hirschmann, Rethinking Obligation, 139.

${ }^{243}$ Kittay and Meyers, 10.

${ }^{244}$ Thomas E. Hill, Jr., "The Importance of Autonomy," in Women and Moral Theory, eds. Eva Feder Kittay and Diana T. Meyers (New Jersey: Rowman and Littlefield, 1987), 130.

${ }^{245}$ Dailey, 1279-1280.

${ }^{246}$ This has been a recent trend among postmodern feminists attempting to move away from relational feminism. 
corresponding appreciation for individual autonomy." 247 Feminists have increasingly questioned this juxtaposition of men's "autonomy" with women's "being in relation," which they see as dangerous theoretical move for women attempting to provide a theory of women's liberation.

As a result, feminists have retained an appreciation for autonomy, however, they support a brand of autonomy built on a relational sense of self. In contrast to "reactive autonomy" (which feminists believe accurately reflects Rawls's style of moral reasoning), "relation autonomy" (which feminists believe capture a women's moral reasoning) has been the favored model of autonomy. Feminists argue that reactive autonomy inaccurately "confuses autonomy with separation and independence from others,"248 while relational autonomy, on the other hand, "operates from a notion that the self is conceived in terms of, and draws strength from, relations with others." 249

Akin to the notion of autonomy, feminists do not reject the normative value of freedom and the concomitant desire for political liberty per se. Feminists, rather, take exception to Rawls's interpretation of freedom as a distinctly "negative freedom," which they again believe invokes an individualistic portrait of persons. According to feminists, freedom for Rawls seems to be a matter of one's overcoming the obstacles of personal attachment and the web of personal relations. Thus, Rawls must work "from an
${ }^{247}$ Dailey, 1280.
${ }^{248}$ Evelyn Fox Keller, Reflections on Gender and Science (New Haven: Yale University Press, 1985), 97.

${ }^{249}$ Hirschmann, Rethinking Obligation, 140. 
assumption of separateness and freedom" in order "to understand how isolated individuals can develop and sustain connections and still be separate, how they can engage in relationships and still remain free. ${ }^{250}$ For Rawls, say feminists, freedom is a normative given: man is assumed to be born morally free.

Feminists, on the hand, argue that what is a normative given is not that we are born free (in the liberal sense of the word), rather we are born attached and connected to others at birth. Thus, the ideal of freedom is one where persons work from a position of interconnectedness and social context. Feminists, such as Hirschmann, advocate an ethic of care or "responsibility mode, beginning with connection, [that] tries to determine how to provide space for the self without violating the moral imperative of care. This perspective would indicate that although freedom is certainly achievable in the context of human relations, it must be achieved; it is not a given. Freedom is an entity that must be created, as an individual carves out space for herself." 251

In brief, feminists are not rejecting the value of freedom and autonomy. What they are rejecting is Rawls's interpretation of these concepts through a masculine lens of the separate self, which feminists believe presents an inherently flawed rendering of these conceptions. Conversely, feminists suggest that these concepts must be reinterpreted in the light of a relational conception of the self; thus, the desire for freedom and autonomy takes on a different complexion than that valued by the Rawlsian self. While the social

\footnotetext{
${ }^{250}$ Ibid., 237.

${ }^{251}$ Ibid.
} 
self indeed finds some value in the ability to act autonomously and free, it is always exercised within the limits of a particular social context and within certain communal and personal attachments that must be maintained and protected.

\section{Conclusion}

In examining feminist contentions with Rawls, we find them making a series of claims regarding the nature of the Rawlsian self and its relationship to society. Plainly feminists believe Rawls's conception of the self is metaphysically abstracted from social context. This is demonstrated by their claim that Rawls assumes: (1) persons exist ontologically prior to social context; (2) that the self is atomistic and asocial; (3) that the self's identity, ends and conception of the good are not socially constituted; rather, they are presocial conceptions that one voluntarily chooses, or self-wills; and (4) that the normative values of freedom and autonomy ascribed to persons are acontextual.

Additionally, feminists have rejected Rawls's theory based on their description of women as relational selves in contrast to the above interpretation of the self. Feminists argue that Rawls's conception of justice does not differentiate persons based on sex-based differences; thus, women are discriminated against because Rawls theory of justice is incapable of detecting existing gender-biases in society and the "real" differences between men and women. Moreover, the Rawlsian self is understood by feminists to make moral decisions based on individualistic rationality which assumes persons make moral judgments based on impartial, universal principles, which is in opposition to the 
way they believe women make moral decisions. Taken together, the above factors have led feminists to conclude that Rawls's portrayal of persons is gender-biased. 


\section{CHAPTER IV}

\section{EVALUATING FEMINISTS' CRITIQUES OF THE RAWLSIAN SELF}

Having outlined Rawls's conception of the self as found in Theory and Political Liberalism and reviewed feminists criticisms of this concept, at this juncture, the investigation will begin evaluating the aptness of feminist claims. In defense of Rawls's conception of persons, I will argue that feminist contentions fail on two accounts. In this chapter, it will be demonstrated that feminist claims are largely based on theoretical misinterpretations of Rawls's conception of the self. In the next chapter, it will be shown that the project of gendering the self-enabling feminists to distinguish male or masculine attributes from female or feminine attributes-has proven highly problematic particularly for those feminists advancing the argument that the Rawlsian self is male or masculine. As a point of clarification, in presenting a rejoinder to feminist critiques, I will draw primarily from Rawls's material as presented in both Theory and Political Liberalism; thus, it should then be considered a defense of Rawls's conception of the self as presented in both texts.

My interest in appraising feminists' critiques of the Rawlsian self is determining whether their descriptions are indeed accurate portrayals of this self. Therefore, I will not be concerned with the ongoing debate between feminists and liberals over an ethic of care 
or "care-based approach" to politics versus an ethic of justice. ${ }^{252}$ While this debate has served as one of the central battlegrounds between liberals (proclaiming the preeminence of justice and rights in matters of politics) and feminists (proclaiming the superiority of relationships and responsibilities in matters of politics), due to the limited scope of inquiry I will attend only to those aspects of the debate that overlap with Rawls's conception of the self.

\section{Moral Individualism}

Based on Rawls's depiction of the parties in the original position, feminists have concluded that he assumes the self can be viewed ontologically prior to social context. Following this assumption, feminists further contend that the Rawlsian self entails a metaphysical conception of the self. These twin factors have subsequently led feminists to argue that Rawls subscribes to an untenable brand of metaphysical individualism, not moral individualism.

The paramount problem with this line of criticism stems from feminists' interpretation of the original position in Rawls's theory of justice. By claiming that the Rawlsian self is a metaphysical construct ontologically prior to its ends, feminists have assumed that the attributes ascribed by Rawls to parties in the original position conversely apply to Rawls's conception of the self. Unfortunately, feminists have not provided any substantive justifications for doing so.

${ }^{252}$ Kymlicka, Contemporary Political Philosophy, 264. 
As Rawls has rightly argued, this criticism is the product of a misinterpretation of the notion of the original position in both Theory and Political Liberalism. Rawls acknowledges that by employing a conception such as the original position there are bound to be "certain dangers" because "its abstractness invites misunderstanding." 253 For those viewing parties in the original position as a metaphysical conception of the self, however, are suffering from an unfortunate "illusion caused by not seeing the original position as a device of representation., 254

As a hypothetical construct, the original position is aimed at modeling our "considered convictions" in crafting a conception of justice. In Theory, Rawls states that the original position was designed to be a fair procedure capable of yielding principles of social justice, which "provide a way of assigning rights and duties" and "appropriate distribution of the benefits and burdens of social cooperation." ${ }^{255}$ Similarly, in Political Liberalism Rawls states that "the original position as a device of representation...models what we regard-here and now-as fair conditions under which the representative of free and equal citizens are to specify the terms of social cooperation in the case of the basic structure of society."256 In either formulation, parties in the original position are explicitly intended to represent persons (in Theory) or persons qua citizens (in Political

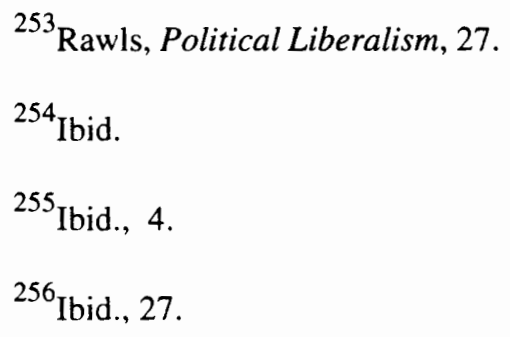


Liberalism). They are not, as feminists would suggest, intended to represent an actual description of the nature or constitution of human beings.

Regarding the veil of ignorance, Rawls explains, that it "has no specific metaphysical implications concerning the nature of the self; it does not imply that the self is ontologically prior to the facts about persons that the parties are excluded from knowing." ${ }^{257}$ At any point in time, embedded and embodied persons can simply "step" into the original position to determine fair principles of justice in accordance with the restrictions modeled into the original position. "When...we simulate beings in the original position," Rawls writes, "our reasoning no more commits us to a particular metaphysical doctrine about the nature of the self than our acting in a play, say of Macbeth or Lady Macbeth, commits us to thinking that we are really a king or a queen engaged in a desperate struggle for political power. Much the same holds for role playing generally. ${ }^{, 258}$

Having illustrated that the original position itself does not yield a metaphysical conception of persons in the way feminists suggest, we may ask whether feminists were entirely wrong to submit that Rawls's theory entails a metaphysical conception of the self. While the attributes ascribed to parties do not prima facie render a metaphysical conception of the self, does this necessarily imply that Rawls's theory in general is not built around a particularly (metaphysical) conception of the self?

$$
\begin{aligned}
& { }^{257} \text { Ibid. } \\
& { }^{258} \text { Ibid. }
\end{aligned}
$$


The suggestion here is that if feminists are intending to charge Rawls's conception of justice as presented in Theory with subscribing to a metaphysical conception of persons, they should refocus their argument if it is to be at all cogent. That is, feminists ought to look "outside" the original position to formulate their claim of metaphysics instead of looking within the original position and extracting from it the attributes given to the parties.

As discussed in chapter two, the original position as a device of representation models what Rawls considers important about people's capacities and interests. Rawls's theory explicitly embodies the claim that, when it comes to matters of justice, people should be regarded as distinct from their particular natural endowments, social position and ends, but possessed of a highest-order interest in their capacity to frame, revise and rationally pursue their conception of the good-and such a claim amounts to an assessment of what is important about people, what constitutes their well-being. ${ }^{259}$

It is in this sense that Rawls's theory is modeled around a particular conception of persons.

Feminists should have been attempting to determine whether Rawls's modeling the original position in this way amounts to a metaphysical conception of persons. Since it looks as though one has to be thoroughly committed to Rawls's liberal understanding of personhood, many theorists have concluded that this amounts "to a claim about the metaphysical essence of people."260

\footnotetext{
${ }^{259}$ Ibid., 206-207.

${ }^{260}$ Swift and Mulhall., 176.
} 
In short, while feminists may not have been erroneous in their contention that Rawls affirms a metaphysics of personhood in Theory, they were inaccurate in their portrayal of this commitment. If feminists were to maintain that Rawls subscribes to a metaphysical account of persons, they need to focus on the fact that the original position frames a particular liberal account of persons-in which case, Rawls's metaphysical conception of persons encompasses more metaphysical attributes than that which is given to parties in the original position. ${ }^{261}$

In Political Liberalism, Rawls outlines a similar set of assumptions about persons, however, he is careful to declare that these normative claims are derived from implicitly shared political ideals manifest in our democratic public political culture. In shifting the theoretical bases of these claims, Rawls has eschewed any reliance on the metaphysical entanglements found in Theory and thereby is insulated from feminist charges of metaphysics.

If feminists want to renew their attack on Rawls's conception of the self from the position taken in Political Liberalism, they must first attend to Rawls's shift from defending his arguments against the charge of metaphysics, to defending his argument against a comprehensive doctrine. In addition, feminists must consider other lines of argument such as questioning the basis and scope of his notion of citizen. They may want to question whether men and women have disparate notions of the ideal of citizenship-

${ }^{261} \mathrm{NB}$ : It is not entirely clear that feminist would reject the metaphysical account of persons on display in Theory. 
perhaps it is a masculine ideal of citizenship that is on display in Rawls's theory of justice.

\section{Individuals and Social Context}

One of the leading planks of feminist criticisms of Rawls's conception of persons is that it is premised upon a brand of abstract individualism. Analogous to the Hobbesian "man as mushroom" notion, feminists claim that the Rawlsian self is painted as having an identity and conception of the good that is formed separately from-or prior to-any particular social context. In light of this interpretation of the Rawlsian self, feminists contend that the Rawlsian self is atomistic, asocial, and egoistic. Thus, Rawls necessarily miscasts the relationship between the individual and society. Society is depicted simply as an arrangement for the mutual advantage of self-interested individuals whose aims are inherently asocial, and whose identities and ends are presocially given.

The above arguments are misguided on two counts. First, feminists have relied entirely on the description of the parties in the original position to make their claim that Rawls's conception of the self is based on abstract individualism. Again, feminists offer no rationale to explain why we should consider characteristics ascribed to parties as those given to Rawls's conception of persons. Second, the charge that Rawls exhibits an inattentiveness to social context and its relationship to persons in either Theory or Political Liberalism seems inaccurate. As outlined in chapter two, Rawls discusses social context and society at length in both presentations of his conception of justice. 
In JAF, Rawls references social factors in four specific ways. He claims human beings are inherently sociable. He acknowledges that social context fashions human desires and identities. He considers society as a cooperative undertaking amongst individuals. Finally, he holds society and social life as a good in themselves.

In political liberalism, Rawls's depends extensively on social context in formulating his political conception of justice as fairness. By situating his notion of justice within a specific political context or community, Rawls's theory takes both as its source and content those communally-derived values and understandings on display in democratic society.

Given that Rawls recognizes the significance of social context in crafting his theory of justice in both JAF and political liberalism how then does this relate to his conception of persons? Does Rawls demonstrate that persons are not atomistic units, that our identities, conceptions of the good, and interests are dependent on social context and personal attachments, and that we are not self-interested, egoistic creatures? The answer to each of these questions is yes.

In response to the feminist claim that Rawls views persons as asocial, atomistic, asocial units it is demonstrated both in political liberalism and JAF that Rawls attends to the idea that persons are embedded within a particular social context and that a person's identity is reflective of the matrix of social influences and personal attachments in which one is embedded. 
In Theory, Rawls demonstrates his concern not only for the "social formation" of our conception of the good and interests, but also the way in which our "affections and desires" and "the way our character develops through social interaction."262 Primarily, this concern is exhibited in his attention to how the "social system" influences these aspects of a persons existence. ${ }^{263}$ In addition, Kymlicka explains that the feminist claim that Rawls subscribed to an atomistic conception persons based on abstract individualism is simply "absurd" because it "add[s] absolutely nothing to the moral argument for liberal politics."264

In political liberalism, Rawls brings the issue of persons and social embeddedness to the forefront. Rawls states that it is plain that

We have no prior identity before being in society: it is not as if we came from somewhere but rather we find ourselves growing up in this society in this social position, with its attendant advantages and disadvantages, as our good or ill fortune would have it...Thus, we are not seen as joining society at the age of reason, as we might join an association, but as being born into society where we will lead a complete life. ${ }^{265}$

It is from this standpoint-as beings positioned (or embedded) within a particular social context-that we make decisions and deliberate over the principles of justice.

This bring us to answer the question: Is the Rawlsian self egoistic? In Theory, according to feminists, Rawls's appears to invoke a form of egoism on two accounts.

\footnotetext{
${ }^{262}$ Kymlicka, Liberalism, Community and Culture, 16.

${ }^{263}$ Rawls, Theory, 259.

${ }^{264}$ Kymlicka, Liberalism, Community and Culture, 15.

${ }^{265}$ Rawls, Political Liberalism, 41.
} 
First, Rawls's employment of rational choice theory appears to be the explanation offered regarding why citizens would agree to entering society and a conception of justice in the first place. Second, because parties are touted as being mutually disinterested, feminist contend, that this necessarily invokes a form of egoism.

On the first account: Following Theory's publication, Rawls's admitted that his employment of rational choice theory was misleading as it suggested that persons enter society (or agree to principles of justice) based on egoistic reasons of mutual advantage. Rawls claims that he "should have said...that the conception of justice as fairness uses an account of rational choice subject to reasonable conditions to characterize the deliberations of the parties as representatives of free and equal persons; and all of this within a political conception of justice, which is, of course, a moral conception."266 In political liberalism, then, Rawls clarifies that rational choice is not used as a method for explaining why persons would submit to the original position.

Careful not to invoke the sort of latent egoism on display in JAF, in political liberalism Rawls emphatically draws a separation between the "Rational," which provides the basis of how parties in the original position are motivated, and the "Reasonable," which is the public reason citizens in a democratic society would agree to the original position. "Since this means that the Reasonable is prior to the Rational, and embodies a variety of moral concerns, including claims about what sort of political community is worthy of allegiance," Mulhall and Swift contend that we in turn "have no grounds for 
regarding Rawls's use of rational choice machinery as a sign that he is an asocial [egoistic] individualist in the substantive sense."267

On the second account: The notion that Rawls's conception of persons is egoistic, based on his description of parties in the original position, is also groundless. As discussed in chapter two, there is no way to determine whether interests of parties in the original position are egoistic, altruistic, etc. Because the interest of parties are simply of a self, not in a self.

Contrary to feminists' depiction of Rawls's conception of persons as “the radically individuated man-as-mushroom," Rawls does take into account the social embeddedness of persons. ${ }^{268}$ As Moore and others correctly argue, feminists have erred "in tarring Rawls with the brush of Hobbesian individualism" and "discounts the broader context within which Rawls places his subject, which is first and foremost a social order." 269 Indeed, both JAF and political liberalism are attentive to social context and to the fact that human identities are developed within a social context.

\section{Equality and Moral Personality}

Feminists' contentions with Rawls's conception of equality do not deride it as a normative principle. In arguing for sexual equality, feminists have often appealed to the

$$
\begin{aligned}
& { }^{267} \text { Ibid. } \\
& { }^{268} \text { Moore, } 166 . \\
& { }^{269} \text { Ibid., } 164 .
\end{aligned}
$$


notion of moral equality between the sexes. What feminists are concerned with is two things: whether Rawls's conception of equality can account for the "real" differences between men and women (e.g. reproductive capabilities) which place women at a disadvantage; and does equal consideration based on moral personality exclude women.

First, given Rawls's description of the principles of justice in both Theory and Political Liberalism, there is no reason to reject Rawls's notion of equality. It proves capable of taking into account not only gender differences that handicap women as a group, but also the fact that there exists a gender-structured society that has systematically discriminated against women because of their sex.

In modeling the original position, Rawls has attempted to restrict factors that have traditionally led to gender injustices and inequality of opportunity for women. Rawls maintains that the "contingencies of endowment" are to be held morally arbitrary. That is, "no one deserves his place in the distribution of native endowment, any more than one deserves one's initial starting place in society." 270 Since parties in the original position will not know their gender, and will have access to general knowledge about society as gender-biased, Rawls contends that parties will choose principles "to the greatest benefit of the least advantaged."271 Parties, cognizant of the existing gender prejudices in contemporary social institutions, would not choose principles discriminatory against one gender. Thus, the distribution of basic social goods (necessary for equal opportunity)

${ }^{270}$ Rawls, Theory, 104.

${ }^{271}$ Ibid., 83. 
would not be based on natural endowments which could therein favor one sex over the other. A theory supporting gender-biased institutions and patriarchal gender divisions that place women at a disadvantage would be inconsistent with Rawls's principles of justice.

While Rawls contends that all persons deserve equal consideration this does not translate-as feminists suggest-into the principle that men and women should be treated exactly alike when it come to matters of formal equality. Rawls's conception of equality, according to the difference principle, theoretically allows for men and women to be treated differently so that those "real" aspects that undermine equality between the sexes can be accounted for. Accordingly, there is no reason to assume that Rawls's theory of justice would be insensitive to gender differences.

The second contention feminists have directed at Rawls's notion of equality arises from its dependence on moral personality. Consonant with the definition in Theory, Rawls states in Political Liberalism that "[a] sense of justice is the capacity to understand, to apply, and to act from the public conception of justice which characterizes the fair terms of social cooperation's." ${ }^{272}$ (I will treat feminists contentions with Rawls's "sense of justice" here, and a conception of the good in the next section.)

Feminist contentions with Rawls's "sense of justice" stems primarily from Gilligan's "two voice" thesis (also dubbed the "connection thesis") which contends that men's moral reasoning is based on a sense or "ethic of justice" while women's is based

${ }^{272}$ Rawls, Political Liberalism, 19. 
on an of "ethic of care."273 As has been noted, Gilligan has been broadly interpreted as suggesting "that women's morality is concrete and contextual rather than abstract; that it is nonprinciples rather than principles; that it is personal rather than impersonal; that it motivates through care rather than through awareness of duty; and that it is structured around responsibilities rather than rights." 274

While the empirical evidence alone effectively undercuts feminist arguments that there exists notable psychological differences between men and women which manifests in two different moral dispositions (which will be discussed in the following chapter) many theorists have pointed to a second problem: that is, they have questioned the potential of an "ethic of care" (versus an "ethic of justice") in providing a viable alternative for selecting principles of justice by which to order society. While I will not treat this at length for reasons explained at the outset, many theorists have concluded: (1) an "ethic of care" and an "ethic of justice" converge on many points so that an "ethic of care" collapses into an "ethic of justice" in many ways; and (2) an ethic of care is simply

${ }^{273}$ Robin West, "Jurisprudence and Gender," in Feminist Legal Theory, eds. Katharine T. Bartlett and Rosanne Kennedy (Boulder, CO: Westview Press, Inc., 1991), 207. The "connection thesis," West states (207), is that "Women are actually or potentially materially connected to other human life. Men aren't. This material fact has existential consequences. While it may be true for men that the individual is "epistemologically and morally prior to the collectivity," it is not true for women. The potential for material connection engenders pleasures and pains, values and dangers, and attractions and fears, which are entirely different from those which follow, for men, from the necessity of separation. Indeed, it is the rediscovery of the multitude of implications from this material differeree between men and women which has enlivened (and divided)both cultural and radical feminism in this decade (and it is those discoveries which have distinguished both radical and cultural feminism from liberal feminism."

${ }^{274}$ George Sher, "Other Voices, Other Rooms? Women's Psychology and Moral Theory," in Women and Moral Theory, eds. Eva Kittay and Diana T. Meyers (New Jersey: Rowman and Littlefield, 1987), 179-180. 
not a plausible alternative by which to order society where persons are not exclusively connected in personal relations of care and face-to-face contact. ${ }^{275}$

\section{Conceptions of the Good, Rational Plans, and Conflicting Interests}

Feminist contentions with Rawls's conception of the good take two forms. First, feminists argue that his conception of the good does not comprehend the way in which it is influenced by social context. Given that this contention has already been addressed, it is the second contention that will be of interest: that is, feminists argue that Rawls's conception of the good does not include personal attachments and other persons as objects of a self's conception of the good.

In Theory, Rawls does not explicitly account for the way in which a person can have as their conception of the good another person. However, in Political Liberalism, he amends this. Rawls states that it is clear that a conception of "the good normally consists of a more or less determinate scheme of final ends, that is, ends we want to realize for their own sake, as well as attachments to other persons and loyalties to various groups and associations.",276

With regard to Rawls's assumption that parties in the original position are rational in selecting their life plans, feminists have questioned Rawls's use of rationality (i.e., rational choice theory). Parties are rational, Rawls states, if they "schedule their more

${ }^{275}$ For a good discussion and appraisal of the ethic of care-ethic of justice debate, see Kymlicka, Contemporary Political Philosophy, chap. 7.

${ }^{276}$ Rawls, Political Liberalism, 19. 
important endeavors and allocate their various resources (including those of mind and body, time and energy) so as to pursue their conception of the good over a complete life, if not in the most rational, then at least in a sensible (or satisfactory), way."277 This characterization of rationality, however, does not seem to be a bone of contention for feminists.

What feminists appear to be disagreeing with is Rawls's methodology on the whole. That is, the way in which Rawls's derives principles of justice through the employment of an abstract, hypothetical construct is questionable. Thus, the manner feminists object to Rawls's methodology is that it is gender-biased concept.

Unfortunately, feminists rely heavily on the empirical claim that men and women reason differently in generating their argument against Rawls's methodology. Again, as will be discussed in the following chapter, there exists no conclusive empirical evidence that demonstrates men are more adroit at making moral decisions based on hypothetical situations, and women are more apt to make moral decisions based on concrete, contextual situations. If this is the case, then, feminists argument against Rawls's methodology along gender lines collapses.

Lastly, feminists have questioned Rawls's assumption that there will inevitably be conflicting interests, instead they suggest that persons are inherently social and otheroriented. As indicated, Rawls does not present a conception of persons that are asocial, egoists prone to hostility in competing for resources in society. Feminists have

${ }^{277}$ Ibid., 177. 
gratuitously interpreted Rawls's notion of conflicting visions of the good to mean that persons are naturally self-interested individuals inclined to aggressive, asocial behavior. This was not what was intended by Rawls.

By claiming that persons will necessarily come into conflict with each other in society, what Rawls is referring to is that because people have different conceptions of the good, and because they want to secure those social resources requisite to obtain their good, there will exist a certain amount of conflict in society. In Political Liberalism, Rawls states that a "political culture of a democratic society is always marked by a diversity of opposing and irreconcilable religious, philosophical, and moral doctrines."278 Given the fact that people exist in a society that allows persons to form, revise and purpose their conception of the good they are not all going to do so in the same fashion.

However, these differences do not have to manifest armed conflict, violent behavior, or aggression as feminists imply. When Rawls speaks of persons having different and conflicting conceptions of the good, he simply means that there are those in society who hold feminist conceptions of the good alongside those who maintain misogynistic conceptions of the good.

\section{Freedom, Liberty and Autonomy}

For the most part, feminists' contentions with Rawls's conception of freedom, liberty and autonomy arise from their belief that he does not situate these concepts within

${ }^{278}$ Ibid., 3-4. 
a social context, or ground these concepts on a relational sense of selves. Feminists argue that people only exercise autonomy and freedom within a particular society, within a particular community, and within a particular web of intimate personal relations.

Given the previous discussion on social context, it appears that feminist contentions are erroneous. Rawls's commitment to freedom and autonomy presupposes that that individuals exist within a particular social context and hold a variety of personal attachments.

Freedom, for Rawls, is a matter of acting within a particular social milieu in which persons find themselves embedded. As Kymlicka elaborates: "Liberal individualism is....an insistence on respect for each individual's capacity to understand and evaluate her own actions, to make judgments about the value of the communal and cultural circumstances she finds herself in. ${ }^{279}$ Freedom as a normative conception is not valued in and of itself; rather, it is simply an instrumental prerequisite for persons desiring to pursue their own visions of the good. ${ }^{280}$

The fact that JAF takes account of social context in many ways undermines feminists' contentions that freedom is not viewed within a social environment. In political liberalism, Rawls presents an even more situated sense of freedom. As inhabitants of a democratic political society our belief that we are all free and equal, manifests itself in three respects: First, as having the moral power to form, to revise, and

${ }^{279}$ Ibid., 254.

${ }^{280}$ Kymlicka, Liberalism, Community and Culture, 49. 
rationally to pursue a conception of the good; second, as being self-authenticating sources of valid claims; and third, as capable of taking responsibility for their ends." ${ }^{281}$ In this sense, the notion of freedom is derived from our communal existence.

With regard to autonomy, as suggested in chapter two, Rawls's conception of autonomy can be considered "situated" or "embedded" autonomy both in JAF and political liberalism. For Rawls, exercising autonomy in not a matter of separating or abstracting one's self from personal attachments and existing social influences (as it is logically inconceivable). Rather, Rawls's liberal autonomy is situated within a particular context, which "involves critical reflection on inherited values, personal commitments, and based good, not a flight from and abandonment of them"; moreover, it "engages our understanding and responsibility at a deep level by engaging the capacity critically to reflect upon moral and personal identity, itself already constituted by projects plans, commitments, and strong evaluations."282

In short, in both JAF and political liberalism Rawls's conception of freedom, liberty, and autonomy seems to parallel feminist arguments for relational autonomy and freedom based on a relational description of the self.

${ }^{281}$ Rawls, Political Liberalism, 74.

${ }^{282}$ Macedo, 220. 


\section{Conclusion}

By way of this evaluation, it appears that feminist contentions with Rawls was based on several misinterpretations of his theory of justice. Given the fact that Rawls attends to social context and personal attachments, it appears that Rawls's conception of the self is nearer to feminists relational self than their version of the separate self characterized as the Rawlsian self. Indeed, we find that feminists' conception of the relational self and Rawls's conception of the self are not necessarily at cross-purposes as feminist would have us believe.

On the matter of which conception of justice proved the most capable of deflecting feminists' contentions, I think that political liberalism is best suited to counter such claims. While JAF does make a puissant claim that persons are sociable creatures, political liberalism better attends to social context, personal attachments in a persons conception of the good, and deflecting charges of rational egoism. Nevertheless, both formulations of Rawls's theory of justice have the theoretical resources to respond to, and counter, feminist critiques of the Rawlsian self. 


\section{CHAPTER V \\ CONCLUSION: \\ PROBLEMATICS OF GENDERING THE SELF}

In the wake of feminists' abandoning their "focus on the similarities between individual men and women," much of contemporary feminist scholarship has been devoted to the enterprise of articulating the differences between the sexes. ${ }^{283}$ Indeed many feminists have attempted to model a collection of attributes which women as a group share in common-whether it be based on women's psychology, "essence, nature, biology, or universal social position" and so on-that ultimately distinguishes them from men. ${ }^{284}$

This project of generating a fixed set of attributes, traits, characteristics, moral dispositions, and the like, unique to women's gender identity has garnered much support from feminist scholars, particularly from relational feminists. Not only has this undertaking held out the possibility that there exists "real" and discernible differences between the sexes, but also that these differences could be cataloged for the purposes of gendering the self.

\footnotetext{
${ }^{283}$ Williams, 110.

${ }^{284}$ Grosz, 84.
} 
Of late this project of formulating an "essence" of womanhood has become increasingly suspect, however, particularly among feminists influenced by postmodern thought. While this group of feminists seem reluctant to abandon the notion that there exist differences between men and women, and that gender influences a person's identity to some degree, they argue that gender is in no way the primary determinant of identity. Gender is simply one facet of a person's multi-faceted identity, and it intersects with a whole host of other characteristics such as class, race, ethnicity, personal experiences, etc.

Regardless of how feminists go about gendering the self, their capability to do so is of significance here, for it enables them to determine whether Rawls's conception of the self is gendered. If feminists cannot clearly demarcate gender differences between men and women, because the division between the sexes is blurred or inconsequential, then feminists cannot conversely make the claim that the Rawlsian self is gendered one way or the other. Thus, the feminist claim that the Rawlsian self is a male or masculine self would collapse.

The aim of this chapter, then, is to explore the potential of three different feminists' approach to gendering the self. In reviewing each of these paths to gendering the self, I will evaluate the potential each has for gendering the self, and what bearing this has on feminists' critiques of Rawls's conception of the self. In summation of the thesis, I will provide a final answer to the question of whether feminists are correct in their assertion that the Rawlsian self is a male or masculine self. 


\section{Relational Feminism}

Relational feminism's approach to gendering the self is primarily defined by several influential psychological and psychoanalytic works on gender studies, which have aimed at demonstrating gender identity differences based on contrasting psychosexual development. By virtue of the fact that men and women's paths to psychosexual development are divergent, relational feminists contend that men and women have disparate attributes and moral orientations.

For the most part, relational feminists base their claim of gender differences on the works of Dorothy Dinnerstein, Nancy Chodorow, Juliet Mitchell, and Carol Gilligan. ${ }^{285}$ Of these theorists, however, Carol Gilligan's book, In a Different Voice, has proved to be the most influential and widely received theory supporting women and men's difference in contemporary feminist political discourse.

Gilligan's work has been broadly regarded as an undertaking challenging the Freudian notion that women do not have as well-developed a sense of justice as men. In critiquing the work of Lawrence Kohlberg's theory of moral development, which expands Jean Piaget's popular "theory of cognitive growth," Gilligan presented a contrasting vision of women's moral development. In so doing, Gilligan submitted that “Kohlberg's

${ }^{285}$ Nancy Chodorow, The Reproduction of Mothering (Berkeley, CA: University of California Press, 1987); Dorothy Dinnerstein, The Mermaid and the Minotaur: Sexual Arrangements and Human Malaise (New York: Harper Cholophon Books, 1977); Carol Gilligan, In a Different Voice, (Cambridge: MA: Harvard University Press, 1982); and Juliet Mitchell, Psychoanalysis and Feminism (New York: Vintage Books, 1974). 
results were sex-biased against a moral orientation based on care, in contrast to his position of a justice orientation as the goal for mature moral development."${ }^{, 286}$

Gilligan believed that she had "discovered" that women and men have disparate conceptions of morality, two different moral "voices." As highlighted previously, Gilligan explains that: "The moral imperative...[for] women is an injunction to care, a responsibility to discern and alleviate the 'real and recognizable trouble' of this world. For men, the moral imperative appears rather as an injunction to respect the rights of others and thus to protect from interference the rights to life and self-fulfillment."287 Women form moral decisions based on a socio-historical context, or on particular "social contingencies", suggests Gilligan. ${ }^{288}$ Men, on the other hand, are more apt to make moral decisions based on "hypothetical dilemmas" or universal abstractions. Men are better able to extract themselves "from the history and psychology of their individual lives and separate the moral problem from the social contingencies of its possible

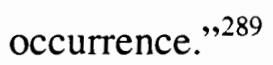

Furthermore, Gilligan argued that women's relationships with others were based on an "ethic of care," while men's relationships with others were based on an "ethic of rights" or an "ethic of justice." Here women's conception of the self emphasizes the way

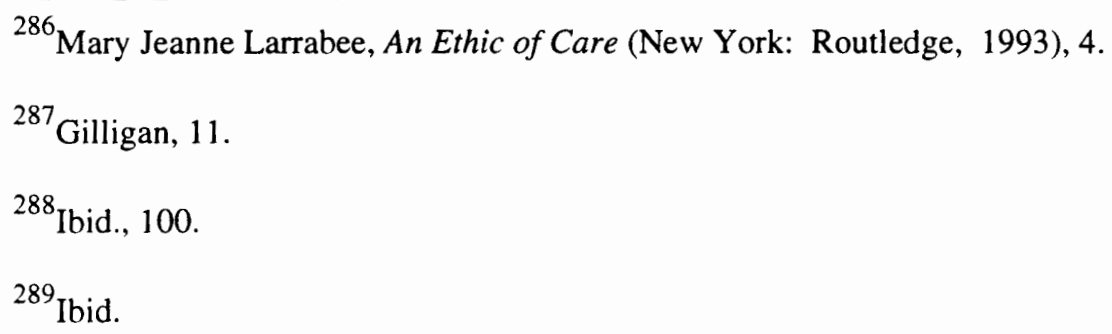


in which moral agent's often eschew formal rights, and instead focus on the cultivation of intimate personal connections based on responsibilities, nurturance, selflessness and empathy; whereas men emphasize a moral agents aptitude in acting autonomously and separately according to formal principles of justice and universal rights.

In claiming that women's morality was based on an ethic of care, while men's morality was based on an ethic of justice, then, Gilligan suggests that women's views of the self are relational. In contrast, men view the self as separate, independent and autonomous. Thus, "the contrast between a self defined through separation and a self delineated through connection, between a self measured against an abstract ideal of perfection and a self assessed through particular activities of care, becomes clear": the female gendered self views moral decisions through the activities of connection and care for others and the male gendered self views moral decisions through the application of abstract, universal principles of justice and rights. ${ }^{290}$

Though Gilligan's study was a work in moral psychology, feminist political theorists have made extensive use of Gilligan's research in their critique of the liberal self. ${ }^{291}$ (Many of the critiques targeting Rawls's conception of the self in chapter three were directly inspired by Gilligan's research on the so-called differences between men and women.) The reason for this, according to Cass Sunstein, is that

Kohlberg's theory of the stages of moral development is closely connected with prominent approaches to questions of social justice. If Kohlberg's theory of
${ }^{290}$ Ibid., 35.
${ }^{291}$ Williams, 100. 
development is based on male norms, and ignore an important alternative, the same may be true of (to take a not entirely random example) contractarian theories of politics. Thus, Gilligan's "ethic of care" is opposed, in much feminist work, to the "ethic of justice" associated with social contract theory, most notably that of John Rawls. ${ }^{292}$

Although one can speculate that Rawls would reject such a connection, Kohlberg has nonetheless drawn a parallel between his highest stage of moral development and Rawls's notion of parties in the original position. ${ }^{293}$

Gilligan's popularity among feminists critiquing liberal conceptions of the self then seems attributable to two things. Gilligan appears to have finally provided empirical evidence in favor of associating particular "themes" and characteristics with female gender identity. ${ }^{294}$ Moreover, as Diana Meyers and Eva Fender Kittay suggest, "Gilligan's work on moral development purports to offer empirical evidence...that undercuts standard [liberal] assumptions about moral autonomy, moral principles and the universality of moral doctrines." 295

The employment of Gilligan's research to gender the self, however, is significantly problematic for feminists on several accounts. First, Gilligan claims that she is not attempting to ascribe traits along gender lines. Though relational feminists have

${ }^{292}$ Sunstein, 2.

${ }^{293}$ Richard Brook, "Justice and the Golden Rule: A commentary on some recent work by Lawrence Kohlberg," Ethics 97 (1987): 363.

${ }^{294}$ Bill Puka, "The Liberation of Caring: A Different Voice for Gilligan's 'Different Voice?'” in Who Cares?, ed. Mary M. Brabeck, (New York: Praeger, 1989), 29.

${ }^{295}$ Kittay and Meyers, 3. 
considered Gilligan's work as outlining a set of gender-based characteristics applicable to women, Gilligan herself argues to the contrary. Gilligan states,

The different voice I describe is characterized not by gender but theme. Its association with women is an empirical observation, and it is primarily through women's voices that I trace its development. But this association is not absolute, and the contrasts between male and female voices are presented here to highlight a distinction between two modes of thought and to focus a problem of interpretation rather than to represent a generalization about either sex. ${ }^{296}$

Despite Gilligan's claim that she was attempting to uncover a pattern of care in moral reasoning, however, relational feminists and critics alike have correctly regarded Gilligan's research as an attempt to "account for care levels or care development... characterized by gender rather than theme."297 The assumption that Gilligan's implicit intention was to articulate generalizations about gender along the lines of distinct moralities, rather than uncovering a gender-neutral theme of care, is based on several factors.

One factor was the type of issues Gilligan raised in her interviews, and who it was she interviewed. For instance, on a study of abortion, Gilligan posed questions to women, which she did not pose to men. Another factor was the fact that Gilligan was inattentive to the differences between women based on age, race, class, and individual particularity. This has led critics to challenge her claim that she did not intend to link

$$
\begin{aligned}
& { }^{296} \text { Gilligan, } 2 . \\
& { }^{297} \text { Puka, } 29 .
\end{aligned}
$$


different moral voices to a specific sex, because it appears as though she was preoccupied with identity differences only along only gender lines. ${ }^{298}$

Another factor, one which Bill Puka points out, is that Gilligan's own statements suggest that her future objective was to uncover differences between men and women's moral judgments. Gilligan states that her

findings were gathered at a particular moment in history, the sample was small, and women were not selected to represent a larger population. These constraints preclude the possibility of generalization and leave to further research the task of sorting out the different variables of culture, time, occasion, and gender.

Additional longitudinal studies of women's moral judgments are needed in order to refine and validate the sequence describe. ${ }^{299}$

It appears here as though Gilligan is again concerned with generalizing gender-based differences, rather than uncovering a gender-neutral theme of care.

Given the above factors, Gilligan's book is generally read by feminists and critics as making the following claims:

The first is the empirical claim that women and men, as a matter of fact, differ in their approaches to moral reasoning, with women emphasizing care and men justice. The second is the value claim that since an ethics of care is at least equal to, and perhaps better than, an ethics based on fairness, moral theory-which has traditionally emphasized justice and ignored or trivialized caring relationshipsought to be restructured to take account of the importance of caring. ${ }^{300}$

Our interest is in the first claim, because unless it is validated-that is, an ethic of care it associated with womanly attributes - the second claim could be discussed in a gender-
${ }^{298}$ Tong, 166.
${ }^{299}$ Gilligan, 126.
${ }^{300}$ Charlene Haddock Seigfried, "Pragmatism, Feminism, and Sensitivity to Context," in Who Cares?, ed. Mary M. Brabeck (New York: Praeger, 1989), 64. 
neutral way. This brings us to the second problem: Is Gilligan's empirical claim conclusive?

From the outset, many theorists have raised serious objections to Gilligan's methodology. In summarizing these objections, the empirical data Gilligan employs in formulating her thesis is suspect in the following ways: First, the "all-female sample" that Gilligan used in formulating a theory regarding the differences between men and women does not include an adequate study of men in which to base her conclusions. The salient question to be asked is how does Gilligan justify making claims about men's morality when they were not included in sample groups and given the same questions as women? $?^{301}$ Second, Gilligan, according to Puka, used "open-ended interviews [where] respondents emitted only those dilemmas they found personally salient." ${ }^{, 302}$ Third, Gilligan interviewed only a small number of people, which was not enough quantitative data to formulate a credible argument. ${ }^{303}$ Fourth, Gilligan did not take into account individual differences among women. For example, samples drew on too wide a range of ages in some of her studies. Fifth, and perhaps most importantly, "Gilligan never actually observed women go through the level of care...Rather Gilligan reconstructs the sequence of development conceptually in her book, by glimpsing a small interval of development in

${ }^{301}$ Brabeck, 38.

${ }^{302}$ Puka, 40.

${ }^{303}$ Deborah L. Rhode, "The politics of paradigms: gender difference and gender disadvantage," in Beyond Equality and Difference: Citizenship, feminist politics and female subjectivity, eds. Gisela Bock and Susan James (New York: Routledge, 1992), Rhode argues (157) "Gilligan's data drew on small unrepresentative samples." 
eight respondents." ${ }^{304}$ Lastly, critics have argued that Gilligan's presentation of the data is confusing. Luria explains "Gilligan does not draw a clear line between theoretical speculation and discussion of data and slips from hunch, example, or metaphor to 'proven fact.,$" 305$

Based on these methodological flaws alone, critics have concluded that Gilligan's empirical evidence probably do not support her thesis. Consequently, many have argued that Gilligan simply "oversimplified the case [for two separate moralities] and overinterpreted the data," and that once "better controls are used the difference between the sexes are more leveled." ${ }^{306}$ Relational feminists, however, continue to insist that there are gender-based differences between men and women. The question thus remains is there any empirical truth to these arguments?

Though its has been over a decade since Gilligan published her findings "there is not a consensus in the psychological literature either on whether females and males reason differently regarding morals and, by extension, politics, or on why they do so when gender differences in moral reasoning have been observed." 307 What seems to be the consensus, Deborah Rhode maintains, is that

${ }^{304}$ Ibid., 40-41. For those familiar with trends in feminist theory, essentialism is a particularly unfavorable position at present.

${ }^{305}$ Zella Luria, "A Methodological Critique," in An Ethic of Care, ed. Mary Jeanne Larrabee (New York: Praeger, 1989), 201-202.

${ }^{306}$ Ibid.

${ }^{307}$ Sinopoli, 223. 
most empirical studies of moral development do not disclose significant gender distinction. Nor does related research reveal the kind of strong sex-linked differences that relational feminism would suggest; there are few psychological attributes in which the sexes consistently vary. For even those attributes, such as aggression, spatial ability and helping behavior, gender typically accounts for only about 5 per cent of the variance, the similarities between men and women are far greater than the disparities, and small statistical distinctions do not support sweeping sex-based dichotomies. ${ }^{308}$

Making a similar conclusion, Muriel Bebeau and Mary Brabeck have tested Gilligan's thesis in light of recent research on gender differences. What they found was that " $[t] o$ date, the literature examining gender differences in moral reasoning as defined by Kohlberg's theory do not support Gilligan's claims." 309 While there is much evidence to suggest that "abstract reason are perceived as masculine traits", the "evidence from observation of behaviors does not support the stereotype." ${ }^{\text {310 }}$ Extensive testing of both men and women showed that "females use conceptions of justice in making moral judgment as often as their male counterparts."

Nancy Eisenberg, Richard Fabes, and Cindy Shea conducted another review of the literature on gender-based differences in moral reasoning. ${ }^{312}$ What they found was that

${ }^{308}$ Rhode, 157.

${ }^{309}$ Muriel J. Bebeau and Mary M. Brabeck, "Ethical Sensitivity and Moral Reasoning among Men and Women in the Professions," in Who Cares?, ed. Mary M. Brabeck, (New York: Praeger, 1989), 146.

${ }^{310}$ Ibid.

${ }^{311}$ Ibid., 147.

${ }^{312}$ Nancy Eisenberg, Richard Fabes, and Cindy Shea, "Gender Differences in Empathy and Prosocial Moral Reasoning: Empirical Investigations," in Who Cares?, ed. Mary Brabeck (New York: Praeger, 1989). 
Based on the existent empirical data, it is not clear whether there are gender differences in empathy, sympathy, and personal distress. Females tend to report more of the emotional responses but they do not differ markedly from males in nonverbal and physiological reactions...The difference that does occur in nonverbal indexes favor females, although it is possible that males simply mask or inhibit their sympathetic and empathic reactions more than females. Given the lack of difference in the physiological data as well as the nonverbal and self-report data indicating more responsibility by females, we hypothesize that males and females do not differ significantly in their tendencies to react emotionally to other's emotional states (i.e., in empathy). ${ }^{313}$

While Eisenberg, Fabes, and Shea obtained some evidence to suggest that women exhibited more other-oriented behavior in attending to emotional needs than men, the differences they located were not great "and account for relatively small amount of the variance in individuals' emotional responding and moral reasoning.",314

At this point in time, it is reasonably safe to assume that there exists little empirical evidence to suggest that men and women have different gender-based approaches to morality. Since this is the case, why have relational feminists and others continued to argue that there exists "real" differences between men and women?

Lawrence Walker hypothesizes that the notion that there are stereotypical differences between the sexes is more mythic in origin that empirical. ${ }^{315}$ "It is clear that women have a greater reputation for altruism and empathy than do men, and that women accept its validity," claim Catherine Greeno and Eleanor Maccoby, even though "studies

${ }^{313}$ Ibid., 136.

${ }^{314}$ Ibid., 139-140.

${ }^{315}$ Lawrence Walker, "Sex Differences in the Development of Moral Reasoning: A Critical Review," in An Ethic of Care, ed. Mary Jeanne Larrabee (New York: Routledge, 1993), 176. 
do not show" this to be the case. ${ }^{316}$ While men and women may intuitively perceive there to be a difference between the male and female conception of the self, there is no empirical evidence to substantiate this claim.

Accordingly, the third problematic presents itself: that is, many feminists are skeptical of relational feminists' project to "rehabilitate traditional stereotypes as 'women's voice,' [because it] fails to come to terms with the extent to which the gender stereotypes were designed to marginalize women." ${ }^{317}$ Relational feminists have not questioned the validity of these stereotype of women's gender identity; they simply want to revalue the so-called feminine virtues traditionally linked to women.

On this point, Joan Williams claims that Gilligan's other voice parallels the patriarchal view of the "pre-modern stereotype of woman" whose virtue and rationality were prominent in Victorian times. ${ }^{318}$ We should be skeptical of the reliance on intuition of gender difference on display in relational feminism, warn Greeno and Maccoby, since "women have been trapped for generations by people's willingness to accept their own intuitions about the truth of gender stereotypes." 319

${ }^{316}$ Catherine G. Greeno and Eleanor E. Maccoby, "How Different is the 'Different Voice?'," in The Essential Difference, eds. Naomi Scholar and Elizabeth Weed (Bloomington, IN: Indiana University Press, 1994), 197.

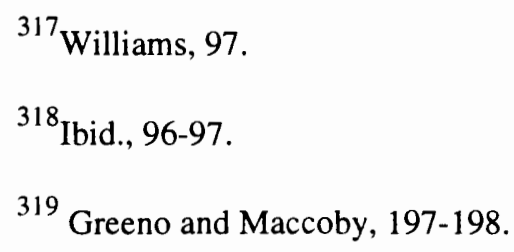


Finally, feminists have criticized relational feminists for employing an essentialist argument for gendering the self since in defining an "essential feminine subject" this "involves positing an essential, asocial core that all women, qua women, share." 320 Because of relational feminists tendency to link women's nature exclusively to some aspect of her biology or physiology (such as childbearing) to explain women's identity, they have "generally failed to address variation across culture, class, race, ethnicity, age and sexual orientation., ${ }^{321}$ Accordingly, relational feminism has fallen to charges of essentialism, which many feminists believe is fundamentally exclusionary.

In conclusion, feminist commentators have argued that relational feminists' conception of the gendered self fails on two accounts. First, they erroneously assume that the experiences of one group of women (e.g. white, middle-class, heterosexual) is by extension the same for all women; thereby, they do not adequately acknowledge the important differences between women. Second, relational feminists overstate the case that gender exclusively constitutes women's identity. ${ }^{322}$

${ }^{320}$ Susan Hekman, "The Embodiment of the Subject: Feminism and the Communitarian Critique of Liberalism," The Journal of Politics, Vol. 54, No. 4 (1992): 1112.

${ }^{321}$ Rhode, 157.

${ }^{322}$ Given the fact that relational feminists assume that women's identity is based on a notion of interconnectedness, they seem to miscast the nature of women's attachments as one that would be towards both men and women. In a study on gender identification, Donna $\mathrm{H}$. Henderson-King and Abigail J. Stewart show that women's attachments are generally not directed towards other women, but rather towards men. Women view their gender as an individual personal identity; rather than an identity shared with all women. Taken together, King and Stewart conclude that "women are less likely to develop high levels of group consciousness." Donna H. Henderson-King and Abigail J. Stewart, "Women or Feminists? Assessing Women's Group Consciousness," Sex Roles 31 (1994): 506. 


\section{Cultural Feminism}

Cultural feminism lies at something of a crossroads between relational and postmodern feminism. Both relational and cultural feminists want to rely on a relational conception of the self. However, the relational feminists emphasize "women's essential connectedness to other human beings," while the latter emphasizes women's sense of self as "a product of cultural forces alone." 323

In attempting to evade the recurrent charges of essentialism plaguing the work of relational feminists, cultural feminists have endeavored to back away from this type of argument and claim that women are relational selves to the extent that they are embedded within a particular culture. Contra relational feminism, they argue that women are not innately or naturally relational selves; rather, women view themselves as relational selves based on certain cultural influences.

For cultural feminist, women's gender identities are "conceive[d] in purely social terms," explains Elizabeth Grosz, and refer "to the attributions of invariant social categories, function, and activities to which all women in all cultures are assigned."324 In short, the concept of the feminine gendered self is a socially constituted figure whose attributes are fixed based on a particular class of gender-based experiences.

Given that women's gender identity is defined by activities and attributes present within a culture, we may ask what culture entails for feminists. Culture, delineates Iris

\footnotetext{
${ }^{323}$ Dailey, 1269.

${ }^{324}$ Grosz, 85 .
} 
Young, "includes the symbols, images, meanings, habitual comportment's, stories, and so on through which people express their experience and communicate with one another." 325 These cultural images in turn become attached to particular persons, actions, institutions, behaviors, etc., in society. Accordingly, a given culture articulates what constitutes femininity and masculinity. For cultural feminists, "The culture identifies masculine with the values associated with individualism-self-sufficiency, competition, separation, the form equality of rights. The culture identifies women, on the other hand, with the values associated with community-affective relations of care, mutual aid and cooperation." 326 To articulate the way these cultural symbols of gender have become internalized in women's gender-identity - that is, how they describe women's sense of self-cultural feminist commonly rely on Gilligan's research; as well as the works of Chodorow, Dinnerstein, Mitchell. ${ }^{327}$ For instance, Hirschmann (a social constructivist or cultural feminist) relies explicitly on Gilligan's psychological studies to make her argument that

${ }^{325}$ Iris Marion Young, Justice and the Politics of Difference (Princeton, NJ: Princeton University Press, 1990), 23.

${ }^{326}$ Iris Marion Young, "The Ideal of Community and the Politics of Difference," in Feminism/Postmodernism, ed. Linda J. Nicholson (New York: Routledge, 1990), 306.

${ }^{327}$ For those familiar with the works of Chodorow, Dinnerstein, and Gilligan, the fact that both relational and cultural feminism relies on these theorists may sound confusing, since all three of these theorists to some degree have attempted to articulate how gender identities are socially constructed. For the most part, the difference is in how cultural and relational feminists have used the works of these authors to explicate their position. For example, relational theorists have interpreted Gilligan's work to establish an essential gender-identity of women with certain inherent traits that are essentially female. If viewed on a continuum, relational feminism lies closest to biological arguments for women's gender difference-that is, women's capacities and traits are related in some fashion to their capacity to bear children. 
women's identities are constructed by the dominant culture, and thus women have a particular gender identity.

While cultural arguments about women's gender identity may seem more appealing to feminists wishing to dodge essentialism, there are two fundamental problems. First, many feminists argue that cultural feminists do not escape the charge of essentialism. Hekman explains that cultural feminists "argue that subjects are essentially socially constructed, that is, they want to replace the essentialism of liberal individualism with an equally essentialist view of the subject as socially conducted." 328

Second—and more importantly—cultural feminists, in order to articulate gender differences between men and women and account for the different conceptions of the self, almost inevitably end up referencing psychological accounts to demonstrate this. Though theorists such as Hirschmann claim to use the work of Gilligan simply to decipher cultural manifestations of gender identity, they do not successfully evade the problem hindering relational feminists' accounts of gender difference: there is no empirical evidence to prove that men and women differ in their moral reasoning capacities and sense of self. ${ }^{329}$

Like relational feminists, what cultural feminists are doing is simply recounting society's mythic notions of womanhood to embody the gendered self. "[C]ultural

${ }^{328}$ Hekman, "The Embodiment of the Subject," 1112.

${ }^{329}$ Nancy Hirschmann, "Feminism and Liberal Theory," American Political Science Review 85, (1991): 226 . 
feminist reappraisal [of feminine characteristics]", Linda Alcoff states, "construes women's passivity as her peacefulness, her sentimentality as her proclivity to nurture, her subjectiveness as here advanced self-awareness, and so forth. Cultural feminism have not challenged the defining of woman but only that definition given by men."330 Accordingly, the cultural feminists attempt at gendering the self does not present a better alternative than that offered by the relational feminists.

\section{Postmodern Feminists}

The term "postmodern feminism" should be regarded less as a fixed and coherent brand of feminism than as a broader philosophical movement which has recently influenced feminist thought; particularly, feminism's approach to gendering the self. While some feminists have rejected this postmodern trend outright for its destructive methodology, many feminists (postmodern or not) embrace postmodernism as a potential corrective to the essentialist theorizing of relational and cultural feminism.

This aside, treating postmodern feminists as a group is difficult. In part, this stems from postmodern feminists' inclination for 'opacity, viewing clarity as one of the seven deadly sins of the phallologocentric order."331 While postmodern feminist share some elements of similarity - that is, "they share what seems a common desire to think

${ }^{330}$ Linda Alcoff, "Cultural Feminism versus Post-Structualism: The Identity Crisis in Feminist Theory," in Signs: A Journal of Women in Culture and Society 13 (Spring 1988): 407.

${ }^{331}$ Tong, 231. 
nonbinary, nonoppositional thoughts"--beyond this postmodern feminists appear to move along different paths. ${ }^{332}$

One theme postmodern feminists' arguments converge, however, is over an approach to gendering the self. Unlike relational and cultural feminists, postmodern feminists question the whole notion of "subjectivity" and in defining a concept or category of women. ${ }^{333}$ Postmodern feminists have accordingly attacked relational and cultural feminists' attempts to identify a particular set of attributes common to all woman, as it reinforces binary thinking.

Instead, postmodern feminists want to embody the self through a concept of "positionality." The differences between cultural and relational feminists' projects at gendering the self, explains Alcoff, and the postmodern feminists' project, is this:

When the concept "woman "is defined not by a particular set of attributes but by a particular position, the internal characteristics of the person thus identified are not denoted so much as the external context within which that person is situated. The external situation determines the person's relative position...The essentialist definition of woman makes her identity independent of her external situation: since her nurturing and peaceful traits are innate they are ontologically autonomous of her position with respect to others or to the external historical and social conditions generally. The positional definition, on the other hand, makes her identity relative to a constantly shifting context, to a situation that includes a network of elements involving others, the objective economic conditions, cultural and political institutions and ideologies, and so on. ${ }^{334}$

${ }^{332}$ Ibid.

${ }^{333}$ Alcoff, 407 .

${ }^{334}$ Ibid., 433. 
Postmodern feminists argue that women and men's identities are reflective of their position within the matrix of social relations; conversely, their identity is always in a process of becoming. The concept of "women" can only be described within a fluid context; thus, it is never fixed as it changes to reflect the context in which individual women are embedded.

What postmodern feminists argue for then is a notion of "woman" as a "discursive subject." That is, women are constituted by cultural factors to some extent, yet they are also capable of constituting their own identity. The identity of woman "is the product of her own interpretation and reconstruction of her history, as mediated through the cultural discursive context to which she has access." ${ }^{335}$

The effect of describing women in the above way departs from the notion that there exists an "essential" quality or set of attributes particular one sex. "Gender differences fall along a continuum, and context matters greatly in eliciting traits traditionally associated with women", Rhode delineates; therefore, "It is misleading to discuss gender-related attributes as if they can be abstracted from the distinctive social expectations, opportunities and hierarchies that are also linked to gender." ${ }^{336}$ Rather than embodying the self with universal, generalized qualities, postmodern feminists contend that we must look at the individual particularities of women-the position individual

\footnotetext{
${ }^{335}$ Ibid., 434.

${ }^{336}$ Rhode, 157.
} 
women find themselves at a particular interval of their lives-to embody the self. Because it is altogether "misleading to try to identify traits as specifically female." 337

Supplanting cultural and relational feminism's project of identifying an "essential" subject, then, postmodern feminists emphasize difference among men and women, and among women themselves. Gender is simply one aspect among many others that constitute a woman's identity, and the differences between women are beyond any "essential" feminine gender. Indeed, it is "the postmodern call to give up the privileging of gender, along with subject-centered forays into women's ways of thinking, acting, and reconcieving theory and politics." 338

While I consider this description of gender accurate, it manifests two problems for feminists gendering the self and providing a critique of the Rawlsian self along gender lines. First, the postmodern feminists approach to the self cannot generate an definitive set of attributes unique to all women. Thus, they cannot really gender the self at all. Second, in being unable to delimit gender differences of men and women, feminists are hamstrung in making the claim that the Rawlsian self illustrates attributes of a self that are distinctly male or masculine. If postmodern feminists do so, they would have to rely on an "essentialist" interpretation of the male or masculine subject. ${ }^{339}$

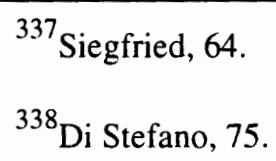

${ }^{339}$ This is not to suggest that postmodern feminists do not make the claim that the Rawlsian self is a male or masculine subject. Indeed, postmodern feminists often make such a claim; however, I would contend that they do so in a theoretically inconsistent way. 
Having reviewed three feminist approaches to gendering the self (for the purpose of providing a critique of the Rawlsian self) we are left with two alternatives. The first is to endorse the relational and cultural feminists' approach to gendering the self, which provides a set of gender-based attributes with which to contrast Rawls's conception of the self. However, as indicated earlier, this alternative is theoretically untenable based on empirical data alone.

The second alternative offered by postmodern feminists is perhaps the best approach to the self: gender is simply one facet of a person's multi-faceted identity. While gender may influence a person's identity at some level and with varying degree among persons, it is in no way a primary determinant of a person's identity. The problem here is that there exists no set of gender-based attributes to gender the self since the division between a male or female gendered self is indeterminate.

Postmodern feminism then does not adequately provide the theoretical tools necessary for claiming that the Rawlsian self is male or masculine; otherwise it would have to invoke a brand of Enlightenment dualism. Relying upon the relational and cultural attempts at gendering the self and claiming that the Rawlsian self is male or masculine, however, proves to be empirically indefensible. We can conclude that none of the feminist paths to gendering the self successfully proves that the Rawlsian self is male or masculine. 


\section{Concluding Remarks}

In the preceding pages, I have tried to explicate both Rawls's conception of the self (in both Theory and Political Liberalism) and feminist criticisms of the Rawlsian self for the purpose of evaluating the debate. In so doing, my primary aim was to bring out certain features of the debate, and to suggest where feminists criticisms have been misplaced.

In the course of this argument, it has been shown that feminists face two tasks if they are to successfully criticize Rawls's conception of persons in the future. First, feminists must provide a better treatment of and more accurate interpretation of Rawls's conception of the self. Moreover, they must attend to the recent theoretical shift within Rawls's conception of justice-from JAF to political liberalism.

Second, if feminists exigency is to claim that Rawls's conception of the self is a gender-biased construction, they will have to produce a theoretically (and empirically) defensible way for doing so. That is, in order to claim that the Rawlsian self is male or masculine, feminists must be capable of clearly articulating a self with gender-based attributes for the purpose of distinguishing subjects. 


\section{WORKS CITED}

Alcoff, Linda. "Cultural Feminism versus Post-Structuralism: The Identity Crisis in Feminist Theory." Signs: A Journal of Women in Culture and Society 13 (Spring 1988): 405-436.

Alexander, Sally. "Women, Class and Sexual Differences." In Feminism and Equality, ed. Anne Phillips, 160-175. New York: New York University Press, 1987.

Bebeau, Muriel J. and Mary M. Brabeck. "Ethical Sensitivity and Moral Reasoning among Men and Women in the Professions." In Who Cares?, ed. Mary M. Brabeck, 144-163. New York: Praeger, 1989.

Benhabib, Seyla and Drucilla Cornell, "Introduction: Beyond the Politics of Gender." In Feminism as Critique, eds. Seyla Benhabib and Drucilla Cornell, 115. Minneapolis, MN: University of Minnesota Press, 1991.

Benhabib, Seyla. "The Generalized and the Concrete Other: The Kohlberg-Gilligan Controversy and Feminist Theory." In Feminism as Critique, eds. Seyla Benhabib and Drucilla Cornell, 77-95. Minneapolis, MN: University of Minnesota Press, 1991.

Benn, S. I. and R. S. Peters. The Principles of Political Thought. New York: The Free Press, 1959.

Berlin, Isaiah. "Two Concepts of Liberty." In Liberalism and Its Critics, ed. Michael Sandel, 15-36. New York: New York University Press, 1984.

Bordo, Susan. "The Cartesian Masculinization of Thought." Signs: Journal of Women in Culture and Society 11, no. 3 (Spring 1986): 439-456.

Brabeck, Mary. "Moral Judgment: Theory and Research of Differences between Males and Females." In An Ethic of Care, ed. Mary Jeanne Larrabee, 33-48. New York: Routledge, 1993.

Brook, Richard. "Justice and the Golden Rule: A commentary on some recent work by Lawrence Kohlberg." Ethics 97, no. 2 (January 1987): 363-373. 
Buchanan, Allen. Marx and Justice: The Radical Critique of Liberalism. Totowa, NJ: Rowman and Littlefield, 1982.

Campbell, Tom. Justice. Atlantic Highlands, NJ: Humanities Press International, Inc., 1990.

Cederblom, Jerry and David W. Paulsen. Critical Reasoning. Belmont, CA: Wadsworth Publishing Company, 1986.

Chodorow, Nancy. The Reproduction of Mothering. Berkeley, CA: University of California Press, 1987.

Dailey, Anne C. "Feminism's Return to Liberalism." The Yale Law Journal 102 (1993): $1265-1286$.

De Lue, Steven M. "The Idea of a Duty to Justice in Ideal Liberal Theory." In Liberals on Liberalism, ed. Alfonso J. Damico, 95-110. Totowa, NJ: Rowman and Littlefield, 1986.

Dinnerstein, Dorothy. The Mermaid and the Minotaur: Sexual Arrangements and Human Malaise. New York: Harper Cholophon Books, 1977.

Di Stefano, Christine. "Dilemmas of Difference." In Feminism/Postmodernism, ed. Linda J. Nicholson, 63-79. New York: Routledge, 1990.

Dworkin, Gerald. "Non-Neutral principles." In Reading Rawls, ed. Norman Daniels, 2nd ed. (1989). New York: Basic Books, Inc., 1975.

Elshtain, Jean Bethke. Public Man, Private Woman: Woman in Social and Political Thought. Princeton, NJ: Princeton University Press, 1981.

Eisenberg, Nancy, Richard Fabes and Cindy Shea. "Gender Differences in Empathy and Prosocial Moral Reasoning: Empirical Investigations." In Who Cares?, ed. Mary M. Brabeck, 127-143. New York: Praeger, 1989.

Flathman, Richard E. Towards a Liberalism. Ithaca, NY: Cornell University Press, 1989.

Flax, Jane. Thinking Fragments: Psychoanalysis, Feminism, and Postmodernism in the Contemporary West. Berkeley, CA: University of California Press, 1990. 
Friedman, Marilyn. "Feminism and Modern Friendship: Dislocating the Community." In Justice and Economic Distribution, eds. John Arthur and William H. Shaw, 304-319. Englewood Cliffs, NJ: Prentice Hall, 1991.

Gardbuam, Stephen. "Law, Politics, and the Claims of Community." Michigan Law Review 90 (1993): 685-760.

Gilligan, Carol. In a Different Voice. Cambridge, MA: Harvard University Press, 1982.

Gray, John. Liberalism. Minneapolis, MN: University of Minnesota Press, 1986.

Greeno, Catherine G. and Eleanor E. Maccoby. "How Different is the 'Different Voice?" In An Ethic of Care, ed. Mary Jeanne Larrabee, 193-198. New York: Routledge, 1993.

Grimshaw, Jean. Feminist Philosophers: Women's Perspectives on Philosophical Traditions. Brighton, Sussex: Wheatsheaf Books, 1986.

Grosz, Elizabeth. "Sexual Difference and the Problem of Essentialism." In The Essential Difference, eds. Naomi Schor and Elizabeth Weed, 82-97. Bloomington, IN: Indiana University Press, 1994.

Gunnell, John. Political Theory: Tradition and Interpretation. New York: University Press of America, Inc., 1987.

Gutmann, Amy. "The Central Role of Rawls's Theory," Dissent (1989): 338-342. . "Communitarian Critics of Liberals." Philosophy and Public Affairs 14 (Summer 1985): 308-322.

Henderson-King, Donna H. and Abigail J. Stewart. "Women or Feminists? Assessing Women's Group Consciousness.” Sex Roles 31 (1994): 505-516.

Hekman, Susan J. Gender and Knowledge: Elements of Postmodern Feminism. Boston: Northeastern University Press, 1990. . "The Embodiment of the Subject: Feminism and the Communitarian Critiques of Liberalism." The Journal of Politics 54, no. 4 (1992): 1098-1119.

Hill, Jr., Thomas E. "The Importance of Autonomy." In Women and Moral Theory, eds. Eva Feder Kittay and Diana T. Meyers. New Jersey: Rowman and Littlefield, 1987. 
Hirschmann, Nancy J. "Feminism and Liberal Theory." American Political Science Review 85, no. 1 (1991): 225-233.

Rethinking Obligation: A Feminist Method for Political Theory. New York: Cornell University Press, 1992.

Holmes, Stephen. "The Permanent Structure of Antiliberal Thought." In Liberalism and the Moral Life, ed. Nancy L. Rosenblum, 227-253. Cambridge, MA: Harvard University Press, 1989.

Jaggar, Alison M. Feminist Politics and Human Nature. New Jersey: Rowman and Allanheld, 1983.

Keller, Evelyn Fox. Reflections on Gender and Science. New Haven, CT: Yale University Press, 1985.

Kittay, Eva Feder and Diana T. Meyers. "Introduction." In Women and Moral Theory, eds. Eva Feder Kittay and Diana T. Meyers. New Jersey: Rowman and Littlefield, 1987.

Kuhn, Thomas S. The Structure of Scientific Revolutions. Chicago: The University of Chicago Press, 1970.

Kukathas, Chandran and Philip Pettit. Rawls: A Theory of Justice and Its Critics. Stanford, CA: Stanford University Press, 1990.

Kymlicka, Will. Liberalism, Community and Culture. New York: Clarendon Press, 1989.

Contemporary Political Philosophy: An Introduction. New York: Clarendon Press of Oxford University Press, Inc., 1990.

Larrabee, Mary Jeanne. "Gender and Moral Development: A Challenge for Feminist Theory." In An Ethic of Care, ed. Mary Jeanne Larrabee, 3-16. New York: Routledge, 1993.

Lloyd, Genevieve. The Man of Reason: "Male" and "Female" in Western Philosophy. Minneapolis, MN: University of Minnesota Press, 1984.

Luria, Zella. "A Methodological Critique." In An Ethic of Care, ed. Mary Jeanne Larrabee, 199-203. New York: Routledge, 1993. 
Macedo, Stephen. Liberal Virtues: Citizenship, Virtue, and Community in Liberal Constitutionalism. New York: Oxford University Press, 1991.

MacIntyre, Alisdair. After Virtue. South Bend, IN: Notre Dame University Press, 1984.

MacKinnon, Catherine. Toward a Feminist Theory of State. Cambridge, MA: Harvard University Press, 1989.

. "Difference and Dominance." In Feminist Legal Theory: Readings in Law and Gender, eds. Katharine T. Bartlett and Rosanne Kennedy, 81-94. Boulder, CO: Westview Press, 1991.

Mendus, Susan. Toleration and the Limits of Liberalism. Atlantic Highlands, NJ: Humanities Press International, Inc., 1989.

Meyers, Diana T. ed. "The Socialized Individual and Individual Autonomy: An Intersection between Philosophy and Psychology." In Women and Moral Theory, eds. Eva Feder Kittay and Diana T. Meyers. New Jersey: Rowman and Littlefield, 1987.

."Moral Reflection: Beyond Impartial Reason," Hypatia 8 (Summer 1993): $21-47$.

Mitchell, Juliet. Psychoanalysis and Feminism. New York: Vintage Books, 1974.

Mulhall, Stephen and Adam Swift. Liberals and Communitarians. Cambridge, MA: Blackwell Publishers, 1992.

Moore, Janet. "Covenant and Feminist Reconstructions of Subjectivity within Theories of Justice." Law and Contemporary Problems 55 (Summer 1992): 159-196.

Neal, Patrick. "Justice as Fairness: Political or Metaphysical?" Political Theory 18 (1990): 24-50.

Okin, Susan Moller. Women in Western Political Thought. Princeton, NJ: Princeton University Press, 1979.

Justice, Gender, and the Family. New York: Basic Books, 1989.

Pateman, Carole. "Feminist Critiques of the Public/Private Dichotomy." In Feminism and Equality, ed. Anne Phillips, 103-126. Washington Square, NY: Basic Books, 1987. 
Phillips, Anne. "Introduction." In Feminism and Equality, ed. Anne Phillips, 1-23. New York: New York University Press, 1987.

Pitkin, Hanna Fenichel. Wittgenstein and Justice. Berkeley, CA: University of California Press, 1972.

Pogge, Thomas W. Realizing Rawls. Ithaca, NY: Cornell University Press, 1989.

Puka, Bill. “The Liberation of Caring: A Different Voice for Gilligan's 'Different Voice." In Who Cares?, ed. Mary M. Brabeck, 19-44. New York: Praeger, 1989.

Rawls, John. A Theory of Justice. Cambridge, MA: Belknap Press, 1971. . Political Liberalism. New York: Columbia University Press, 1993.

Rhode, Deborah L. "The politics of paradigms: gender difference and gender disadvantage." In Beyond Equality and Difference: Citizenship, feminist politics, and female subjectivity, eds. Gisela Bock and Susan James, 149-163. New York: Routledge, 1992.

Sandel, Michael. Liberalism and the Limits of Justice. Cambridge, MA: Cambridge University Press, 1982. ed. Liberalism and Its Critics. New York: New York University Press, 1984.

Schor, Naomi. "Introduction." In The Essential Difference, eds. Naomi Schor and Elizabeth Weed, vii-xix. Bloomington, IN: Indiana University Press, 1994.

Seigfried, Charlene Haddock. "Pragmatism, Feminism, and Sensitivity to Context." In Who Cares?, ed. Mary M. Brabeck, 63-83. New York: Praeger, 1989.

Sevenhuijsen, Selma L. "The Morality of Feminism.” Hypatia 6 (Summer 1991): 173191.

Sher, George. "Other Voices, Other Rooms? Women's Psychology and Moral theory." In Women and Moral theory, eds. Eva Feder Kittay and Diana T. Meyers. New Jersey: Rowman and Littlefield, 1987.

Sinopoli, Richard C. "Feminism and Liberal Theory." American Political Science Review 85, no. 1 (March 1991): 223-225. 
Sunstein, Cass R. "Introduction: Notes on Feminist Political Thought." In Feminism and Political Theory, ed. Cass Sunstein, 1-11. Chicago: The University Chicago Press, 1990.

Sypnowich, Christine. "Justice, Community, and the Antinomies of Feminist Theory." Political Theory 21 (August 1993): 484-506.

Taylor, Charles. Sources of the Self. Cambridge, MA: Cambridge University Press, 1990.

Thiele, Beverly. "Vanishing acts in social and political thought: Tricks of the trade." In Feminist Challenges: Social and Political Theory, eds. Carole Pateman and Elizabeth Gross, 30-43. Boston: Northeastern University Press, 1987.

Thompson, Janna. "Sex Equality in Not Enough for Feminism." In Feminist Challenges: Social and Political Theory, eds. Carole Pateman and Elizabeth Gross, 99-111. Boston: Northeastern University Press, 1987.

Tong, Rosemarie. Feminist Thought: A Comprehensive Introduction. Boulder, CO: Westview Press, 1989.

Walker, Lawrence. "Sex Differences in the Development of Moral Reasoning: A Critical Review." In An Ethic of Care, ed. Mary Jeanne Larrabee, 157-176. New York: Routledge, 1993.

West, Robin. "Jurisprudence and Gender." In Feminist Legal Theory, eds. Katharine T. Bartlett and Rosanne Kennedy, 201-234. Boulder, CO: Westview Press, Inc., 1991.

Williams, Joan C. "Deconstructing Gender." In Feminist Legal Theory: Readings in Law and Gender, eds. Katharine T. Bartlett and Rosanne Kennedy, 95-123. Boulder, CO: Westview Press, 1991.

Wolgast, Elizabeth H. The Grammar of Justice. Ithaca, NY: Cornell University Press, 1987.

Young, Iris Marion. Justice and the Politics of Difference. Princeton, NJ: Princeton University Press, 1990.

"The Ideal of Community and the Politics of Difference." In Feminism/Postmodernism, ed. Linda J. Nicholson, 300-323. New York: Routledge, 1990. 
"Impartiality and the Civic Public: Some Implications of Feminist Critiques of Moral and Political Theory." In Feminism as Critique, eds. Seyla Benhabib and Drucilla Cornell, 56-76. Minneapolis, MI: University of Minnesota Press, 1991. 